\title{
Lettre de Mara bar Sérapion et la paideia hellénistique
}

Par

\section{Izabela Jurasz}

Université de Paris - Sorbonne / Centre Léon Robin

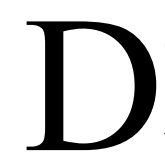

epuis trente ans environ, un vif débat entoure la Lettre de Mara fils de Sérapion en soulevant des questions historiques, théologiques et littéraires et en apportant de nouvelles hypothèses ${ }^{1}$. En effet, ce document mérite toute cette attention, car il s'agit probablement d'un des plus anciens documents écrits dans la langue syriaque, dont l'auteur nonchrétien semble mentionner Jésus. Ce texte est toutefois suffisamment imprécis pour rendre fragile toute hypothèse concernant les circonstances de sa composition. Sans prétendre à résoudre la difficulté, la présente étude propose d'y apporter quelques éclairages, venant de l'analyse de la Lettre de Mara en tant que relative à la paideia syriaque et ses rapports avec le monde grec.

Dès sa première mention, la Lettre est présentée comme ayant quelques traits avec la pensée grecque. En 1852, Ernest Renan en parle comme d'une « lettre assez longue de Bar Sérapion à son fils Sérapion, par laquelle il lui annonce l'envoi d'un ouvrage qu'il avait probablement traduit du grec $»^{2}$. Cette description sommaire est aussi inexacte. La Lettre est une exhortation à l'étude et à la vertu, destinée au jeune fils de l'auteur. Son style est proche d'une consolatio

\footnotetext{
${ }^{1}$ Les principales publications : MCVEY 1990, p. 257-272 ; RAMELLI 2004, p. 77-104 ; NORELLI 2005, p. $197-$ 207; RAMELli 2005, p. 545-570 ; CHIN 2006, p. 145-171 ; MERTZ, TIELEMAN 2008, p. 107-133 ; RENSBERGER 2010, p. 3-21 ; MERZ, TIELEMAN 2012 ; MCVEY 2015a, p. 305-326.

${ }^{2}$ RENAN 1852, p. 328-329.
} 
ou d'un testament spirituel, car l'auteur est emprisonné ou exilé par les Romains. Mara bar Sérapion a reçu une éducation hellénistique : il connaît Achille, Agamemnon, Priam, Archimède, Socrate et Pythagore, mais aussi des « barbares », tels que Darius le roi des Perses et un anonyme « roi sage des Juifs ». Nous ne savons rien de précis sur sa religion, malgré quelques appels à (un) Dieu. Quant à son origine, la mention de Samosate a fait qu'on le considère citoyen de cette ville.

Depuis la publication du texte syriaque par William Cureton, en 1855, sur base du seul manuscrit connu, le ms Londres, British Library, Add. 14658 daté du $7^{\mathrm{e}}$ siècle, la Lettre de Mara a été traduite en plusieurs langues modernes ${ }^{3}$. Nous proposons sa première traduction française, basée sur le texte édité par Cureton et corrigé par Schulthess. Par conséquent, la présente étude poursuit un double but : elle se propose tout d'abord de lire la Lettre de Mara comme un document relatif à la paideia hellénistique, mais elle veut aussi donner au lecteur francophone un aperçu du débat qui entoure ce texte depuis quelques décennies. Compte tenu de l'ampleur de ce débat, il est impossible de passer sous silence la question épineuse de la date et des circonstances de la rédaction. Or, la perspective pédagogique met en évidence les liens de la Lettre avec la seconde sophistique et favorise l'hypothèse de la rédaction réalisée entre la fin du $2^{\mathrm{e}}$ et le début du $3^{\mathrm{e}}$ siècle. Cette proposition nécessite néanmoins un examen attentif des aspects historiographiques des informations sur le « roi sage des Juifs » et sur l'exil de l'auteur. Par rapport à cette thématique riche et variée, l'exhortation à « étudier les lettres et suivre la sagesse » aide à retrouver la cohérence de la Lettre.

\section{Pourquoi la paideia?}

L'étude des aspects pédagogiques de la Lettre de Mara nécessite quelques précisions préalables, concernant sa forme et son objectif. En effet, la Lettre est une exhortation à l'éducation et à la vie philosophique, mais elle contient également des réflexions éthiques, des proverbes, des exemples édifiants, ainsi que quelques passages d'allure autobiographique. À l'évidence, l'auteur de la Lettre mélange l'exhortation à l'étude avec quelques souvenirs amers et les réflexions qui en découlent. Par conséquent, l'aspect pédagogique de ce texte peut être abordé sur le plan rhétorique et sur le plan social.

La présence de nombreuses figures stylistiques dans la Lettre fait penser qu'il s'agit d'un pur exercice rhétorique et non d'une vraie lettre. Telle est l'hypothèse défendue par Catherine Chin qui compare la Lettre avec les indications données par les manuels de rhétorique de l'époque hellénistique. En effet, une exhortation à la vie philosophique, donnée par un père à son fils, est une forme littéraire bien connue ${ }^{4}$. Plus récemment, ce caractère rhétorique et didactique de la Lettre de Mara a été souligné par Henri Hugonnard-Roche et Daniel King, à partir de l'examen du manuscrit BL 14658 lequel, en plus de la Lettre, contient une collection d'écrits

\footnotetext{
${ }^{3}$ CURETON 1855. Cette traduction a été revue par Benjamin P. Pratten, avec l'aide de Robert Payne-Smith, pour la collection The Ante-Nicene Fathers, voir PRATTEN 1978 [1867], p. 735-739. En 1897, le texte et la traduction de Cureton ont été révisés par Friedrich Schulthess, voir SCHULTHESS 1897, p. 366-375. La traduction tient compte d'une vingtaine de corrections grammaticales et lexicales. La traduction de Schulthess a été reprise dans AUfHAUSER 1925, p. 5-11. Quelques fragments de la Lettre ont été traduits en russe déjà en 1861, par A.V. Gorskij et la traduction partielle est faite par АВЕРИНЦЕВ 1985, p. 67-75. La plus récemment parue est la traduction italienne, faite par I. Ramelli, voir RAMELLI 2004, p. 77-104 ; RAMELLI 2005, p. 564-570. La nouvelle traduction anglaise de David Rensberger attend encore sa publication, voir RENSBERGER 2010, p. 3-21. Pour le commentaire philologique à cette traduction, voir RAMELLI 2012, p. 205-231.

${ }^{4}$ CHIN 2006, p. 161-162.
} 
pédagogiques en langue syriaque ${ }^{5}$. Il est donc possible que la Lettre soit un simple exercice stylistique, un texte pédagogique à l'usage des jeunes élèves. Cependant, rien n'empêche qu'un certain Mara, adepte de la paideia grecque, se serve de ses connaissances pour écrire une lettre à son fils ou qu'une telle lettre subisse des remaniements stylistiques postérieurs ${ }^{6}$. Même les efforts de présenter Mara comme un stoïcien et sa Lettre comme une œuvre philosophique ne peuvent pas perdre de vue qu'elle est destinée à un jeune garçon ${ }^{7}$. En tout état de cause, à l'époque du manuscrit BL 14658, à savoir au $7^{\mathrm{e}}$ siècle, la Lettre de Mara a été certainement utilisée à des fins pédagogiques. Ces différentes propositions, bien que n'étant pas nécessairement inconciliables, entraînent néanmoins des conséquences importantes pour déterminer la date et les circonstances de la composition de la Lettre. À ce stade de notre étude, nous adhérons à l'opinion la plus largement partagée, selon laquelle il s'agit d'une vraie lettre, dont l'auteur mobilise les connaissances littéraires qu'il a reçues de son éducation hellénistique pour encourager son fils à l'étude.

On peut se demander si le fils de Mara n'est pas trop jeune pour qu'on lui adresse ce type d'enseignement. En règle générale, l'enfant commençait son éducation à l'âge de six ou sept ans, sous l'autorité d'un maître de lecture et d'écriture $(\gamma \rho \alpha \mu \mu \alpha \tau i ́ \sigma \tau \eta \varsigma)^{8}$. On peut donc supposer que le fils de Mara avait cet âge-là. Or, comme l'a noté H. Hugonnard-Roche, la Lettre transmet une éducation de base, destinée aux jeunes, et non l'étude de la philosophie stricto sensu. Cependant, un certain contenu philosophique a déjà été intégré dans cette première étape de l'éducation; Quintilien, dans l'Instruction oratoire, nous renseigne sur ses méthodes et son contenu. Il explique que le premier stade d'instruction consiste en des exercices préparatoires, les $\pi \rho \circ \gamma v \mu v \alpha ́ \sigma \mu \alpha \tau \alpha$, destinés à «ceux dont l'âge n'est pas encore en mesure de recevoir l'enseignement du rhéteur $\iota^{9}$. Il s'agit de paraphrases (par ex. des fables d'Ésope), aphorismes, chries et étiologies ${ }^{10}$. Quintilien recommande que l'enseignement de la rhétorique soit donné aux enfants " au premier âge », dès qu'ils sont aptes à étudier toutes les matières indispensables - y compris la mathématique et la musique. Ce projet pédagogique idéal est partiellement confirmé par les informations trouvées dans les papyrus scolaires : le premier apprentissage se faisait avec des vers d'Homère, des proverbes, des sentences, des fables et de courtes anecdotes moralisatrices ${ }^{11}$. Or, les sentences et les exemples édifiants se retrouvent facilement dans la

\footnotetext{
${ }^{5}$ HugOnNARD-Roche 2004, p. 99-119 ; HugOnNARD-Roche 2007, p. 279-291 ; KING 2011, p. 189-212.

${ }^{6}$ Sur Mara comme adepte de la paideia grecque, voir SCHULTHESS 1897, p. 375-376 ; BLANK 2012, p. 167182

${ }^{7}$ A. Mertz, T. Tieleman attribuent l'absence des termes techniques de la philosophie stoïcienne dans la Lettre au fait qu'elle est adressée à un jeune enfant, voir MERTZ, TIELEMAN 2008, p. 111 n. 20.

${ }^{8}$ Ilsetraut Hadot cite dialogue pseudo-platonicien Axiochos, datant du $1^{\mathrm{er}}$ siècle av. J.-C. : « À sept ans - nous dit-il - l'enfant passe sous l'autorité du pédagogue, du maître de lecture et d'écriture ( $\gamma \rho \alpha \mu \mu \alpha \tau i ́ \sigma \tau\rceil)$, du maître

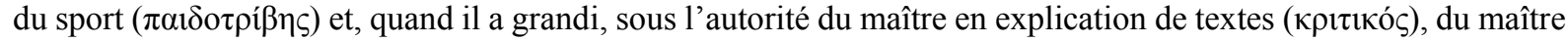
de géométrie et des instructeurs militaires; puis il devient éphèbe et c'est le troisième stade d'instruction. » (HADOT 1992, p. 32).

${ }^{9}$ Inst. or. I, 9. Quintilien décrit une éducation idéale, mais ses informations peuvent concerner le parcours scolaire en général, dans la mesure où elles sont confirmées par d'autres sources - ce qui est le cas dans la description des premiers exercices scolaires, voir MORGAN 1998, p. 190-199.

${ }^{10}$ À la seconde moitié du $1^{\text {er }}$ siècle, il existe déjà une liste canonique de ces exercices, héritée des époques précédentes, les mêmes chez les Romains et chez les Grecs, voir M. Patillon dans introduction à Aelius Theon, Progymnasmata, p. XII-XIII, n. 22. Sur les progymnasmata comme produit de la période romaine, voir MORGAN 1998, p. 64 ; PERNOT 1993, p. 57-58.

${ }^{11}$ À la tête des auteurs grecs étudiés se trouve Homère, derrière lui Eurypide, Isocrate et Ménandre, voir MORGAN 1998, p. 69-80 ; les critères du choix, p. 94-100 et 198-226. Le choix de ces textes peut être déterminé
} 
Lettre de Mara. De même, les recommandations du père conviennent bien à cette étape d'études : il ne parle pas de disciplines telles que la musique et les sciences, caractéristiques pour les étapes suivantes de l'éducation, mais il montre à l'enfant l'utilité de tout ce qui lui était offert dans un premier temps de l'instruction. Il écrit alors : " Même si cela te paraît très amer pendant un court temps, quand tu apprends, il te sera très doux ; parce que la même chose m'est arrivée » (Lettre 7).

Le souci d'éducation possède aussi une importante dimension sociale. Teresa Morgan, dans son ouvrage sur l'éducation littéraire, a mis en évidence les aspects sociaux et culturels de la paideia grecque à l'époque romaine. En tant qu'ouverte aux non-Grecs, elle devient symbole du statut social et de l'identification avec la culture dominante. Cette éducation hellénistique, reçue jadis par Mara, reflète le climat intellectuel des villes grecques en Asie, qui se manifeste surtout à partir de la fin du $1^{\text {er }}$ siècle de l'ère chrétienne et qu'on attache à la seconde sophistique. Il s'agit d'un mélange habile de l'art de la rhétorique avec des connaissances littéraires et philosophiques, une prise de conscience de l'héritage hellénistique - sous l'empire romain -, un nouveau rôle social revêtu par les adeptes de cet art : voici quelques-unes de ses caractéristiques. On peut oublier le regard critique porté jadis par Socrate sur l'opposition entre philosophe et sophiste. À la période hellénistique, l'alliance entre la philosophie et la rhétorique se prolonge jusque dans la paideia offerte aux enfants de la classe moyenne ${ }^{12}$. La paideia, selon les sophistes, devient davantage une « culture générale », très littéraire, une sorte de renaissance grecque sous l'empire romain. Et pour les sophistes asiates, attachés à la tradition littéraire et rhétorique du passé, la paideia permettait de conserver l'identité grecque - ou d'y adhérer.

Philostrate (170-240 env.), dans les Vies des sophistes, donne les dates d'activité et les noms de ces rhéteurs philosophes connus dans les cités d'Asie - avant tout à Smyrne et Éphèse. D'après Philostrate, ce nouveau mouvement sophistique débute dans les années $70 \mathrm{du} 1^{\mathrm{er}}$ siècle après J.C., avec Nicétès de Smyrne ${ }^{13}$. Après lui, Smyrne a connu une lignée de sophistes célèbres : Scopélianos, Marc Antoine Polémon et surtout Aelius Aristide. Leur style a été brillant, baroque, plein d'emphase et d'affectation. À la même époque a vécu aussi Isée l'Assyrien, un sophiste d'origine orientale, célèbre par son élocution naturelle et sobre et la justesse de ses formules élégantes. Les sophistes sont célèbres pour avoir proclamé de brillants discours publics, mais ils étaient également magistrats, bienfaiteurs, porte-parole de leurs concitoyens ; dans toutes leurs fonctions, ils représentaient la culture grecque face aux Romains.

Un certain nombre d'éléments rattachent la Lettre de Mara à la littérature grecque du $2^{\mathrm{e}}$ siècle, notamment à la production littéraire des sophistes. Il y a d'abord le rapport à la philoso-

par des facteurs très variés : la beauté du texte, son application morale, son contenu, des informations jugées utiles - sur la grammaire, l'histoire, les mythes, la géographie, etc. Ainsi certains passages de l'Iliade et l'Odyssée apparaissent plus souvent que les autres - choisis selon leur utilité pédagogique. Les élèves connaissent assez rapidement les différents types de simples exercices rhétoriques : le résumé et la paraphrase des mythes ou des histoires ; la composition d'une fable ou d'une chrie à partir des situations de la vie quotidienne ou de la littérature ; la composition sur les sujets historiques (p. ex. adopter un personnage homérique). Voir aussi la liste des premiers exercices rhétoriques (narration, description, réfutation, comparaison, éloge, blâme, chrie) dans l'éducation des sophistes : ANDERSON 1993, p. 47-64.

${ }^{12}$ L'époque hellénistique a connu d'importants changements dans l'approche de la paideia, depuis Platon, Isocrate et Aristote, voir HADOT 1992, p. 25-61.

${ }^{13}$ Même si les sources historiographiques et littéraires donnent les noms de grands sophistes actifs au $1^{\text {er }}$ siècle avant J.-C., il y a des lacunes concernant le début du $1^{\mathrm{er}}$ siècle après J.-C., voir BoULANGER 1923, p. 74-108. 
phie. Or, les sophistes sont capables de faire cohabiter des courants extrêmes comme le pythagorisme et le scepticisme ${ }^{14}$. Certains d'entre eux, comme Dion de Pruse, Favorinus d'Arles, Cassius Longin sont à la fois rhéteurs et philosophes, tandis qu'Aelius Aristide s'inspire dans ses discours de certains points de la philosophie platonicienne. Cette utilisation littéraire et rhétorique de notions et de thèmes philosophiques se retrouve chez Mara, car ses références philosophiques restent variées, bien que les éléments stoïciens soient les plus importants ${ }^{15}$. Même l'expérience de l'exil peut trouver sa place parmi les écrits des sophistes asiates, surtout si on pense à la manière dont Dion de Pruse a parlé du sien ${ }^{16}$. Si Mara a reçu son éducation dans ce milieu, il n'y a aucune contradiction dans sa manière de mélanger l'expérience personnelle à l'exercice rhétorique, ni dans l'utilisation éclectique et superficielle des notions philosophiques, voisinant la philosophie populaire.

Notre lecture de la Lettre de Mara est orientée vers cette « sagesse populaire », utilisée à des fins pédagogiques. Certes, la Lettre intègre de nombreux éléments stoïciens, notamment les notions comme la vertu, le convenable ou l'utile. Néanmoins, on constate seulement la présence de ces notions et non une reprise doctrinale.

\section{La Paideia selon Mara fils de Sérapion}

Les premières phrases de la Lettre nous donnent déjà quelques renseignements sur sa visée pédagogique. Mara souligne que son fils est très jeune et qu'il a l'âge d'un $\pi \alpha \iota^{\prime}$ ív $^{17}$. Son éducation est confiée à une personne désignée comme son " maître et tuteur ", sans doute un

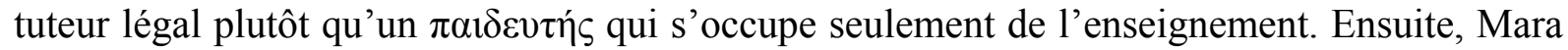
explique clairement ses intentions de parler de l'éducation et de transmettre sa propre expérience des études au jeune garçon qui vient de commencer les siennes. Il décrit ainsi le genre

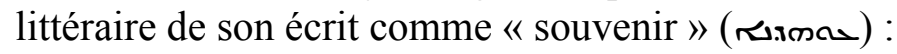

«3. Voilà, pourquoi j'ai écrit pour toi ce souvenir [de] ce que j'ai cherché dans le monde, car j'ai scruté la façon de vivre des hommes et j'ai été amené à l'étude. <4. Tout ce que j'ai trouvé dans l'étude [des sciences] des Grecs est lié à la naissance de la liberté.>»

Le «souvenir» dont parle Mara correspond au genre littéraire des "mémoires», نं $о \mu v \eta ́ \mu \alpha \tau \alpha$, qui consiste en un exercice de lecture attentive des notes, souvent fragmentaires, prises au cours de l'enseignement, faisant partie d'une formation à la fois intellectuelle et spirituelle $^{18}$. Ainsi, la Lettre de Mara semble se présenter comme un souvenir du père, rédigé pour que le fils puisse le relire et méditer. Les termes utilisés pour décrire le caractère de

\footnotetext{
${ }^{14}$ ANDERSON 1993, p. 133-143 ; PERNOT 2000, p. 250-257.

${ }^{15}$ Sur le caractère éclectique de la Lettre, voir MCVEY 1990, p. 261-270 ; BLANK 2012. Le caractère stoïcien et philosophique de la Lettre est défendu par SCHULTHESS 1897, p. 381-391; АВЕРИНЦЕВ 1985, p. 67-75; RAMELli 2005, p. 553-564; MERTZ, TIELEMAN 2008, p. 107-116.

${ }^{16}$ Dion de Pruse exploite l'exil pour faire passer un message plus général, portant sur la politique et la psychologie, sur la situation de l'Empire de son époque ; voir DESIDERI 2007, p. 193-207. Le rapport entre la Lettre de Mara et l'écrit de Dion Sur l'exil a été analysé par K. McVey dans sa communication au $7^{\mathrm{e}}$ North American Syriac Symposium, en 2015.

${ }^{17}$ L'information sur le jeune âge du destinataire de la Lettre revient à plusieurs reprises, voir Lettre 1, 2, 32, 48, 76. Sur $\pi \alpha$ ííov, voir MARROU 1948, p. 157.

${ }^{18}$ Voir le commentaire de Michel Foucault au sujet des lettres de Sénèque : FouCAULT, Dits et écrits, IV, $\mathrm{n}^{\circ} 329$, p. 418-423. Le rapprochement avec les $\dot{\pi}$ o $\mu v \eta ́ \mu \alpha \tau \alpha$ a été fait par SCHULTHESS 1897, p. 366. En revanche, I. Ramelli rapproche ce terme du genre de commentarii latins, à caractère historiographique, voir RAMELLI 2012, p. 211.
} 
l'enseignement reçu évoquent son double rôle - théorique et pratique. L'expression « manière de vivre » (حمدن), comme faisant partie de l'éducation, revient souvent dans la Lettre de manière plus significative. Dans ces premières lignes, Mara utilise deux fois le terme " étude ", (مهلم/a) qui signifie à la fois le contenu et l'acte. Le même terme lui sert à décrire

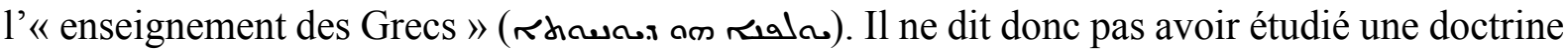
philosophique concrète, mais plutôt de suivre une formation intellectuelle hellénistique, la paideia, décrite ainsi :

«5. Désormais, consacre-toi alors, mon fils, aux choses qui conviennent aux hommes libres : l'examen des lettres ( مiqo مisل) et la poursuite de la sagesse ».

En effet, la paideia est bien une éducation de l'homme libre et Mara, même étant exilé et emprisonné, rappelle qu'il n'est pas un esclave. Certaines phrases de la Lettre montrent qu'il tient à son statut d'homme libre, qu'il espère retrouver un jour ${ }^{19}$. Cette éducation des hommes libres est décrite comme «l'examen des lettres et la poursuite de la sagesse ». Ce que Mara appelle « examen des lettres » correspond en grec à $\gamma \rho \alpha ́ \mu \mu \alpha \tau \alpha \mu \alpha v \theta \alpha ́ v \varepsilon ı v$, même si le verbe syriaque ni désigne l'action de scruter, de chercher à comprendre, plus proche de

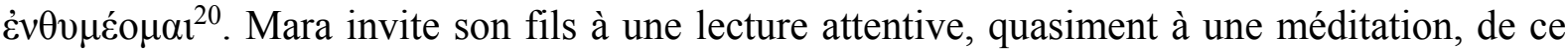
qu'il nomme en syriaque seprō ( مiqo) : les écrits, les lettres au sens large. Le terme syriaque correspond aux $\gamma \rho \alpha ́ \mu \mu \alpha \tau \alpha$ qui signifiaient «les lettres » et pas à une catégorie spécifique de textes. Il n'est donc pas question d'approfondir une doctrine philosophique, mais bien d'obtenir une éducation générale, fondée sur des textes littéraires variés. D'autres informations sur la nature de cette formation intellectuelle se trouvent dans les phrases qui suivent :

«6. Et souviens-toi de mes préceptes avec diligence, comme un homme de paix qui aime l'instruction. 7. Même si cela te paraît très amer pendant un court temps, quand tu apprends, il te sera très doux; parce que la même chose m'est arrivée. "

Dans ce passage se trouve le terme le plus important pour comprendre l'intention de la Lettre de Mara ; il s'agit de l'instruction, mardutō ( مhaxis). Il vient de la racine verbale qui signifie « marcher, avancer, s'instruire » ( $\sim_{\text {ri }}$ ) et à partir d'elle sont formés tous les termes dérivant du verbe $\pi \alpha 1 \delta \varepsilon v \varepsilon^{21} v^{21}$. Le terme mardutō correspond à $\pi \alpha 1 \delta \varepsilon i ́ \alpha$. Lorsqu'il est traduit systématiquement par « instruction », il permet de saisir la visée pédagogique de la Lettre ${ }^{22}$ dans des affirmations très variées.

On note ainsi le passage qui parle des Romains et précise à quelle condition ils méritent

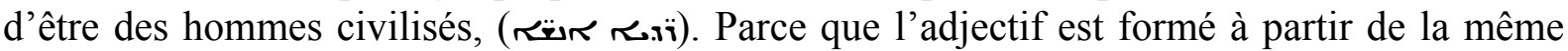
racine que mardutō, il s'agit d'hommes qu'on appelle des $\pi \varepsilon \pi \alpha \imath \delta \varepsilon v \mu \varepsilon ́ v o r$, des hommes « éduqués » et civilisés :

\footnotetext{
${ }^{19}$ Sur le statut de Mara, voir Lettre 67-73. Il parle aussi des « hommes faibles », mais sans que cela puisse signifier des esclaves, voir Lettre 40, 48, 65. Sur la paideia des hommes libres, voir HADOT 1992, p. 263-293 ; MORGAN 1998.

${ }^{20}$ ThesSyr, col. 3936.

${ }^{21}$ ThesSyr, col. 3819-3822. Les exemples de cette utilisation viennent du texte biblique : 2 Tim 2, 25 ; Tt 2 , 12 ; Hébr 12, 6. 7 ; Apoc 3, 19.

${ }^{22}$ Une exception s'impose néanmoins. En Lettre 15 nous lisons : « Et plus encore la naissance des enfants bienaimés nous blesse au moyen de deux choses, également de part et d'autre : lorsqu'ils sont honnêtes, l'amour pour eux nous tourmente et nous sommes charmés par leur conduite ; lorsqu'ils sont méchants, nous nous lamentons de leur rébellion et de leur perversité. » Le terme « leur rébellion » (_onłoasis), peut être traduit aussi comme « leur instruction », si on le considère à partir d'une autre racine verbale. Cette possibilité - qui n'a été adoptée par aucune traduction - a été signalée par RAMELLI 2012, p. 216. En effet, la traduction «leur rébellion » permet de conserver le contraste entre les deux conduites des enfants.
} 
"73. Si alors les Romains nous permettent de revenir dans notre pays en justice et en honnêteté, ils agiront comme des hommes civilisés et ils seront appelés bons et honnêtes, avec le pays pacifique où ils habitent ; car ils nous montreront leur grandeur en nous laissant en hommes libres. »

L'autre emploi de mardutō est moins évident dans un passage où Mara parle de ses multiples expériences et cite des exemples de conduites contradictoires :

«27. Que pouvons-nous donc dire au sujet de l'erreur qui s'est installée dans le monde et pour progresser il reçoit une dure instruction (م.is) - et dans ses troubles nous sommes secoués comme un roseau au vent? 28. Car je me suis étonné de nombreuses [gens] qui exposent leurs nouveau-nés et j'ai été stupéfait par d'autres qui élèvent ceux qui ne sont pas à eux. Il y a des gens qui obtiennent les richesses avec labeur; et même j'ai été stupéfait par d'autres qui héritent ce qui ne leur appartient pas. Ainsi comprends et vois que nous progressons en instruction (Rhaxis) qui se fait dans l'erreur. "

La première et la dernière phrase du texte pose de sérieux problèmes de traduction, notamment à cause des termes qui dérivent de la racine $r d a$ ( $\left.\kappa_{x i}\right)$, la même qui donne mardutō. Son premier sens est de marcher, avancer et aussi s'égarer. Il est possible de traduire le premier terme, qui est un participe, comme « discipline », « effort» ou aussi « ignorance $»^{23}$. Cependant, à notre avis, le texte parle d'un avancement dans l'instruction, dans la connaissance, qui se fait à travers l'observation de comportements humains contradictoires, tous forcément marqués par l'erreur. En conséquence, on reprend aussi la conclusion du texte, car Mara au début et à la fin parle de l'erreur (هo (ب), mais ce terme signifie aussi l'égarement, l'oscillation entre des avis contraires. Ces emplois font penser à la $\delta$ ó $\xi \alpha$ en grec ${ }^{24}$. Ainsi, on peut supposer que Mara parle d'une « instruction » qui s'acquiert face à des opinions contradictoires. Bien que le passage soit obscur, notre proposition rejoint les traductions existantes quant à l'insistance sur l'idée de progrès, d'avancement dans la connaissance. Toutefois, la présence du terme mardutō semble traduire l'intention d'associer les deux types d'apprentissage : l'examen des lettres et son application pratique ${ }^{25}$. La mise en évidence de l'usage systématique du mot « instruction » donne une plus grande cohérence à ce passage et permet de mieux l'inscrire dans la logique du texte entier.

Le fragment sur les attitudes contradictoires contient une information sur l'exposition des enfants, discutée dans le contexte du rapport de Mara au christianisme. Mara observe deux pratiques opposées : l'abandon des nouveaux-nés d'un côté et l'accueil des enfants d'autrui de l'autre, mais il ne porte pas de jugement sur ces pratiques ${ }^{26}$. Or, dans l'Antiquité, l'exposition

\footnotetext{
${ }^{23}$ Dans les traductions existantes, il y a des choix différents, voir Both the progress in it with heavy labour (CURETON 1855, p. 72); und sie mit schwerer Strafe züchtig (SCHULTHESS 1897, p. 369); E il progresso si ha per questo in dura fatica (RAMELli 2005, p. 566). Il y a aussi plusieurs possibilités de traduire 'almō: comme « monde », « siècle » ou " progrès ». B. Pratten corrige le texte syriaque et lit « travail ». Je traduis l'expression « dans / pour le progrès » par l'infinitif « pour progresser ». En outre, I. Ramelli voit dans ce passage l'influence de l'idée stoïcienne de progrès, voir RAMELLI 2012, p. 217-220.

${ }^{24}$ D. Rensberger traduit ce terme par delusion, voir RAMELLI 2012, p. 217-218.

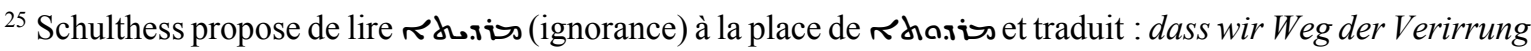
wandeln (SCHULTHESS 1897, p. 369, note 6).

${ }^{26} \mathrm{D}$. Rensberger a souligné que Mara n'exprime pas de condamnation de cette pratique ; contrairement à ce que suggère K. McVey qui y voit une critique de l'exposition et une marque du christianisme de l'auteur de la Lettre, voir RENSBERGER 2010, p. 8-9.
} 
des nouveau-nés, bien que pratiquée et légalement permise, était tolérée plutôt que recommandée et surtout à l'époque hellénistique les avis des auteurs païens sur cette question sont partagés ${ }^{27}$. L'étonnement de Mara correspond à la perplexité de ses contemporains et reflète également son souci de distinguer entre la vérité et l'opinion ${ }^{28}$.

La présence de cette problématique ne s'oppose pas à l'idée d'une visée pédagogique de la Lettre de Mara: bien au contraire. Plutarque, dans son traité Sur l'éducation des enfants, se montre assez proche de Mara lorsqu'il exprime le souci d'une éducation en tant qu'acquisition de la connaissance et de la vertu :

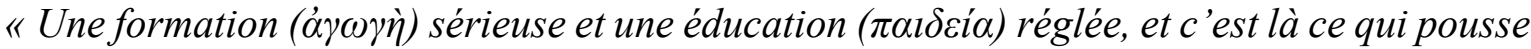
et qui aide, je l'affirme, à trouver la vertu et le bonheur. Les autres biens, eux, sont humains, insignifiants, indignes d'être recherchés. La naissance est, certes un bien, mais c'est un bien appartenant aux aïeux. Les richesses sont précieuses, mais elles sont aux mains de la chance qui souvent les enlève à leur détenteur pour aller les porter à ceux qui ne l'espéraient pas, et une grosse fortune constitue une cible pour ceux qui visent à la bourse ... La gloire, certes, est respectable, mais inconstante. La beauté est très enviable mais de peu de durée. La santé est chose précieuse mais instable. La force est désirable, mais à la merci de la maladie et de la vieillesse. ... L'éducation au contraire est, de tous les biens qui sont en nous, le seul immortel et divin ${ }^{29} . " 1$

Dans la Lettre de Mara se trouve un passage semblable :

«29. Viens nous parler, ô sage parmi les hommes : à quelles choses l'homme peut-il se fier? De quels biens désirés pouvons-nous dire qu'ils sont durables? De l'abondance des richesses? Elles sont arrachées. De forteresses? Elles sont pillées. De villes? Elles sont dévastées. De gloire? Elle est humiliée. De puissance? Elle est renversée. De beauté ? Elle se fane. De lois ? Elles tombent [en désuétude]. De pauvreté ? Elle est méprisée. D’enfants ? Ils meurent. D’amis? Ils deviennent infidèles. Des honneurs? La jalousie les précède. »

Mara s'exprime ainsi, quand il encourage son fils à s'attacher à la vertu et la bonne réputation, provenant de l'étude des lettres et à la pratique d'une bonne manière de vivre. Or, l'éducation, la paideia, est un moyen qui permet d'y parvenir. Ce rapport étroit entre l'instruction et la vertu, la philosophie et la vie bonne, est aussi annoncé dans les premières lignes de la Lettre, quand Mara associe l'étude des lettres et la poursuite de la sagesse. Nous allons donc examiner son projet pédagogique, défini comme «étude des lettres et poursuite de la sagesse », en commençant toutefois par sa dimension pratique et ses liens avec le stoïcisme.

\footnotetext{
${ }^{27}$ Le dossier des textes anciens relatifs à cette pratique a été établi par CAMERON 1932, p. 105-114. Parmi les auteurs qui en parlent figurent Platon, Théét 160d-e ; Rep 372b, 459d ; Lois V 740, XI, 930c; Aristote, Polit. 1335b; Sénèque, De ira I, 15, 2 ; les avis négatifs sur l'exposition : Plutarque, De genio Soc. 590 ; Or. Syb. II, 280 et III, 762 ; Musonius, Hiérocles, Philon d'Alexandrie. Intéressante pour notre sujet est l'opinion de Démocrite qui admet qu'il est naturel d'engendrer des enfants, mais il semble penser qu'il est plus raisonnable de les adopter, voir CAMERON 1932, p. 109. Les juifs et les chrétiens sont connus pour leur opposition à cette pratique, voir Didaché 2, 2 ; Épitre de Barnabé 19, 5. Parmi les auteurs syriaques, Bardesane s'exprime à ce sujet en des termes proches de la Lettre de Mara, voir Livre des lois des pays, trad. F. NAU, p. 39. Le parallèle est signalé par RAMELLI 2005, p. 566.

${ }^{28}$ D. Blank souligne l'idée d'étonnement ( $\left.\theta \alpha v \mu \alpha ́ \zeta \xi \varepsilon v\right)$ exprimée dans ce passage et propose de la confronter à la distinction parménidienne entre vérité et opinion $(\dot{\alpha} \lambda \hat{\eta} \theta \varepsilon 1 \alpha-\delta o ́ \xi \alpha)$, voir BLANK 2012, p. 172.

${ }^{29}$ Plutarque, De l'éducation des enfants, VIII, 5c11-e6, éd. A. PHILIPPON, J. SiRINELli, p. 43-44. Voir aussi : PRESTON 2001, p. 86-119. Le passage de Plutarque ressemble à la Lettre de Mara 29.
} 


\section{Paideia et la « manière de vivre " ou vertu pratique}

Les éléments de la Lettre qui concernent la dimension pratique de la paideia, ont été étudiés à cause de leur proximité avec l'enseignement moral des stoïciens. Les travaux de F. Schulthess, S.S. Averincev, I. Ramelli, A. Merz et T. Tieleman ont mis en évidence l'influence de l'éthique stoïcienne sur la Lettre de manière tout à fait convaincante, en se basant sur l'étude du vocabulaire. Ainsi Schulthess a signalé que certains termes éthiques utilisés par Mara se

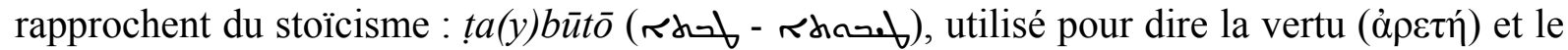

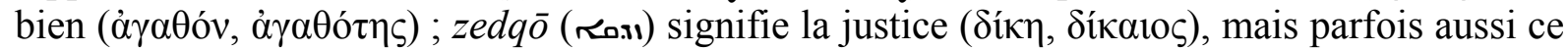

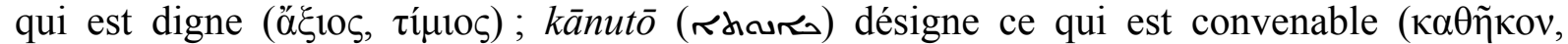
$\kappa \alpha \tau o ́ \rho \theta \omega \mu \alpha)^{30}$. La plupart de ces notions sont signalées par A. Merz et T. Tieleman qui ajoutent à la liste la joie ( $\chi \alpha \rho \alpha ́)$, le convenable et l'avantage au sens moral (ő $\varphi \varepsilon \lambda \circ \varsigma)^{31}$. I. Ramelli voit

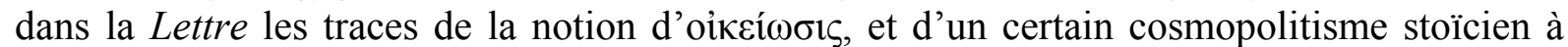
l'endroit où Mara parle d'une parenté élargie; elle tente ainsi des rapprochements avec les stoïciens romains, notamment avec Musonius Rufus ${ }^{32}$. Plus nuancée est l'analyse de D.L. Blank, qui, d'un côté, parle des liens possibles avec Épictète, Sénèque et Chrysippe, mais il montre aussi que l'enseignement éthique de la Lettre comporte plusieurs accents épicuriens, ainsi qu'aristotéliciens, platoniciens ou socratiques, ce qui plaide en faveur d'une connaissance superficielle du stoïcisme, acquise dans le cadre de la paideia. En fait, certaines opinions de Mara "sonnent stoïcien », mais s'écartent dans les détails de la doctrine du Portique. Telles sont les attitudes de Mara par rapport aux thèmes principaux de sa lettre, à savoir les biens, les inégalités, les adversités du destin, la justice, la figure du sage, etc. Le traitement de ces thèmes est « socratique », fondé sur l'expérience et destiné à expliquer comment vivre dans les temps troublés ${ }^{33}$.

Le lien avec l'éthique stoïcienne, bien présente dans l'enseignement scolaire, nous paraît néanmoins essentiel, dans la mesure où les propos de Mara reflètent un thème stoïcien de la pratique de la vertu et du « bon usage » $(\chi \rho \tilde{\eta} \sigma ı))$ des choses et des événements. Cependant, il s'agit d'une question bien connue et traditionnellement liée à l'éducation - celle de la vocation pratique et pédagogique de la philosophie - ; ses origines remontent à Platon et Aristote, mais peut-être les stoïciens et les épicuriens lui ont-ils accordé une importance particulière ${ }^{34}$. Cette approche de la doctrine stoïcienne a été étudiée par Thomas Bénatouïl, selon qui «l'homme stoïcien se définit par ses rapports pratiques à des ressources naturelles offertes par la providence et accompagnées de modes d'emploi plus ou moins explicites. Dans ces usages et

\footnotetext{
${ }^{30}$ SCHULTHESS 1897, p. 383-384. Les conclusions de Schulthess sont reprises par Аверинцев 1985.

${ }^{31}$ Mertz, Tieleman 2008, p. 110-116.

32 RAMELLI 2005, p. 553-555 ; voir aussi RAMELLI 1999, p. 197-212. Ramelli signale aussi le thème de la justice divine et la dimension éthique de la philosophie stoïcienne en général.

${ }^{33}$ BLANK 2012, p. 173 (sur les biens et les inégalités) ; p. 175-177 (sur la providence et la justice) ; p. 178 (sur les épreuves à endurer). Il y a encore le souci de bonne réputation - important pour Mara, mais moins pour les stoïciens (p. 179-181). Ces écarts ont été signalé aussi par SCHULTHESS 1897, p. 375-376.

${ }^{34}$ Chez Platon et Aristote on trouve déjà l'idée que la philosophie est essentiellement une paideia, qui fait acquérir des bons habitus aux auditeurs, voir HADOT 1998b, p. 223-229. À part les stoïciens, les disciples d'Épicure prônent la visée pratique de la philosophie : " Notre seule occupation doit être la guérison de nous-mêmes » et « Vide est le discours de ce philosophe par qui aucune passion de l'homme n'est soignée », voir HADOT 1998b, p.
} 212. 
leurs réglages réside la possibilité de la sagesse comme savoir du bon rapport à soi-même et au monde ${ }^{35}$. »

Cette thématique est véhiculée par le terme ${ }^{c} \bar{u} m r \bar{o}$ (حهـ), qui veut dire la manière de vivre et apparaît très souvent dans la Lettre pour faire le lien entre l'éducation scolaire et sa mise en pratique. Le 'cümrō n'est pas un terme technique, mais il semble néanmoins avoir son correspondant grec - le $\sigma \chi \tilde{\eta} \mu \alpha$, employé en transcription syriaque, askemō : "Quand un homme est séparé des siens, qu'il soit capable de garder sa manière d'être (askemō) et qu'il fasse avec justice ce qu'il lui convient [de faire] » (Lettre 8). Cet emploi est unique, car Mara utilise surtout le terme syriaque, ${ }^{c} \bar{u} m r \bar{o}$. Sa première occurrence se trouve en début de la Lettre, où Mara raconte ses propres études : «j'ai scruté la façon de vivre des hommes ( $\left.{ }^{c} \bar{u} m r \bar{o}\right)$ et j'ai été amené à l'étude (yulponō) » (Lettre 3). La condition humaine comme objet d'étude est indiquée aussi plus loin : «Moi alors, mon enfant, j'ai scruté les hommes - dans quelle misérable condition ils se trouvent! » (Lettre 48). Les causes de cette situation se trouvent dans leur mode de vie, car les hommes, " dans leur manière de vivre, ils se conduisent comme sourds et aveugles" (Lettre 52) ; « ils n'ont aucune manière de vivre déterminée, à laquelle ils s'adonnent » (Lettre 53). Mara cite l'exemple des guerriers - peut-être des Romains : « Et chaque homme libre parmi eux, quand [il est] dans la bataille, cherche à acquérir le nom de vainqueur, mais les vaillants ne voient pas par combien de désirs insensés l'homme est emprisonné dans le monde » (Lettre 55). Ces «désirs insensés» poussent les hommes à chercher des choses périssables et sans valeur : « ceux qui conquièrent par leur force et se condamnent par leur propre cupidité » (Lettre 56).

En réponse à ce tableau plutôt sombre, Mara donne des conseils à son fils. Il lui recommande, entre autres, de mettre en pratique l'enseignement éthique qu'il reçoit : « En fait, tout ceci m'est venu à l'esprit pour t'en écrire ; il ne suffit pas d'en parler, mais il convient que cela soit mis en pratique. Car je sais aussi que lorsque tu pratiqueras cette manière de vivre, elle te rendra vertueux et tu seras hors des ennuis » (Lettre 60-61). Cette bonne manière de vivre est guidée par le désir de la sagesse. "Consacre-toi à la sagesse, source de toutes les vertus et trésor qui ne périt pas; là-bas tu poseras ta tête et tu te reposeras, car elle sera pour toi un père et une mère, et une bonne compagne pour ta vie (litt. ta manière de vivre) » (Lettre 65).

Les emplois du terme ${ }^{c} u m r o ̄$ montrent l'importance de la dimension pratique de la vertu dans la Lettre. Faisant écho au titre de l'article de Pierre Hadot, on peut dire que la philosophie de Mara n'est pas une éthique mais une pratique ${ }^{36}$ et sa Lettre parle de la vertu en tant que « bon usage » des choses, sans chercher à proposer une théorie de la vertu en général. Cette dimension pratique est particulièrement visible dans le texte. Mara parle souvent de gens très divers : les riches, les pauvres, les prisonniers, les vainqueurs, ceux qui ont hérité, ceux qui ont tout perdu, ceux qui élèvent les enfants et ceux qui les abandonnent. Certains exemples sont racontés dans une perspective très personnelle, avec un « je » bien appuyé, parce qu'il s'agit probablement du vécu de l'auteur ; d'autres ressemblent davantage à une sorte de sagesse populaire. L'autre catégorie d'expériences sont des exemples provenant de la littérature. Ces différents types d'exemples racontent tous des expériences humaines, des manières de vivre.

Mara ne se limite pas à raconter des anecdotes et les parties relatives aux pratiques combinées avec des passages exhortatifs, contenant des enseignements éthiques sous forme de

\footnotetext{
${ }^{35}$ BÉNATOUÏL 2006, p. 136. L'auteur retrace le débat sur l'usage de la vertu chez les principaux représentants du stoïcisme, en passant par des questions sur la vertu du sage et le caractère permanent ou non de celle-ci ; BÉNATOUÏL 2006, p. 169-174.

${ }^{36}$ HADOT 1998 b.
} 
sentences ou de préceptes. Chaque expérience significative est accompagnée d'un enseignement. Ainsi, la description du départ de Samosate (Lettre 16-23) est suivie par un passage où Mara rassure son fils de ne pas craindre l'exil (Lettre 24-26). Ensuite, vient la première série d'exemples où les souvenirs se confondent avec les expériences de personnages historiques (Lettre 27-31). Mara cite les attitudes contradictoires qui ont suscité son étonnement et évoque ensuite les exemples de personnages qui ont connu un retournement inattendu du destin Darius, Achille, Polycrate, Priam, Archimède, Socrate et Pythagore. Dans le conseil qui suit, il exhorte son fils à chercher des biens impérissables (Lettre 32-41), à savoir l'éducation et la sagesse. C'est ainsi que Mara rapporte l'exemple des sages persécutés (Lettre 42-47), suivi d'un long souvenir des conduites humaines répréhensibles (Lettre 48-59). Cette description se termine par une nouvelle exhortation à s'appliquer à la sagesse et à la pratique de la vertu, ce qui permet de supporter les persécutions (Lettre 60-67). La dernière expérience est la plus dramatique, car elle concerne le changement de la situation de l'exil (Lettre 68-75). De même, le dernier avertissement donné au fils est celui de ne pas être affligé lorsque Mara mourra (Lettre 76-79).

Cette structure permet de réaliser à quel point les réflexions éthiques de Mara sont étroitement liées aux «manières de vivre» bien concrètes. Cela expliquerait aussi des écarts par rapport au stoïcisme ou toute autre doctrine philosophique. Cependant, la longue liste des thèmes philosophiques sous-jacents aux conseils de Mara, est toujours conditionnée par son vécu : l'idée de la parenté élargie est inséparable de la réflexion sur l'absence de parents naturels, l'affirmation que « pour les hommes sages chaque lieu est pareil » est née du souvenir de l'exil, la réflexion sur les biens durables correspond au souvenir de la perte des biens, la critique des richesses comme source de malheur vient de l'expérience de « la convoitise » par laquelle « les hommes faibles sont emmenés captifs », etc.

Au cours de ces exhortations, la sagesse est élevée au rang du seul bien durable. Mara en conclut que la seule bonne manière de vivre est l'exercice de la sagesse ${ }^{37}$. Car, selon lui, la

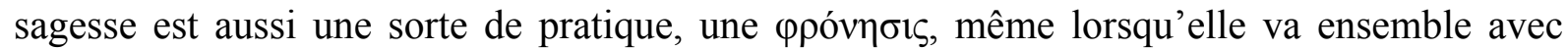
l'étude des lettres.

\section{Paideia et la poursuite de la sagesse}

La lecture des passages où apparaît le mot «sagesse », hakimutō, montre que les termes grecs correspondants sont $\varphi \rho o ́ v \eta \sigma 1 \varsigma$, qui indique la sagesse pratique, ou $\sigma \omega \varphi \rho \circ \sigma u ́ v \eta$ qui signifie la prudence, la tempérance et la maîtrise de soi. De même, l'adjectif hakim désigne un homme doté de cette sagesse en pratique : artisan, médecin ou savant ${ }^{38}$. Cependant, la question du rapport entre cette sagesse et la philosophie est d'autant plus légitime que ces deux termes sont

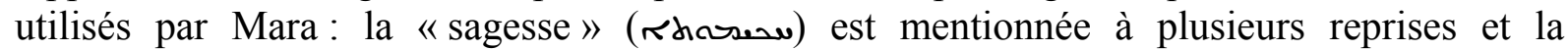
"philosophie » (rhraol.a) une fois seulement. En outre, l'aveu de Mara, selon lequel : «Tout ce que j'ai trouvé dans l'étude [des sciences] des Grecs est lié à la naissance de la liberté » (Lettre 4), est parfois traité comme concernant les études de la philosophie ${ }^{39}$. D'après F.

\footnotetext{
${ }^{37}$ Sur ce sujet, voir HADOT 2003, p. 289-304.

38 ThesSyr, col. 1265-1268. Les exemples cités par le Thesaurus Syriacus proviennent pour la plupart des versions syriaques de la Bible.

${ }^{39}$ Voir RAMELLi 2005, p. 551-552 ; MERZ, TIELEMAN 2008, p. 111. Schulthess, qui défend le stoïcisme de Mara, ne traduit pas cette phrase parce qu'elle est très abîmée, voir SCHULTHESS 1897, p. 366. Cureton reconstruit la phrase et pense qu'elle est relative à l'éducation grecque, abandonnée par l'auteur au moment de sa rencontre avec le christianisme, voir CURETON 1855, p. 70 et 101.
} 
Schulthess, le rapprochement entre la sagesse et la philosophie est bien stoïcien et on peut le trouver chez Mara qui voit dans la sagesse un exercice à la fois intellectuel et spirituel, apportant la consolation dans les épreuves ${ }^{40}$. Cependant, D.L. Blank, propose de distinguer dans le vocabulaire de Mara la « philosophie » au sens fort et la « sagesse » transmise par l'éducation ${ }^{41}$. Regardons alors les passages qui traitent de la sagesse, hakimutō-de sa nature et des méthodes de son acquisition.

Nous avons déjà vu sa première mention, dans la phrase où la poursuite de la sagesse est présentée comme occupation digne des hommes libres, de pair avec l'étude des lettres. La place de la sagesse par rapport à l'éducation et la philosophie est bien expliquée quelques lignes plus loin :

"10. Car ces hommes qui suivent l'instruction (mardutō), cherchent à se libérer des épreuves ( $\dot{\alpha} \gamma \omega \dot{v})$ du destin; et ceux qui persévèrent dans la sagesse (hakimutō), sont soutenus dans l'espérance de la justice; et ceux qui se tiennent dans la vérité montrent signe de leur vertu; et ceux qui se consacrent à la philosophie (filosofutō) sont libérés de l'attention portée aux misères du monde. »

Dans ce texte, Mara enchaîne les éléments constitutifs de l'éducation. Il explique les avantages de l'éducation, mardutō, de la sagesse, de la vérité et, enfin, de la philosophie - ce dernier terme est une translittération syriaque du mot grec. Cette longue phrase, apparemment redondante, retrace en réalité le chemin qui s'ouvre devant celui qui commence l'éducation. Ce texte montre aussi que l'auteur distingue entre l'éducation, la sagesse et la philosophie ; puis, cette distinction permet de nuancer le rapport de Mara à la philosophie en général. En fait, la philosophie serait plus proche de l'instruction, car l'une et l'autre ont pour résultat la libération de l'homme des malheurs apportés par le destin. En revanche, la sagesse et la vérité sont relatives à l'acquisition de la vertu. Or, Mara parle de la « bonté », tabutō, le terme qui, dans le

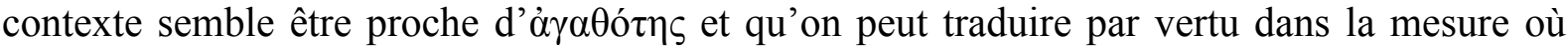
à $\gamma \alpha \theta$ ó $\varsigma$ possède un sens moral.

Ainsi, la sagesse est une composante pratique de l'éducation et elle est présentée comme telle dans les autres passages de la Lettre. La phrase suivante, Lettre 11, est significative quant à la nature de la sagesse : « Et toi alors, mon fils, dans ces choses-là, agis avec sagesse, comme un homme sage qui cherche à mener une vie pure. » Mara utilise deux fois le terme hakimutōd'abord, pour décrire la conduite qu'il recommande à son fils, ensuite pour dire qu'il y a des « hommes sages » qui l'ont pratiquée. Les autres occurrences montrent que la sagesse est avant tout une chose à pratiquer, une certaine caractéristique de la manière de vivre. Les évocations des « hommes sages » sont très importantes dans cette perspective, car ils servent d'exemple de cette sagesse pratique. Il ne faut pas oublier que les « sages » de la Lettre de Mara ne sont pas à confondre avec le sage stoïcien, représentant un idéal moral presque inatteignable ${ }^{42}$. Mara parle plusieurs fois des hommes sages et vertueux, des hommes bien : « Pense plutôt ainsi : que pour les hommes sages chaque lieu est pareil, et pour les vertueux il y a dans chaque ville de nombreux pères et mères » (Lettre 25). Dans le même sens, il s'exprime plus loin : « La crainte est une excuse qui n'existe pas dans l'esprit de [ceux] qui sont sages, mais de ceux qui s'égarent

\footnotetext{
${ }^{40}$ D'après Schulthess, la philosophie dans la Lettre de Mara serait un exercice spirituel conduisant à la vertu et à la consolation dans les épreuves, voir SCHULTHESS 1897, p. 382-383. Il évoque Antisthène (Diog. Laërt. VI, 105), Sénèque (Ad Polyb I, 2 ; De vita beata V, 3) et Marc Aurèle (VIII, 1). Cette problématique est traitée par P. Hadot 2003 [1993]. Hadot étudie surtout Socrate, Epictète et Marc Aurèle.

${ }^{41}$ BLANK 2012, p. 168-169.

${ }^{42}$ Sur les aspects stoïciens et épicuriens dans la figure du sage, voir HADOT 1998a [1991], p. 9-26. Sur le caractère éclectique des « sages » de la Lettre de Mara, voir les observations de BLANK 2012, p. 174-177.
} 
loin de la loi. Car personne n'a jamais été dépouillé de sa sagesse de la même manière que de sa propriété. » (Lettre 35) La sagesse est donc une qualité de vie, une attitude, une disposition de l'esprit.

Dans ce contexte s'inscrivent les exemples des sages persécutés (Lettre 42-47). Les exemples de Socrate et de Pythagore peuvent être trompeurs et orienter l'interprétation du terme hakimutō vers une doctrine philosophique, tandis que l'intention de Mara est d'évoquer les fruits impérissables de leurs vies vertueuses et non leurs doctrines. Le fait que le « sage roi » soit cité en raison de son action législatrice, concorde avec cette observation. Si on admet l'hypothèse de K. McVey, selon laquelle la mention du " sage roi des Juifs » est une interpolation et que le texte original parlait de Palamède, la dimension pratique de la sagesse dans la Lettre reste intacte ${ }^{43}$. Ces exemples prouvent que la sagesse ne peut pas protéger de la mort physique, mais elle confère toutefois une sorte d'immortalité liée aux œuvres que le sage laisse après lui. C'est ainsi que la sagesse est un bien impérissable, plus précieux que toutes les richesses matérielles. Pour cela Mara exhorte son fils : "Consacre-toi à la sagesse, source de toutes les vertus et trésor qui ne périt pas ...» (Lettre 65) et, en prévision de sa propre mort, il parle de lui-même et de ses camarades : «Et ici, en prison, nous rendons grâce à Dieu parce que nous avons gagné l'amour de beaucoup, car nous nous soumettons à l'épreuve de tenir dans la sagesse et dans la joie » (Lettre 70).

À première vue, la ressemblance entre cette sagesse pratique et la philosophie stoïcienne paraît tout à fait évidente bien que superficielle. Or, certains passages de la Lettre de Mara donnent l'impression de formules stéréotypées, de clichés philosophiques, de proverbes. Cette particularité a été déjà observée par Catherine Chin qui rappelle l'utilisation scolaire de ce genre de formules ${ }^{44}$. Il s'agit d'affirmations provenant d'une " morale populaire », transmise sous forme de sentences $(\gamma \nu \omega ́ \mu \eta)$, proverbes, fables ou anecdotes moralisatrices ${ }^{45}$. Il est, certes, possible d'y reconnaître des éléments caractéristiques d'une doctrine philosophique concrète stoïcienne, en l'occurrence - ; néanmoins ces expressions restent trop sommaires pour qu'on puisse trouver des citations leur correspondant dans les écrits philosophiques. La reconnaissance de l'origine gnomique de certains passages de la Lettre est révélatrice de ses liens avec la paideia, mais aussi avec la rhétorique - comme l'a montré C. Chin. Ces formules proverbiales, bien frappées et facilement reconnaissables ont été souvent utilisées dans toutes sortes d'exercices scolaires et aussi appréciées par les orateurs. En outre, le recours aux sentences n'a pas été préjudiciable pour le contenu philosophique de l'écrit. Teresa Morgan a analysé quelques textes de la " haute philosophie » qui sont néanmoins marqués par la philosophie populaire exprimée dans les sentences ${ }^{46}$. Ainsi, dans le cas de la Lettre de Mara, l'usage des sentences et des proverbes pourrait bien expliquer cette «forme populaire du stoïcisme» évoquée par les chercheurs ${ }^{47}$.

Étant donné que les sentences, fables et proverbes ont été utilisés dans les premières étapes de l'enseignement, il paraît tout à fait cohérent que Mara les intègre dans un écrit ayant pour but l'exhortation à l'instruction, à la paideia. En effet, les élèves apprenaient à lire et écrire en

\footnotetext{
${ }^{43}$ MCVEY 2015a, p. 316-322.

${ }^{44}$ CHIN 2006, p. 156-157.

${ }^{45}$ Consulter les travaux de T. Morgan : MoRgan 1998 et 2007.

${ }^{46}$ Ces textes de la « haute philosophie » sont: lettre $A$ Marcia de Sénèque, De la tranquillité de l'âme de Plutarque, Oraison 32 de Maxime de Tyr et discours Aux gens combatifs et brutaux provenant du livre IV, 5 des Entretiens d'Épictète, voir MORGAN 2007, p. 285-299.
}

${ }^{47}$ BLANK 2012, p. 169 ; RAMELli 2012, p. 208, 212. 
recopiant ces phrases courtes, chargées d'un contenu utile pour leur éducation, comme par exemple : «La sagesse ( $\varphi \rho o ́ v \eta \sigma ı)$ ) est le plus grand bien », conservée dans un papyrus scolaire d'Égypte ${ }^{48}$. Mais ce recours à la littérature gnomique permet de réviser le titre de " philosophe » ou de «stoïcien» qu'on attribue à Mara, au profit de «rhéteur». En effet, son éducation apparaît davantage rhétorique que philosophique, dans la mesure où les recueils des dires et des histoires édifiantes ont été utilisés dans l'apprentissage de l'art oratoire ${ }^{49}$. Le côté rhétorique de la Lettre a été autrement remarqué par David Rensberger qui a comparé la Lettre de Mara avec les formes poétiques de la littérature sapientielle : biblique, araméenne et arabe ${ }^{50}$. Dans ce cas également, il s'agit d'une littérature qui exprime la morale populaire ${ }^{51}$.

Le lien entre la Lettre de Mara et la littérature gnomologique pourrait être établi à partir de l'observation des collections de sentences qui ont été traduites en syriaque, sans doute à la même époque. Il s'agit des Sentences de Sextus, Sentences de Pythagore, La sagesse de Ménandre, Sentences de Théano, dont les ressemblances avec la Lettre de Mara ont été signalées par Ute Possekel ${ }^{52}$. À titre d'exemple, prenons quelques sentences du recueil attribué à Sextus ${ }^{53}$. Dans ce recueil on trouve presque quatre-vingt sentences ayant pour objet la sagesse et l'attitude du sage. Un des thèmes principaux est l'ascèse du sage, son renoncement aux richesses et même à toute propriété. Or, certaines sentences ressemblent bien aux conseils donnés par Mara : "Le sage qui méprise les richesses est semblable à Dieu » (18); "Le sage, qui pendant la vie a été mal jugé des hommes, reçoit des éloges glorieux après sa mort » $(53)$; «Le sage croit n'avoir rien en propre» $(227)$; «Le bien qui se trouve en toi provient de la sagesse » (316) et encore " Le destin ne forme pas les sages ; car la grâce de Dieu est supérieure au destin » (436). Le même type de conseils se trouve également dans la Sagesse de Ménandre : «Si ton fils, au sortir de l'enfance, se montre humble et prudent, initie-le aux lettres et à la philosophie. Le livre lui sera un bon moyen d'instruction, à la fois regard lucide et langue diserte » $(6,1-2)$; "La vie, les richesses et les propriétés, sont aimables, mais plus désirable encore est la bonne réputation » (71); «Ainsi maux et biens sont-ils mêlés dans la vie humaine. (...) Personne ne peut choisir ni prendre pour soi un beau destin, ni se préserver de tout mal.

\footnotetext{
${ }^{48}$ P.Oxy 3006.16. Les papyrus scolaires (schooltext papyri) ont été analysés par MORGAN 1998 (voir le chapitre "Structures of enkyklios paideia", p. 50-89). Sur la sagesse dans les genres littéraires de la « morale populaire », voir MORGAN 2007, p. 43-47 (les proverbes sur la sagesse et la folie) ; p. 70-73 (sagesse dans les fables) ; p. 102105 (sagesse dans les gnomai).

${ }^{49}$ T. Morgan analyse surtout les collections latines, connues pour leur utilisation dans l'apprentissage de l'art rhétorique : comme la collection des dires de mémorables de Valerius Maximus ou celle du Pseudo-Diogenianus, voir MORGAN 1998, p. 1-22; 191-206.

${ }^{50}$ RENSBERGER 2010, p. 12-13.

${ }^{51}$ Sur les coïncidences entre le stoïcisme et la sagesse populaire d'inspiration biblique, voir KAMINKA, 1926, p. $233-252$.

52 Étant donné que les proverbes transmettent une sagesse populaire et immémoriale, il est impossible de dater ces recueils avec précision. Les rapports entre la Lettre de Mara et les collections des sentences - surtout celles contenues dans le même manuscrit BL Add. 14658, ont été signalés par PosSEKEL 1998, p. 7-36, et signalés par HUGONNARD-ROCHE 2004, p. 99-119. Voir aussi ZEEGERS-VANDER VORST 1978, p. 163-177.

${ }^{53}$ Les Sentences de Sextus sont un recueil très important et progressivement amplifié (jusqu'à 600 sentences), dont l'origine est attribuée à Sextus, un philosophe pythagoricien du $1^{\text {er }}$ siècle de notre ère ou à Sextus, évêque de Rome. Cette attribution chrétienne a fait qu'il est conservé en plusieurs versions. Largement cité par les auteurs païens et chrétiens, le recueil est systématiquement christianisé à partir du $4^{\mathrm{e}}$ siècle jusqu'au Moyen Âge : voir CHADWICK 1959 (édition critique du texte grec) ; PEVARELlo 2013.
} 
Suivant le sort que Dieu leur octroie, ainsi vont les humains, pour le temps qu'il leur est donné à vivre $\gg(96)^{54}$.

Le rapprochement entre la littérature gnomologique et la Lettre nous donne une autre vision de la connaissance de la philosophie par Mara et ouvre la possibilité d'interpréter autrement sa manière peu rigoureuse de se référer à l'éthique stoïcienne. On peut supposer que Mara recherche surtout un effet rhétorique, qu'il veut convaincre son interlocuteur et lui prouver l'importance de l'éducation. Pour atteindre ce but, Mara mobilise ses connaissances des doctrines philosophiques, mais aussi un bon nombre d'outils rhétoriques. Même si les connaissances de Mara en philosophie restent superficielles, elles sont adroitement utilisées dans le discours. On peut supposer également que sa formation intellectuelle a été marquée davantage par la rhétorique que par la philosophie et l'utilisation massive des sentences conviendrait bien à ce type de formation intellectuelle. Mara serait-il alors un apprenti sophiste ? Cette hypothèse n'est pas à exclure, car depuis la fin du $1^{\text {er }}$ jusqu'au début du $3^{\text {e }}$ siècle, les cités grecques de l'Asie Mineure connurent le phénomène de la seconde sophistique et il n'est pas impossible que la Lettre de Mara dépende de ce mouvement, unissant la philosophie et la rhétorique ${ }^{55}$. Cependant, les références littéraires et les exemples moralisants utilisés par Mara attestent davantage les liens étroits qui l'attachent à la culture littéraire de son époque.

\section{"À quelles choses l'homme peut-il se fier ? " - les hommes face au destin}

La démonstration de l'utilité de l'éducation est fondée aussi sur des exemples tirés de l'histoire et de la littérature. Ils se trouvent à deux endroits de la Lettre (30-31 et 42-47) et sont utilisés pour illustrer des propos légèrement différents. La première série d'exemples (Lettre 30-31) porte sur la permanence des choses : «Viens nous parler, ô sage parmi les hommes : à quelles choses l'homme peut-il se fier? De quels biens désirés pouvons-nous dire qu'ils sont durables ? » Ayant posé cette question, Mara cite une série d'exemples de vanité des choses auxquelles les hommes attachent une grande valeur - richesse, puissance, beauté, etc. Et il évoque le destin de quelques personnages :

"30. Quelqu'un se réjouit donc de son royaume comme Darius, et de sa prospérité comme Polycrate, ou de sa bravoure comme Achille, ou de sa femme comme Agamemnon, ou de sa descendance comme Priam, ou de ses compétences comme Archimède, ou de sa sagesse comme Socrate, ou de sa connaissance comme Pythagore ou de sa clairvoyance comme Palamède. 31. Passent, mon fils, les vies des hommes dans le monde, mais leurs honneurs et leurs vertus demeurent pour toujours. "

Mara évoque les personnages « littéraires » au sens antique du terme, historiques et mythologiques, dont les destins ont été ambigus et que rien dans leur vie ne les prédestinait à une fin funeste. Ils ont tous connu un destin tragique, au mépris de leur puissance, de leur sagesse et de leurs vertus. Néanmoins, l'examen attentif des exemples cités dévoile de nombreuses approximations qui montrent la superficialité des connaissances de Mara.

Qui est le roi Darius qui se réjouissait de son empire et qu'il a-d'après le contexte - perdu ? Ce nom est porté par deux souverains achéménides. Darius $1^{\text {er }}$ le Grand (550-486) fut bâtisseur de l'empire perse et adversaire des Grecs à la bataille de Marathon, mais il avait transmis l'empire à son fils Xerxès. Hérodote lui consacre presque la moitié de son Histoire où il le

\footnotetext{
${ }^{54}$ Les phrases citées proviennent de la version grecque du recueil, voir AUDET 1952, p. 59, 73, 75-76.

${ }^{55}$ Sur les liens de la Lettre avec la rhétorique et notamment la seconde sophistique, voir CHIN 2006, p. 161162 ; MCVEY 2015a, p. 305-326. Sur les rapports entre la seconde sophistique et la philosophie, voir BoULANGER 1923 ; PERNOT 2000, p. 244-254 ; BOWERSOCK 2002, p. 157-170.
} 
présente comme grand conquéreur. L'autre est Darius III (380-330), le cousin des rois achéménides arrivé au pouvoir au milieu de coups d'État, l'héritier d'un empire vacillant, vaincu par Alexandre le Grand. Dans la littérature consacrée à Alexandre, le personnage de son adversaire perse est plutôt ambigu : Diodore de Sicile, Quinte-Qurce et Plutarque dressent une image contradictoire d'un souverain beau, courageux et extrêmement riche, mais aussi lâche et vaniteux. La perte de l'empire par Darius est présentée par les auteurs grecs comme une juste punition $^{56}$ ou comme une conséquence de son orgueil ${ }^{57}$. C'est sans doute à lui que Mara pense.

Quant aux autres personnages cités, la plupart sont des exemples bien connus. Polycrate, tyran de Samos, fameux à cause de ses talents militaires et politiques, passait pour l'homme le plus chanceux au monde, mais il fut assassiné par une ruse du gouverneur perse de Sardes ${ }^{58}$. Trois héros de l'Iliade : Achille, Agamemnon et Priam figurent parmi les personnages littéraires les plus connus dont le destin pouvait servir à illustrer des propos différents. Chez Mara, ils représentent chacun un bien précieux, mais perdu contre toute attente. Ensuite, Mara cite les noms de quatre sages par excellence: Archimède, Socrate, Pythagore et Palamède. Il leur attribue les vertus pratiques, conformément au sens qu'il donne au mot sagesse, que nous traduisons par compétence, connaissance et clairvoyance. L'anecdote sur la mort d'Archimède est transmise par Plutarque - le philosophe fut tué par un soldat romain vexé par l'exclamation «Ne marche pas sur mes cercles! " ${ }^{59}$ Quant à Socrate, c'est un personnage presque autant connu que les héros homériques. Dans les écrits de Platon et de Xénophane, la mort de Socrate est comparée avec celle de Palamède - ce qui explique peut-être sa présence dans ce passage ${ }^{60}$. D.L. Blank a étudié les sources littéraires relatives à Palamède, pour en arriver à la conclusion que, malgré de nombreux textes sur sa mort injuste, l'idée la plus proche de la Lettre de Mara serait celle de Dion de Pruse pour qui Palamède a péri parce qu'Ulysse a utilisé contre lui sa propre sagesse ${ }^{61}$. Quant à la mention de Pythagore, il faut noter que parmi les Vies de Pythagore, celle rédigée au $2^{\mathrm{e}}$ siècle par Diogène Laërce synthétise les différentes traditions antérieures ${ }^{62}$. Ainsi le choix de personnages et surtout quelques rapprochements avec Plutarque,

${ }^{56}$ Cette idée se trouve chez Diodore de Sicile. Charidème, mercenaire athénien à la cour de Darius, est condamné à mort pour avoir parlé outrageusement au roi pendant un conseil de guerre. Au moment d'expirer, Charidème s'écrie que pour ce châtiment injuste Darius sera puni par la perte de son empire : voir Bibliothèque, XVII, 30. La mort de Charidème est racontée autrement par les autres auteurs.

${ }^{57}$ Une image positive de Darius se trouve chez Diodore de Sicile, qui le décrit comme « le plus brave des Perses » (Bibliothèque, XVII, 6). Quinte-Qurce est plus sévère : « Darius était d'un caractère doux et traitable ; mais la fortune gâte souvent le meilleur naturel» (L'histoire d'Alexandre, III, 2). Plutarque, dans la Vie d'Alexandre et La vertu d'Alexandre, présente Darius comme n'ayant pas beaucoup de caractère, car il sert d'arrière-plan pour la figure héroïque et vertueuse d'Alexandre.

${ }^{58}$ Hérodote, Histoires III, 40-43.

${ }^{59}$ Plutarque, Vie de Marcellus, XIX, 8-12.

${ }^{60}$ L'explication la plus connue de la mort injuste de Palamède est attribuée à Socrate. « J'ai de plus une consolation, c'est le souvenir de Palamède, de sa mort presque semblable à la mienne. Maintenant encore il fournit le thème de chants beaucoup plus beaux que ne fait Ulysse, injuste auteur de sa mort. » (Platon, Apologie 41b). Voir aussi Xénophon, Apologie 26.

${ }^{61}$ Dion de Pruse, Or. 13, 21. Voir la documentation étudiée par BLANK 2012, p. 180-181 et surtout par MCVEY 2015a, 316-322.

${ }^{62}$ Les Vies de Pythagore ont été rédigées à partir du $2^{\mathrm{e}}$ siècle. Dans l'ordre chronologique, il s'agit du livre VII des Vies des philosophes de Diogène Laërce $(† 180)$, la Vie de Pythagore par Porphyre $(\dagger 306)$ et enfin celle de Jamblique $(\uparrow 325)$. Diogène Laërce utilise amplement les sources historiques et biographiques plus anciennes et l'éditeur contemporain qualifie cette écriture de «conglomérat» doxo-biographique, voir le commentaire dans 
Dion de Pruse et Diogène Laërce rapprochent la Lettre de Mara de la littérature de la seconde moitié du $2^{\mathrm{e}}$ siècle.

Ce genre d'exemples moralisateurs fait partie des moyens de transmission de la « morale populaire ». Tout comme Mara, les sophistes ont une prédilection pour les grands personnages littéraires (homériques de préférence) et les événements de l'histoire grecque, en tant que mine d'exemples et de sujets pour les discours. Cette même attitude caractérise leur rapport à l'histoire, où les sophistes privilégient une histoire romanesque, sans le moindre souci du détail ; les personnages sont formés selon les besoins du discours ${ }^{63}$.

Il semble que tous ces personnages sont réunis autour de l'idée de la vanité des choses : tout est passager, tout peut être détruit, il n'y a rien qui demeure ${ }^{64}$. Dans le discours de Mara, à côté des biens matériels apparaissent les vertus et même la sagesse, car rien ne peut délivrer l'homme de son destin imprévisible. Cependant, Mara conclut : «Passent, mon fils, les vies des hommes dans le monde, mais leurs honneurs et leurs vertus demeurent pour toujours » (Lettre 31), et il poursuit : "Ainsi toi, mon petit enfant, choisis pour toi ce qui ne périt pas, car ceux qui s'occupent de telles choses, sont considérés modestes, aimés et estimés » (Lettre 32). Mais ce qui semble être un souci excessif de bonne réputation, se révèle être une manière de supporter les retournements du destin, sans s'attacher à quoi que ce soit : « À chaque fois quand un mal t'arrive, ne blâme personne, ne te mets pas en colère contre dieu et ne murmure pas contre ton destin » (Lettre 33). Cette conscience de l'imprévisibilité du destin est, finalement, une marque de sagesse : «La crainte est une excuse qui n'existe pas dans l'esprit de [ceux] qui sont sages, mais de ceux qui s'égarent loin de la loi. Car personne n'a jamais été dépouillé de sa sagesse de la même manière que de sa propriété » (Lettre 35). Cela étant dit, Mara revient sur le sujet principal de sa lettre : il vaut mieux s'occuper des lettres que des richesses (Lettre 36).

Dans la réflexion sur les biens périssables, tout semble être soumis au destin, le principal responsable des changements imprévus et immérités. Dans sa soumission au destin, Mara dévoile son côté oriental, peut-être même influencée par le zoroastrisme ${ }^{65}$. Cependant, ses positions ne sont pas aussi radicales que celles de l'adversaire chaldéen de Bardesane dans le Livre des lois des pays, qui prétend que les bonnes et les mauvaises actions des hommes sont décrétées par le destin et ne dépendent pas de la volonté ${ }^{66}$. Mara reconnaît la puissance du destin, mais il exhorte néanmoins son fils à étudier les lettres et surtout à suivre la sagesse ; cette attitude modérée lui vient sans doute de son éducation hellénistique et de la fréquentation des doctrines philosophiques nettement moins fatalistes. Voici comment parle Plutarque, dans le traité Sur la fortune :

Vies et doctrines des philosophes illustres, Livre VIII, introd., trad. et notes par J.F. BALAUDÉ et L. BRISSON, p. 921-1023 (les informations sur les sources pythagoriciennes, p. 924-932).

${ }^{63}$ ANDERSON 1993, p. 69-85 (sur les classiques: Homère, Hérodote, Thucydide, Xénophon, Euripide, Eschyle) ; p. 105-114 (sur l'historiographie des sophistes). L'exemple type est Arrien et sa Vie d'Alexandre, mais aussi Plutarque. Voir aussi PERNOT 1993, p. 257-263.

${ }^{64}$ Cette lecture est proposée par RAMELli 2005, p. 555-556. K. McVey note la discontinuité entre les deux listes des exempla et la difficulté à percevoir clairement les intentions de Mara par rapport à la première, voir MCVEY 2015a, p. 315-316. Dans le même sens BlanK 2012, p. 180.

${ }^{65}$ La conception orientale du destin / temps chez Mara est présentée par RENSBERGER 2010, p. 14-18. D’autres influences zoroastriennes (ou zurvanites) ont été signalées par DE JONG 2012, p. 141-153.

${ }^{66}$ Livre des lois des pays 25-27 ; trad. F. NAU, p. 37-40. I. Ramelli note la présence de la même thématique dans les deux écrits, sans faire un rapprochement chronologique, voir « Gesù tra i sapienti greci », p. 552-554. 
"C'est la fortune seule, et non pas le conseil, qui régit les mortels, a dit un poète. Quoi! ni la justice, ni l'équité, ni la tempérance et la modestie ne règlent les actions des hommes? Estce donc la fortune qui fit qu'Aristide préféra la plus extrême pauvreté aux grands biens qu'il pouvait amasser? Est-ce par elle que Scipion, s'étant rendu maître de Carthage, ne prit rien pour lui de ses riches dépouilles, et refusa même les voir? Que Philocrate, au contraire, avec l'argent qu'il reçut de Philippe, acheta des courtisanes et des poissons? Que Lasthène et Euthicrate, attachant le bonheur aux voluptés les plus criminelles, trahirent la ville d'Olynthe? Qu'Alexandre respecta les femmes de Darius, ses captives, et châtia sévèrement ceux qui voulurent les insulter? Est-ce enfin par un caprice de la fortune que le fils de Priam séduisit la femme de son hôte, et que, l'ayant emmenée à Troie, il remplit l'Europe et l'Asie de toutes les horreurs de la guerre ? ${ }^{67} "$

Dans ce passage il y a une étonnante ressemblance avec la Lettre de Mara quant à la manière de citer les personnages dont les actions témoignent au sujet de la liberté humaine et du destin. Or, le Syrien et le Grec affichent des positions très différentes : Plutarque défend la liberté et énumère les cas où la vertu ou le vice l'emportent sur les circonstances, tandis que Mara cite les décrets du destin qui tombent indépendamment des vertus. Le premier défend le libre arbitre, tandis que le second croit au destin, insensible à la bravoure, la sagesse et la clairvoyance des hommes. La comparaison entre ces deux passages met en évidence la place que Mara accorde à la question du destin. D. Rensberger insiste particulièrement sur l'importance de cette problématique, bien qu'il ne soit pas le premier à observer que l'auteur syriaque donne au mot

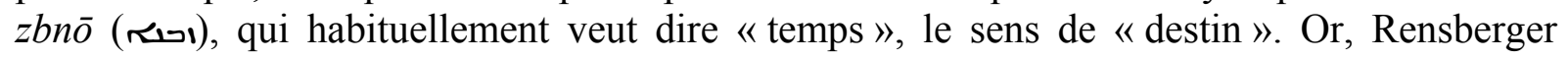
montre que les termes correspondants en grec seraient $\tau \dot{\chi} \chi \eta$ ou peut-être $\dot{\varepsilon} \rho \mu \alpha \mu \varepsilon ́ v \eta$, mais pas $\chi \rho o ́ v o \varsigma$ ni אaıpó $\varsigma^{68}$. Cette utilisation du terme $z b n o ̄$ est particulièrement intéressante, étant donné que la langue syriaque possède déjà la racine verbale hlaq, "déterminer », d'où vient le substantif helqō, utilisé pour dire "destin »; ce vocabulaire est employé notamment par Bardesane et ses disciples dans le Livre des lois des pays. On peut alors supposer que Mara a choisi un terme qui fait du destin un flot de changements plutôt qu'une fatalité. ${ }^{69}$

Cette nuance est très importante du point de vue de l'objectif pédagogique de la lettre, parce que Mara paraît être tiraillé entre l'importance de l'éthique et le déterminisme : ce qui explique peut-être certaines faiblesses de son argumentation. En réalité, il ne trouve pas de réponses à ses questions : pourquoi les hommes n'obtiennent-ils pas ce qu'ils méritent, conformément à leurs vertus ou leurs vices, mais leur vie est secouée par les retournements imprévisibles du destin? Cette question est d'autant plus dramatique que Mara est lui-même témoin d'un tel retournement. Dans la Lettre, le déterminisme oriental se heurte à la foi des Grecs en des vertus morales acquises par l'éducation. La solution vient peut-être de l'étude des exemples - et en particulier ceux des sages opprimés par les tyrans - car la sagesse seule peut offrir les moyens d'affronter les épreuves du destin.

\section{Les sages face aux tyrans et au destin}

La deuxième série d'exemples concerne trois personnages seulement : Socrate, Pythagore et le mystérieux « roi sage des Juifs ».

\footnotetext{
${ }^{67}$ Plutarque, Sur la fortune, 97c-e ; trad. F. FrAZIER, C. FroIdEFOnd, Paris, 1990.

${ }^{68}$ RENSBERGER 2010, p. 16.

${ }^{69}$ La différence entre l'attitude de Mara et celle de l'adversaire de Bardesane dans le Livre des lois des pays a été remarquée par RAMELLI 2005, p. 556. Ramelli suppose toutefois que Mara précède Bardesane de plusieurs décennies, ce qui - à notre avis - est une explication possible, mais pas nécessaire.
} 
«42. Quoi d'autre, en fait, avons-nous à dire, lorsque les sages sont menés sous contrainte par les mains de tyrans, leur sagesse est emmenée en captivité par la calomnie et ils sont méprisés pour leur clairvoyance, sans pouvoir se défendre? 43. Quel profit les Athéniens ontils tiré du meurtre de Socrate? En punition de ceci ils ont reçu la famine et la peste. 44. Ou les gens de Samos pour avoir brûlé Pythagore? En une heure leur pays tout entier a été recouvert de sable 45. Ou les Juifs pour leur sage roi ? A partir de ce temps-là leur royaume a été pris. 46. Avec justice, en fait, Dieu a vengé la sagesse de ces trois-là, car les Athéniens sont morts de famine, les Samiens ont été irrémédiablement submergés par la mer, et les Juifs, après être combattus et chassés de leur royaume, sont dispersés partout. 47. Socrate n'est pas mort, grâce à Platon ; ni Pythagore, grâce à la statue d'Héra, ni le sage roi, à cause des lois nouvelles qu'il a données. »

Les particularités des informations données par Mara ont été soulevées par tous les spécialistes qui ont, en outre, réuni une documentation concernant les exempla des sages persécutés dans la littérature ancienne ${ }^{70}$. L'interprétation de la mort de Socrate comme un banal assassinat commis par les Athéniens paraît surprenante, compte tenu de traditions transmises par Platon et Xénophon, dont les Apologies dressent un tableau complexe du procès. Cependant, une lecture considérablement déconnectée du contexte de la démocratie athénienne est faite par Diogène Laërce, au livre II des Vies des philosophes. Ce Socrate laërtien est entouré d'un climat hostile, très différent des écrits de Platon et de Xénophon. Diogène récolte des moqueries, des propos des comédiens et des rumeurs scandaleuses au sujet du philosophe, auxquelles il oppose les réactions après sa mort, à savoir une série de repentances publiques, comparables aux honneurs posthumes rendues à Homère ${ }^{71}$. Il y a ici une certaine ressemblance avec le Socrate de la Lettre de Mara. Mais il y a aussi une différence, car Diogène ne parle pas de famine, ni de peste comme une punition divine dont les Athéniens seraient victimes. Toutefois, la version de Mara, bien que fantaisiste, n'est pas dénuée de tout fondement. L'histoire connaît une fameuse « peste d'Athènes » (430-427) et plus tard une famine non moins importante (404) qui avait obligé les Athéniens à rendre la ville aux Spartiates ${ }^{72}$. Or, ces événements ont eu lieu pendant la vie de Socrate et non après sa mort (399). Cependant, ces épisodes ont été bien connus et la description de la peste d'Athènes par Thucydide a donné naissance à un topos rhétorique qui attribue les pestes à la colère des dieux ${ }^{73}$. Comment expliquer alors la lecture de

${ }^{70}$ K. McVey compare les exemples de Mara avec ceux qu'on trouve chez Cicéron Tusc. V, 37 ; Nat. deorum III, 36-37 ; Musonius Rufus ; Plutarque, Stoic. Rep. 37 ; Philon d'Alexandrie Probus XVI ; Justin Martyr, Apologie II, 7, 3 et 8, 1,2 ; Athénagore, Supplique 31, 1-2; Origène, CCelse I, 3 ; II, 41 ; Aphraate, Dem 14, 21 et 21, 13 ; voir MCVEY 1990, p. 263-268. Une documentation concernant les stoïciens romains - Perse, Juvenal et Musonius - a été réunie par RAMELLI 2005, p. 556-558. Pour plus d'informations et une bibliographie complète, voir Stoici romani minori, éd. I. RAMELLI, 2008. La Lettre de Mara fait partie de ce recueil.

71 «Lui, donc, n’était plus parmi les hommes ; mais les Athéniens se repentirent aussitôt, au point de fermer palestres et gymnases. Et les uns, ils les bannirent, tandis que Mélétos, ils le condamnèrent à mort. Et à Socrate, ils firent hommage de son effigie en bronze, qui fut l'œuvre de Lysippe, et qu'ils placèrent dans le Pompéion » II, 43. Voir l'introduction de M. Narcy dans Diogène Laërce, Vies et doctrines des philosophes illustres, Livre II : introd., trad. et notes par M. NARCY et M.-O. GOULET-CAZÉ, Libraire Générale Française, 1999, p. 170-172.

${ }^{72}$ Sur la famine en 404, voir Xénophon, Histoire grecque, II, 2. C'est le dernier épisode de la longue guerre du Péloponnèse (431-404) qui a opposé Athènes à Sparte et s'est terminée par la défaite d'Athènes. C'est aussi une période d'activité politique de Socrate - il est la voix d'opposition solitaire dans le procès des généraux des Arginuses et il s'oppose à la tyrannie des Trente au péril de sa vie.

${ }^{73}$ Dans les années 430-427, la fameuse «peste d'Athènes » coûta la vie à Périclès. Sa description vient surtout de Thucydide (II, 51), voir BYL 2011, p. 89-93. Les échos de la description de Thucydide se retrouvent chez les historiographes et aussi chez Philon d'Alexandrie, voir BYL 2011, p. 96-98. 
Mara ? On peut, certes, parler de confusion ${ }^{74}$. Cependant, ce traitement de l'histoire de Socrate montre que Mara raisonne en sophiste, capable de transformer son personnage selon les besoins de l'argumentation. Cela est d'autant plus probable qu'un sophiste célèbre, tel que Dion de Pruse, interprète l'histoire de Socrate de manière semblable ${ }^{75}$.

Les informations de Mara au sujet de Pythagore sont encore plus difficiles à démêler : il est mort brûlé à Samos et son héritage est une statue d'Héra. Déjà à l'époque de Mara, la vie de Pythagore est entourée de légendes. Diogène Laërce connaît trois versions de sa mort: le philosophe meurt égorgé par les habitants de Crotone (il la prend pour vraie); il meurt de son plein gré, suite à un jeûne de quarante jours ; il est tué par les Syracusains pendant la guerre entre Agrigente et Syracuse ${ }^{76}$. Bien que ces traditions soient différentes, elles ont un point commun : Pythagore est mort en Sicile et pas à Samos comme le prétend Mara. Ainsi l'inter-

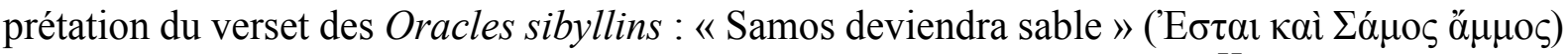
comme prophétie de la mort de Pythagore semble être une pure invention ${ }^{77}$. Outre le problème du lieu, la version de la mort de Pythagore dans le feu est très probablement influencée par un épisode assez connu des persécutions des pythagoriciens, brûlés dans une maison ${ }^{78}$.

Il existe toutefois plusieurs liens entre Pythagore et Samos. Le philosophe a vécu là-bas pendant un certain temps - peut-être même y est-il né - et Polycrate, tyran de Samos (cité aussi par Mara) fut d'abord son mécène, puis son ennemi ${ }^{79}$. La mention déroutante concerne la sculpture d'Héra comme l'œuvre de la connaissance de Pythagore et la raison principale de sa gloire posthume. En fait, Samos posséda un fameux sanctuaire d'Héra, érigé aux temps de Polycrate, et ce temple abrita une ancienne statue de la déesse ${ }^{80}$. En confondant Pythagore philosophe avec un sculpteur samien, Mara commet une erreur assez commune, répertoriée par Diogène Laërce ${ }^{81}$. Or, la même erreur se retrouve chez un autre auteur, Tatien $(\dagger 180)$, un

\footnotetext{
${ }^{74}$ NORELLI 2005, p. 199.

${ }^{75}$ Selon Dion de Pruse, Socrate fut tué par ses concitoyens et que ceux-ci furent punis de sa mort par les malheurs qui leur arrivèrent, voir Or. XLVII, 2-7. Voir RAMELLI 2005, p. 561.

${ }^{76}$ Vies des philosophes, VIII, 39. En VII, 45 Diogène Laërce cite une épigramme qui attribue le meurtre de Pythagore aux habitants d'Agrigente. Un point commun entre la première et la troisième version est le détail sur le champ de fèves. Pour les pythagoriciens, les fèves furent l'objet d'un interdit alimentaire particulièrement sévère : «C'est crime égal de manger des fèves et la tête de ses parents ». Il y avait plusieurs raisons à cet interdit, voir Vies des philosophes VIII, 24, 34. Voir DETIENNE 1970, p. 141-162 (sur les fèves, p. 152-154).

77 Sur l'oracle, voir CURETON 1855, p. 101. Selon Cureton, cette citation plaide en faveur du $2^{\mathrm{e}}$ siècle comme date de la rédaction.

${ }^{78}$ Sur la mort de Pythagore dans l'incendie, voir LÉVY 1927, p. 63-78. La même information se trouve chez Plutarque, Des contradictions des stö̈ciens, 37. L'information sur une quarantaine de pythagoriciens brûlés dans une maison se trouve chez Polybe, Histoires II, 7 ; Diodore de Sicile, Bibliothèque X et Diogène Laërce, VIII, 39. Les persécutions des pythagoriciens sont davantage racontées dans les Vie de Pythagore de Porphyre et de Jamblique.

${ }^{79}$ Sur l'incertitude du lieu de naissance de Pythagore (Samos, Lemnos, plus tard Syrie, Tyr), voir Diogène Laërce, Vie VIII, 1 et la note complémentaire, p. 1020 ; Clément d'Alexandrie, Stromates I, 62. Les rapports entre Polycrate et Pythagore sont assez obscurs et les sources parfois contradictoires, surtout en ce qui concerne les raisons pour lesquelles Pythagore quitta Samos, voir Diogène Laërce, VIII, 2, n. 3 (p. 941 ) et 5 (p. 942).

${ }^{80}$ Les légendes samiennes sur l'Héraion sont répertoriées par Pausanias, mais aucune ne parle de Pythagore, voir Description de la Grèce, VII, 4, 4.

81 «Certains prétendent qu'il y eut un autre Pythagore, un sculpteur originaire de Rhégion, qui fut le premier à viser l'apparence de la proportion et de la symétrie ; un autre, un sculpteur originaire de Samos ; un autre encore, mauvais orateur ; un autre médecin qui rédigea des ouvrages sur les hernies et qui écrivit des traités concernant
} 
chrétien oriental qui a vécu à Rome et en Grèce : « Je condamne Pythagore pour avoir représenté Europe assise sur le taureau, et vous pour avoir honoré son art de cet accusateur de Zeus ${ }^{82}$.

Les références à Samos dans la Lettre ont attiré l'attention des chercheurs qui ont essayé de trouver des raisons à cette connaissance particulière des traditions d'une région particulière, d'autant plus que Pythagore et Polycrate ne sont pas les seuls samiens mentionnés dans sa Lettre. En fait, le roi Darius est aussi lié à cette île. Hérodote nous renseigne qu'au temple samien d'Héra se trouva un tableau offert par un certain Mandroclès, l'ingénieur du roi Darius et constructeur du pont du Bosphore. Le tableau représenta ledit pont, avec le roi Darius assis sur son trône et regardant défiler ses troupes ${ }^{83}$. Il est tout à fait impossible de déterminer les raisons pour lesquelles Mara aurait pu avoir une meilleure connaissance de cette région de $1^{\prime} \mathrm{Asie}^{84}$. Les inscriptions attestent que les gens originaires de Commagène habitèrent dans de nombreuses cités grecques et que certaines d'entre elles (Éphèse, Athènes et l'île de Chios) ont reçu d'importantes donations de la part des rois de Commagène ${ }^{85}$. En même temps, Samos n'est pas loin d'Éphèse qui fut un des centres culturels de l'Ionie, connu par l'activité de ses sophistes. Mara aurait donc pu acquérir ces informations à un moment de sa formation intellectuelle, sans jamais visiter la région.

Les informations de Mara au sujet de Socrate et de Pythagore, bien qu'inexactes, sont bien adaptées aux besoins de son argumentation. Un exemple semblable se trouve chez Chrysippe, cité par Plutarque dans Des contradictions des stoïciens :

"Il dit aussi qu'il y a un fort mélange de nécessité. Que des malheurs arrivent aux gens de bien, tels que la condamnation de Socrate, la mort de Pythagore brûlé vif par les partisans de Cylon, les morts de Zénon et d'Antiphon mis en croix l'un par le tyran Demylos, l'autre par Denys, - que ces malheurs, dis-je, soient comparés à du son tombé, je laisse de côté le mauvais goût de la comparaison; mais dire que, du fait de la providence, il se constitue des mauvais démons pour de pareilles fonctions, comment n'est-ce pas un reproche à faire à Dieu ? ${ }^{86}$ »

Chrysippe évoque ici les malheurs arrivés aux gens bien - en l'occurrence aux philosophes pour illustrer les paradoxes de la providence et proposer une théodicée. L'analogie avec la Lettre de Mara est saisissante, car les présentations très sommaires des morts de Socrate et Pythagore sont suivies par la mention de la crucifixion des deux autres philosophes. Cette série d'exemples est particulièrement importante dans l'hypothèse que le " roi sage des Juifs » est identique à Jésus. La ressemblance entre Mara et Chrysippe concerne aussi le contexte : les deux auteurs citent les exempla des vertueux persécutés pour réfléchir au rôle du destin. Plutarque y voit un motif de reproche à faire à Dieu, tandis que Mara rejette $a$ priori toute forme de rébellion contre le destin et croit que, tôt ou tard et d'une façon ou d'une autre, le mal sera puni et le bien récompensé. Évidemment, les exempla ne servent pas à renseigner le lecteur sur les circonstances de la mort d'un personnage, mais à utiliser cette mort comme illustration d'une thèse. Dans la Lettre de Mara, chaque « sage persécuté » remporte une victoire posthume sur la mort violente, l'une des pires épreuves du destin. Néanmoins, cette victoire est due autant à

Homère ; un autre qui écrivit un traité sur les Doriens, comme le rapporte Denys. » (Vies des philosophes, VIII, 47, p. 977). Plusieurs Pythagore sont mentionnés aussi par Pline.

82 Tatien, Discours aux Grecs 31.

${ }^{83}$ Hérodote, Histoires, IV, 88.

${ }^{84}$ Selon A. Merz et T. Tieleman, Mara s'est rendu à Samos en tant que représentant de l'aristocratie et peutêtre dans la suite du roi de Commagène, voir MERTZ, TIELEMAN 2008, p. 120.

${ }^{85}$ FRASER 1978, p. 359-373.

${ }^{86}$ Plutarque, Des contradictions des stoïciens, 37. 
la sagesse du personnage qu'à l'action d'un Dieu qui punit les persécuteurs. Parce que le rapport entre ce Dieu et le destin n'est pas clair, on peut supposer que les biens et les maux proviennent de la même source et que le sage est celui qui sait les recevoir de manière égale. Le rapport entre les deux est peut-être semblable à celui qu'on instaure entre Dieu et la providence : ils sont distincts, mais la providence demeure un mode d'action divine envers le monde.

Mara parle peu de Dieu. Il le bénit, même en prison (Lettre 1, 9 et 70), il croit que Dieu aide les gens (Lettre 38). Mais quant aux sages persécutés, ce même Dieu « avec justice [...] a vengé la sagesse de ces trois » (Lettre 46). Enfin, il instruit son fils : « ne te mets pas en colère contre dieu et ne murmure pas contre ton destin » (Lettre 33), ce qui fait penser que l'action de Dieu et du destin sont identiques. Néanmoins, les épreuves pénibles sont vues comme l'œuvre du destin (Lettre 10, 16, 58, 63, 74, 80). Parfois Mara mentionne « les hauts et les bas des destins » (Lettre 13) et les « changements du destin » (Lettre 24). Il est possible que "l'amour et la dignité » dont il parle en Lettre 69, viennent aussi de la main du destin. Cette façon de parler du destin pourrait simplement traduire le refus d'attribuer à Dieu l'origine du mal, sans pourtant les opposer l'un à l'autre. La proposition de les opposer vient de D. Rensberger, selon qui dans la Lettre le destin dernier est la source des malheurs tandis que les choses bonnes viennent de Dieu $^{87}$. Comme nous venons de le montrer, cette observation n'est pas tout à fait exacte. En revanche, l'hypothèse de l'influence zurvanite, avancée par Albert de Jong, explique mieux le rapport étroit entre Dieu et le destin ${ }^{88}$.

Une seule fois Mara parle de « dieux » au pluriel et cette expression lui vaut le titre de païen : «Et ils parlaient ainsi : 'Désormais, nous sommes éloignés de notre foyer et nous ne pouvons pas retourner dans notre ville, ni voir nos proches, ni nous adresser à nos dieux en louanges' » (Lettre 16). Mara utilise ici le discours direct et il attribue ces paroles aux gens qui ont quitté Samosate. De Jong voit dans cette formule une expression de la religion populaire polythéiste, qui s'oppose au « Dieu des philosophes » que Mara confesse personnellement, mais à laquelle il retourne dans le souvenir d'une douloureuse expérience collective ${ }^{89}$. Cependant, l'idée d'un Dieu suprême ne s'oppose pas au polythéisme traditionnel et les philosophes grecs ont su concilier les deux.

Pour conclure l'analyse des exempla, rappelons que le point commun entre les deux listes est sans doute l'appel : " ne te mets pas en colère contre Dieu et ne murmure pas contre ton destin. » Tôt ou tard, le bon et le mauvais reçoivent ce qu'ils méritent. Sur ce point, la deuxième série, concernant les sages persécutés, montre une belle maîtrise de l'art rhétorique. L'auteur n'hésite pas à recréer ses personnages à partir des détails biographiques et historiographiques, agencés avec une certaine ingéniosité pour montrer les contrastes entre la grandeur de la vertu et la violence de la mort, la violence de la punition divine et la grandeur de l'œuvre posthume. Ce qui, de prime abord, se présente comme confusion ou erreur, pourrait être plutôt une manière de mettre en évidence des retournements du destin que seul le sage véritable est capable d'affronter.

\footnotetext{
${ }^{87}$ Rensberger 2010, p. 14-18. Ce choix de traduction apparaît déjà chez Schulthess et chez Cureton, mais Rensberger en fait un terme technique.

${ }^{88}$ DE JONG 2012, p. 148-153. Un des noms de Zurvan est « Temps », au sens proche de la notion grecque d'aí́v.

${ }^{89}$ DE JONG 2012, p. 148. Sur la religion traditionnelle à Samosate, voir BlÖMER 2012, p. 95-128. Selon K. McVey, Mara en disant ceci fait seulement semblant d'être païen, voir MCVEY 1990, p. 272. En revanche, les autres chercheurs considèrent cette expression comme une marque authentique du paganisme.
} 


\section{Un exemple à part - le roi sage des Juifs}

La mention du « roi sage des Juifs » est probablement l'élément le plus commenté de la Lettre de Mara et pour cela nous lui réservons un traitement à part. Elle est reconnue presque à l'unanimité comme relative à Jésus, au point que certains chercheurs l'ont utilisée pour envisager l'origine chrétienne du document entier ${ }^{90}$. Nous proposons de distinguer entre deux aspects de cette question - rhétorique et historique - et de les traiter séparément.

Une analyse rhétorique de l'exemple du « roi sage » permet de signaler des points communs et des différences par rapport aux autres exemples de la Lettre. D'abord, il s'agit d'un personnage anonyme, ce qui autorise à penser qu'il s'agit d'une interpolation : quelqu'un aurait remplacé la mention de Palamède - un parfait complément de Socrate et Pythagore dans la littérature grecque à l'âge de la seconde sophistique - par le roi sage des Juifs ${ }^{91}$.

L'autre observation concerne le caractère inhabituel de la caractéristique du personnage, car aucun texte ancien - chrétien, juif ou païen - ne parle d'un personnage qui serait à la fois sage, roi, législateur, tué par son peuple et dont la mort aurait causé la fin du royaume des Juifs. Ainsi, Enrico Norelli, en admettant l'identification du « roi sage des Juifs » avec Jésus, montre que ce titre n'est pas attesté par rapport à Jésus ${ }^{92}$. Les exemples de Socrate et Pythagore montrent néanmoins que les informations sur le roi sage risquent d'être aménagées en fonction de la thèse à démontrer. Il est donc hautement probable que Mara - si l'exemplum n'est pas interpolé - a forgé son troisième sage persécuté à partir de plusieurs éléments, dont il convient d'interroger la cohérence. En fait, le roi sage des Juifs réunit au moins deux archétypes : l'un, du sage et philosophe persécuté et l'autre, du roi des Juifs. L'un et l'autre peuvent être joints à sa qualité de législateur. Le dernier élément qui s'ajoute, c'est la destruction de Jérusalem et la dispersion des Juifs comme une punition divine pour sa mort. Nous allons analyser la portée théologique de ces éléments, afin d'éclairer l'identification du « roi sage » avec Jésus.

L'identification du « roi sage » repose en bonne partie sur la comparaison entre la Lettre de Mara et un topos apologétique qui consiste à interpréter la mort de Jésus comme un « martyre philosophique » et de la comparer surtout à la mort de Socrate ${ }^{93}$. Pour les auteurs chrétiens (Justin Martyr, Athénagore, Théophile d'Antioche, Origène), la mort de Socrate, Héraclite, Pythagore et quelques autres philosophes est due au fait qu'ils ont reconnu la vérité au sujet de Dieu et de son Logos. Ils sont victimes des mauvais démons ou de gens pervers et à ce titre ils ressemblent davantage aux chrétiens persécutés qu'à Jésus ${ }^{94}$. Si Socrate est un homme bon et vertueux pour Justin, Tatien et Athénagore, des auteurs comme Théophile d'Antioche et

\footnotetext{
${ }^{90}$ CURETON 1855, p. xiii-xv. La critique de cette position par F. Schulthess a été généralement admise, voir SCHUlTHESS 1897, p. 379-380. L'origine chrétienne de la Lettre est vue autrement par K. McVey. Dans sa première étude, elle a conclu qu'il s'agit d'un écrit pseudépigraphe chrétien rédigé au 4e siècle, voir MCVEY 1990, p. 257-272. Cette opinion est modifiée dans un article récent, où la mention du « roi sage » est considérée comme une correction faite par un chrétien, voir MCVEY 2015a, p. 322.

${ }^{91}$ Cette hypothèse est étayée par MCVEY 2015a, p. 316-322.

92 NORELLI 2005, p. 201. Voir aussi EVANS 1994, p. 455-457 ; VAN VOORST 2000, p. 53-58.

${ }^{93}$ Sur l'analyse des exempla cités par Mara comme « philosophical martyrs », voir MCVEY 1990, p. 265-266 ; RAMELLi 2005, p. 556-562 ; MERTZ, TIELEMAN 2008, p. 116-121.

94 Justin Martyr, Apologie I, 46, 3 ; II, 7,1 ; Athénagore, Supplique 31, 1-3 ; Théophile d'Antioche, A Autolycus III, 30 ; Origène, Contre Celse I, 3. Dans tous les cas cités, la comparaison se fait entre les philosophes et les chrétiens persécutés. Cette analogie a été connue chez les païens, car Origène cite Celse qui se moque des chrétiens lorsqu'ils se comparent à Socrate.
} 
Tertullien lui refusent la moindre vertu ${ }^{95}$. La comparaison entre Jésus et Socrate se fait donc avec précaution.

Les rapprochements entre Jésus et les philosophes se rencontrent néanmoins dans la littérature chrétienne, bien qu'ils ne fassent pas l'unanimité : rappelons l'opposition entre la « folie » des philosophes et la «sagesse de Dieu » dont parle Paul dans la première Épître aux Corinthiens (1 Cor 1, 17-25) ou Quid ergo Athenis et Hierosolymis de Tertullien ${ }^{96}$. Dans l'Évangile selon Thomas, la confession "Tu ressembles à un homme philosophe sage », est une mauvaise réponse à la question de Jésus « Comparez-moi, et dites-moi à qui je ressemble ${ }^{97}$. À la fin du $2^{\mathrm{e}}$ siècle, Irénée de Lyon est scandalisé par le fait que les disciples de Carpocrate, un gnostique platonisant, possèdent les images de Jésus et «les exposent avec celles des philosophes profanes, c'est-à-dire avec celles de Pythagore, de Platon et d'Aristote et des autres ${ }^{98}$. $\gg$ Au scandale du culte des images, s'ajoute le fait reprochable de traiter Jésus comme un des philosophes.

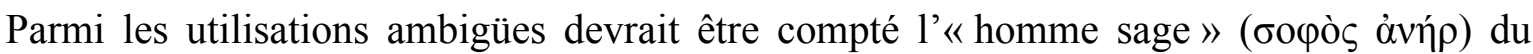
Testimonium Flavianum, évoqué par rapport à la Lettre de Mara ${ }^{99}$. Même si on admet l'authenticité du Testimonium, sous la plume de Flavius Josèphe « homme sage » signifie, dans le meilleur des cas, un sage juif, un rabbi, parce que la suite du texte présente Jésus comme

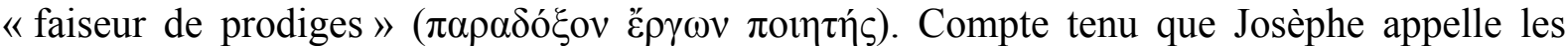

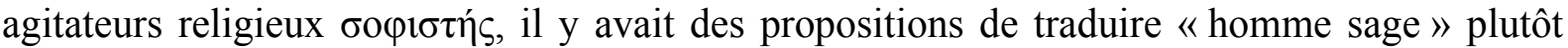
comme « sophiste ${ }^{100}$. La traduction d' « homme sage » par « sophiste » amène au « sophiste crucifié » de Lucien de Samosate qui appelle ainsi Jésus dans l'opuscule Sur la mort de Pérégrinus ${ }^{101}$. En plus d'être condescendante et moqueuse, cette appellation refuse à Jésus la qualité du vrai sage, comparable à Socrate et Pythagore.

Et si le « roi sage » n'est pas Jésus, quel autre Juif pourrait être comparé aux philosophes ? Il semble que les Grecs ont connu un seul Juif sage et philosophe - Moïse qui a été comparé à Pythagore ou à Socrate ${ }^{102}$. À l'époque proche de Mara, cette opinion est partagée par Numenius

95 Justin Martyr, Apologie 5, 3-4 ; 18, 5 ; 46, 3 ; II, 6(7), 3 ; 8(3), 6 ; 10, 5. Tatien apprécie Socrate et Héraclès, mais critique d'autres philosophes, voir Discours aux Grecs 3. Les critiques de Socrate se trouvent chez Théophile d'Antioche, A Autolycus, III, 2 et chez Tertullien, Apologétique, 14, 22, 39, 46 ; Aux nations I, 4, 10 ; Sur l'âme 1.

96 Tertullien, De praescr. VII, 9. Le passage paulinien s'inspire aussi des Écritures juives, du livre d'Isaïe : Is 29, 14 ; 33, 18 LXX ; 19, 12.

${ }^{97}$ Évangile selon Thomas 13, 3. D'après J.-D. Dubois, cette réponse peut représenter les idées d'un groupe de chrétiens de la région d'Antioche, voir DuBOIs 2011, p. 45-46.

${ }^{98}$ Irénée de Lyon, Contre les hérésies, I, 25, 6. Cette information est reprise par Épiphane de Salamine, Panarion, VII, 20, 6.9.

${ }^{99}$ RAMELLI 2005, p. $559 ; 562$.

${ }^{100}$ Sur l'histoire des traductions du « homme sage », voir BARDET 2002, p. 51 ; 98-99.

${ }^{101}$ Sur la mort de Pérégrinus, 11. Le charlatan Pérégrinus est salué par des chrétiens comme «nouveau Socrate », voir DE LABRIOLLE 2005, p. 100-106.

102 Hermippos de Smyrne ( $2^{\mathrm{e}}$ siècle avant J.-C.) compare les Juifs aux pythagoriciens et Moïse à Pythagore. Le rapprochement entre judaïsme est pythagorisme se trouve aussi chez Aristobule de Panéas ( $2^{\mathrm{e}}$ siècle av. J.-C.). Selon Posidonios d'Apamée ( $1^{\text {er }}$ siècle avant J.-C.) les Juifs sont un «peuple de sages », semblable aux habitants des cités idéales de Platon et de Zénon. Cette attitude change après les guerres judéo-romaines. Sur les auteurs grecs et leurs visions des Juifs, voir PUECH 2012, p. 129-131 ; 138-143 ; MiMOUNI 2012, p. 649-650 ; BARKochVA 2010, p. 164-205 (sur Hermippos) ; p. 355-398 (sur Posidonios). 
d'Apamée qui appelle Platon « un Moïse qui parle attique » ${ }^{103}$. Cette attitude est partagée par un auteur chrétien d'origine syriaque, Tatien ${ }^{104}$.

La deuxième qualité de notre personnage est « roi des Juifs ». Ce titre fait appel à l'écriteau placé par Pilate au-dessous de la croix de Jésus, dont parlent les quatre évangiles canoniques ${ }^{105}$. L'examen de ces textes révèle les difficultés liées à attribuer ce titre à Jésus. Selon les synoptiques, l'écriteau annonce le «motif de condamnation » (Mt 27, 37 ; Mc 15, 26; Lc 23, 38 ; en outre, dans les évangiles selon Matthieu et selon Marc, Jésus n'assume pas ce titre-là devant Pilate (Mt 26, 11 ; Mc 15, 2-5). Mais avant tout, le titre « roi des Juifs » est une moquerie et une insulte ${ }^{106}$. L'évangile selon Jean aborde davantage les problèmes liés à ce titre, notamment dans un long échange entre Jésus et Pilate au sujet de la royauté (Jn 18, 33-38), au cours duquel Jésus déclare : « Mon royaume n'est pas de ce monde » $(\mathrm{Jn}$ 18, 36). Dans ce même évangile, les Juifs s'opposent farouchement à l'idée de nommer Jésus « le roi des Juifs » (Jn $12,21 ; 19,12-22)$. Selon Raymond Brown, cette situation exprime les opinions de la première communauté johannique, où certains voyaient en Jésus le Roi-Messie, venu pour restaurer le royaume d'Israël ${ }^{107}$. Cette idée a rapidement disparu, car, d'après le témoignage des Actes des Apôtres $(17,7)$, le titre « roi des Juifs » a été utilisé par les Juifs pour accuser les chrétiens d'un complot anti-romain. En fait, les chrétiens ont vite abandonné des visées politiques, pour attribuer à Jésus, le Christ, une royauté eschatologique et divine ${ }^{108}$. Pour défendre l'identification entre " roi sage des Juifs » et Jésus, il faut donc chercher dans les milieux judéo-chrétiens, attachés à l'idée de Jésus - Messie politique, et le fait que ce roi a laissé la « nouvelle loi » est un lien supplémentaire avec ces milieux-là. Le titre de «législateur » a été étudié par Petr Pokorny, dans le but de renforcer l'identification du « roi sage » avec Jésus ${ }^{109}$. Cependant, pour

\footnotetext{
${ }^{103}$ Numénius, Fr.8 (cité par Eusèbe de Césarée, Prép. Ev. XI, 10, 12-14). Voir aussi Fr. 1a, 1b et 1c, sur l'accord entre Platon et Moïse chez Numénius ; l'information est relayée par Eusèbe de Césarée, Prép. Ev. IX 7, 1 et Origène, CCelse I, 15 ; IV, 51.

104 Tatien rédige une critique féroce de tous les philosophes grecs, tous inférieurs à Moïse, voir Discours aux Grecs, 31, 36-51. Comme Tatien qui est fier d'être « barbare » et comme son compatriote Lucien de Samosate, Mara s'exprime en oriental sans complexe, participant de la culture hellénistique commune, voir FACELLA 2012, p. 67-94.

${ }^{105}$ RAMELLI 2005, p. 559 ; POKORNY 2012, p. 136.

${ }^{106}$ Le titre « roi des Juifs » apparaît d'abord pendant l'interrogatoire par Pilate (Mt 26, 11 ; Mc 15, 2. 9.12 ; Jn 18, 33. 39), mais seulement dans l'évangile selon Luc se trouve l'information qu'il s'agissait d'une fausse accusation, avancée dans le but de faire condamner Jésus à mort par les autorités romaines (Lc 23, 1-5 ; voir aussi Jn 18, 31). Le titre « roi des Juifs » est une moquerie des soldats romains disant « Salut, roi des Juifs » (Mt 27, $27-$ 31 ; Mc 15, 16-20 ; Jn 19, 2-3). Il est mentionné aussi parmi les insultes lancées à Jésus en croix : «Il est roi d'Israël ... » (Mt 27, 42 ; Mc 15, 23 ; Lc 23, 37). L'Evangile de Pierre parle dans ce contexte de « roi d'Israël» (EvP 3, $7 ; 4,11)$

${ }^{107}$ L'évangile selon Jean contient les traces d'un messianisme politique juif (voir Jn 1, 49 et Jn 12, 13). Selon R. Brown, ce messianisme caractérisait le groupe d'origine de la communauté johannique. Il était composé des Juifs, majoritairement disciples de Jean-Baptiste, qui ont accueilli Jésus comme Messie davidique, voir BROWN 1994, p. 29-33. Or, la déclaration «mon royaume n'est pas de ce monde » correspond à la « haute théologie » johannique, apparue dans les années 55-80, suite à la rupture entre la communauté johannique et les autorités juives, voir BROWN 1994, p. 44-52. Pour l'importance de la version de Jean sur cette question, voir MILLAR 2006, p. 162.

${ }^{108}$ L'expression « roi des Juifs » ne figure pas parmi les emplois du mot basileus dans la littérature patristique, voir LAMPE, 1986, p. 292. La royauté de Jésus est conçue selon le modèle de la royauté de Yahvé et elle même parfois opposée à une royauté humaine ; voir 1 Tim, 1, 17 ; Apoc. 15, 3 ; Didache 14, 7 ; Clément de Rome, Épître aux Corinthiens, 61, 2, À Diognète 7, 4 ; Homélie du $2^{e}$ siècle, 17, 5.

${ }^{109}$ POKORNY 2012, p. 129-139.
} 
les premières générations chrétiennes, le terme «Loi » signifie immanquablement la Loi de Moïse (plus de cent occurrences dans le corpus du Nouveau Testament), tandis que l'enseignement de Jésus est seulement six fois appelé « loi », et cela toujours au sens métaphorique ${ }^{110}$. S'il n'est pas théologiquement impossible de présenter Jésus comme législateur, ce titre a été différemment interprété par les chrétiens, surtout pendant les trois premiers siècles.

Au vu des ambigüités qui caractérisent la description du « roi sage des Juifs », son identification avec Jésus ne peut être traitée comme un témoignage concernant le Jésus historique. Compte tenu des procédés rhétoriques de Mara, il n'y a aucune raison de croire que la biographie du « roi sage » soit moins artificielle que celle de Pythagore et Socrate. Sur ce point, Mara s'est probablement inspiré de Moïse, souvent comparé aux philosophes grecs. Les autres éléments de la description font penser davantage à Jésus, mais on constate que les sources chrétiennes ne sont pas unanimes quant au sens théologique des éléments qui composent le titre « roi sage des Juifs ». Si Mara parle de Jésus, ce Jésus est seulement un homme, un législateur choisi par Dieu. Notons qu'il attribue sa survivance aux «nouvelles lois » qu'il a laissées, et non à ses miracles et encore moins à sa résurrection. Or, une christologie empreinte du messianisme politique se retrouve surtout dans les milieux judéo-chrétiens, mais elle continue à exister pendant trois siècles environ chez les judéo-chrétiens « hétérodoxes » : les ébionites, les nazoréens et les elkasaïtes ${ }^{111}$. Une christologie du même type se rencontre aussi chez certains chrétiens de langue syriaque, notamment parmi les disciples de Bardesane. Nous lisons dans le Livre des lois des pays : "Que dirons-nous encore de cette nouvelle famille de nous autres chrétiens, que le Messie a produite en tout pays et en tout lieu par son arrivée ? »; l'auteur insiste sur le fait que les chrétiens " partout où ils sont, les lois des pays ne les éloignent pas de la loi de leur Messie $»{ }^{12}$. Il nous paraît donc envisageable que Mara ait entendu parler de Jésus par ses compatriotes chrétiens ou judéo-chrétiens, car la présence de ces derniers en Syrie a été très importante pendant au moins trois siècles ${ }^{113}$. L'avantage de cette solution est double : premièrement, elle ne demande pas d'avancer la date de la composition de la Lettre et, deuxièmement, elle soutient l'idée que le « roi sage des Juifs » a pu venir remplacer Palamède dans

\footnotetext{
${ }^{110}$ Voir Rm 3, 27 « loi de la foi »; 8, 2 « loi d'esprit»; Ga 6, 2 « loi du Christ »; Jacques 1, 25 et 2, 2 « loi de la liberté »; 2, 8 « loi royale ». Les références à la « Loi » concernent principalement la loi de Moïse et le seul législateur est Dieu, surtout dans l'épître de Jacques 2, 4 ; 4, 12 ; 5, 7-9. Aussi Mt 7, 1-5 ; Lc 6, 37-42 ; Mc 4, 24 ; Rm 2, 1-2. $19 ; 1$ Co 4, 5. Dans les écrits du $1^{\text {er }}$ et du $2^{\mathrm{e}}$ siècle, la « loi » du Christ est mentionnée rarement et au sens métaphorique; voir Ignace d'Antioche, Magn. 2; Lettre de Barnabé 2, 6 ; Hermas, Pasteur, 5, 6; 8, 3 ; Athénagore, Supplique, 32, 2. Chez Méliton de Sardes la « loi » signifie généralement la loi juive, celle de Moïse. Il établit une opposition entre « loi » (nomos) et le « verbe » $(\log o s)$ dans la partie introductive de l'homélie $\left(\mathrm{n}^{\circ} 3\right.$ 4, 6-7) et plus loin entre la Loi (de Moïse) et l'Évangile (voir n ${ }^{\circ}$ 39-43) où il montre que la loi a connu son terme avec l'arrivée du Messie. Sur le rapport entre Jésus et Moïse dans la théologie johannique, voir BOISMARD 1988.

${ }^{111}$ Simon C. Mimouni établit une distinction entre le judéo-christianisme «orthodoxe » et le judéochristianisme « hétérodoxe », ce dernier étant représenté surtout par les ébionites, les nazoréens et les elkasaïtes. Le critère d'hérésie était théologique, à savoir la conception de Jésus comme homme élu par Dieu et non le Fils de Dieu, voir MimOuni 1998, p. 73-90 ; STANLEY JONES 2009, p. 333-347. En particulier, les elksaïtes ont été actifs en Babylonie et en Syrie transeuphratène à partir du $2^{\mathrm{e}}$ siècle ; ils pensaient que le Christ était un ange qui a fait plusieurs incarnations dont Jésus est la plus récente ; ils l'appelaient « le grand roi ». En outre, les elkasaïtes pratiquaient la Loi et croyaient aux doctrines astrologiques, voir STANLEY JONES 2012b [2007], p. 467-490.

${ }^{112}$ Livre des lois des pays 57 ; trad. F. NAU, p. 55

${ }^{113}$ Sur la place du judaïsme et du judéo-christianisme dans l'histoire du christianisme syriaque, voir DRIJVERS 1992, p. 124-146 ; DRIJVERS 1996, p. 159-177 ; MiMOUNI 1994, p. 269-279. Sur les différents aspects du judéochristianisme syriaque, voir les travaux de STANLEY JONES 2012.
} 
une série des exempla, mais sans que ce remplacement soit fait postérieurement ${ }^{114}$. Néanmoins, la mention du « roi sage des Juifs » renvoie aux problèmes épineux liés à la date de la rédaction de la Lettre de Mara et son rapport aux événements historiques - la dispersion des Juifs après la mort du « roi sage » et les guerres romaines dans la région de Samosate.

\section{Questions historiographiques - la dispersion des Juifs et la prise de Samosate}

La Lettre de Mara ne livre que très peu d'informations de type historiographique. Ainsi la mention de la dispersion des Juifs, comme conséquence de la mort du « roi sage des Juifs » (Lettre 45), mais aussi les informations sur l'exil et l'emprisonnement de Mara (Lettre 16-23 et 68-75). Maintenant, essayons de situer le contexte historique, à partir des informations venant des autres sources.

\section{La mort du « sage roi » et la dispersion des Juifs}

La question historique qu'on pose au sujet du « roi sage des Juifs » concerne le rapport entre la mort de celui-ci et la dispersion des Juifs. Toutefois, la Lettre de Mara ne parle pas de la « mort », car la phrase concernant le roi sage est elliptique ; elle reprend la première question posée au sujet de Socrate et, littéralement, elle dit : « Ou les Juifs pour leur sage roi ? » ${ }^{115}$. Étant donné que Mara a déjà parlé de cette manière de la mort de Socrate («Quel profit les Athéniens ont-ils tiré du meurtre de Socrate ? ») et de Pythagore (« Ou les gens de Samos pour avoir brûlé Pythagore ? »), on peut supposer qu'il s'agit également de la mort du roi des Juifs. En revanche, le texte dit explicitement que le comportement des Juifs par rapport à leur roi a été sévèrement puni par Dieu : «À partir de ce temps-là leur royaume a été pris » (Lettre 45) et «les Juifs, après avoir été combattus et chassés de leur royaume, sont dispersés partout » (Lettre 46).

Ces fragments ont été interprétés par $\mathrm{K}$. McVey par rapport à un argument chrétien, selon lequel la destruction du Temple et la dispersion des Juifs sont une punition divine pour la mort de Jésus, et le débat qui s'ensuivit porte sur le moment de l'apparition dudit argument ${ }^{116}$. La situation s'avère compliquée, car le thème de la punition du peuple d'Israël par Dieu remonte à la destruction du Temple de Salomon et l'exil de Babylone (597-581) - qui est l'origine historique de la diaspora juive. De même, dans les réactions des auteurs juifs après la guerre judéo-romaine (66-73) et la révolte de Bar Kokhba (132-135), ces mêmes motifs apparaissent. Par conséquent, il est possible de rapprocher la Lettre de Mara de nombreux écrits judéo-

\footnotetext{
${ }^{114}$ La mention du « roi sage des Juifs » est interprétée par I. Ramelli comme indice de la rédaction haute, voir RAMELLi 2005, p. 561-563. Selon K. McVey, la Lettre de Mara a été rédigée au $3^{\mathrm{e}}$ siècle ou peut-être même vers la fin du $2^{\mathrm{e}}$ siècle, mais la mention du « roi sage des Juifs » est une interpolation postérieure, voir MCVEY 2015a, p. 326.

${ }^{115}$ Cet ajout est parfois signalé dans la traduction ou dans la note, voir CURETON 1855, p. 73 ; SCHULTHESS 1897, p. 371 n. 6 ; MCVEY 1990, p. 264 ; CHIN 2006, p. 165-166.

${ }^{116}$ Initialement K. McVey situait l'apparition de cet argument aux $3^{\mathrm{e}}$ et $4^{\mathrm{e}}$ siècles (chez Aphraate, Origène, Eusèbe de Césarée), voir MCVEY 1990, p. 267-270. En réaction à ceci, E. Norelli cite des exemples bien plus anciens (Evangile de Pierre, 4 Esdras), voir NORELLI 2005, p. 200-204 ; NORELLI 1984, p. 231-282. Les positions de Justin et de Tertullien sont évoquées par RENSBERGER 2010, p. 9-11. Plutôt problématiques sont les témoignages ajoutés à cette liste par I. Ramelli, A. Merz et T. Tielemann : le Testimonium Flavianum et la Doctrine d'Addai, voir RAMELLI 2005, p. 561-563 ; MERTZ, TIELEMAN 2008, p. 127-131.
} 
hellénistiques, notamment des Oracles sibyllins, de 4 Esdras, des livres sapientiaux (la Sagesse d'Ahikar) et de la poésie araméenne ${ }^{117}$.

Dans les différents milieux juifs, les réactions à la destruction du Temple et la dispersion du peuple ont été extrêmement variées ${ }^{118}$. Parfois ces événements - notamment la destruction du Temple et de la ville - sont présentés comme une punition pour des actions bien précises, y compris pour la mort de quelqu'un. Flavius Josèphe interprète ainsi le meurtre du grand prêtre Jonathan, commis par les brigands juifs en pleine ville ${ }^{119}$. Il y a une certaine ressemblance avec l'historien chrétien Hégésippe, cité par Eusèbe de Césarée, qui interprète le siège de Jérusalem comme une punition pour la mort de Jacques, le frère du Seigneur, jeté en bas du pinacle du Temple $^{120}$. En outre, les sources rabbiniques présentent la destruction du Temple comme conséquence de la mort prématurée et mystérieuse d'un autre roi, « roi Agrippa », Agrippa $1^{\text {er }}$ $(† 44)^{121}$. D'après ces témoignages, différentes interprétations de la tragédie de Jérusalem comme punition divine pour la mort d'un juste, existaient parmi les Juifs et certaines ont été aussi connues des chrétiens. Si Mara a pu rencontrer des judéo-chrétiens, il aurait pu également connaître les Juifs de la diaspora installés dans l'Empire des Parthes arsacides et en Mésopotamie (Adiabène, Arménie, Osrohène) et la conversion de la famille royale d'Adiabène au judaïsme, au $1^{\mathrm{er}}$ siècle après J.C., montre la popularité de cette religion dans les provinces euphratéennes ${ }^{122}$.

Néanmoins, l'idée de la punition divine infligée aux Juifs pour la crucifixion de Jésus est une version bien chrétienne des événements, mais elle n'est pas apparue au lendemain de la destruction du Temple, ni de la ruine de Jérusalem. Dans les évangiles canoniques, ces événements sont mentionnés comme des signes apocalyptiques (voir Jn 18, 32) ${ }^{123}$. Bien que

${ }^{117}$ Il s'agit du Talmud et aussi de la littérature judéo-hellénistique, notamment du 4 Ezra, 2-3 Baruch, 4 Baruch (Paralipomènes du prophète Jérémie), Oracles sybillins 4 et 5, Apocalypse d'Abraham. Sur la littérature judéohellénistique, voir DENIS 2000. Les lamentations après la destruction du Temple ou de la ville de Jérusalem sont très fréquentes dans la littérature judéo-hellénistique; voir Flavius Josèphe, La guerre juive, V, 1, 3, 19 ; Apocalypse d'Abraham, 27 ; 4 Esdras 10, 21-23 ; 2 Baruch 10-12, 35 ; 3 Baruch 1, 1-2 ; 4Q 179 ; Oracles syb. 5, 379-410. Voir RENSBERGER 2010, p. 6-13 ; BEENTJES 2012, p. 155-165.

${ }^{118}$ Cette réflexion peut prendre la forme d'une théodicée, avec l'idée que le peuple a été puni pour ses fautes. On trouve aussi une relecture de l'histoire (à la manière ancienne du Deutéronomiste) ou une vision du futur, eschatologique et apocalyptique. On y trouve aussi des appels à l'apaisement dans les rapports entre les Juifs et Rome, malgré la prédominance de l'attente d'une punition divine qui va toucher les Romains. Sur les réactions des Juifs à propos des guerres contre Rome, voir JONES 2011; NEUSNER 1972, p. 312-327 ; STONE 1981, p. 195 202 ; ESLER 1994, p. 99-123; HADAS-LEBEL 1990 ; GOLDENBERG 1982, p. 517-525.

119 «C'est pourquoi, à mon avis, Dieu, détestant leur impiété, se détourna de notre ville et, jugeant que le Temple n'était plus pour lui une résidence pure, excita contre nous les Romains et lança sur la ville la flamme purificatrice en infligeant aux habitants, à leurs femmes et à leurs enfants la servitude pour nous rendre plus sages par ces calamités » (Flavius Josèphe, Antiquités juives, XX, 5).

${ }^{120}$ Eusèbe de Césarée, Histoire ecclésiastique II, 22, 20. Sur le récit du martyre de Jacques et ses conséquences, voir Histoire eccl. II, 23, 3-25. Eusèbe lui-même se range à cette interprétation, car il explique la destruction de Jérusalem comme une punition pour les persécutions du Christ et de ses apôtres ; voir III, 7 ; 11 . Voir aussi Mimouni 2015 ; STANLEY JONES 2012a [1990].

${ }^{121}$ Malgré certains comportements peu glorieux, Agrippa $1^{\mathrm{er}}$ a réussi à se donner la bonne réputation d'un roi pieux et sage, voir SCHWARTZ 1990, p. 157-171 ; HADAS-LEBEL 2009.

${ }^{122}$ Sur le judaïsme babylonien, voir NEUSNER 1965.

${ }^{123}$ Les versets prophétiques, relatifs à la destruction du Temple, sont insérés dans les récits de la passion, voir Mt 26, 13. 64 ; 27, 9-10. 46 (et parallèles) ; Jn 19, 24. 28. 36. Les circonstances de la mort de Jésus sont à comparer avec Is 26, 19; Dn 12, 2, Am 8, 9. Justin Martyr présente également la destruction du Temple comme accomplissement des prophéties, voir Apologie 47. 
dans Mt 27, 25 les Juifs soient tenus pour responsables de la mort de Jésus, l'idée que la destruction du Temple soit une punition divine pour ce fait n'y apparaît pas ${ }^{124}$. Elle est absente chez les auteurs comme Ignace d'Antioche ( $†$ 110) et Polycarpe de Smyrne (†155), même s'ils accusent les Juifs d'hostilité à l'égard des chrétiens ${ }^{125}$. Enrico Norelli a montré qu'un des premiers témoignages du lien causal entre la mort de Jésus et la destruction de Jérusalem se trouve dans le quatrième livre d'Esdras, dans le contexte pascal. Il fait aussi appel à l'homélie pascale de Méliton de Sardes, rédigée dans les années 160-170. Ainsi Méliton serait sans doute le premier auteur chrétien qui interprète la perte du royaume et la dispersion des Juifs comme conséquence de la mort de Jésus ${ }^{126}$. L'analyse faite par Norelli lui permet de proposer le $2^{\mathrm{e}}$ siècle comme "l'hypothèse la moins fragile » de la datation ${ }^{127}$, d'autant plus que Mara parle de la dispersion des Juifs et de la perte de «leur royaume » : ce qui correspond mieux à la situation des Juifs après 135 qu'après 70. En fait, la simple attribution aux Juifs de la responsabilité de la mort de Jésus aurait pu permettre un rapprochement avec l'évangile selon Matthieu, mais l'idée que la destruction du Temple et la dispersion en soient des conséquences, renvoie inévitablement vers un motif théologique apparu seulement dans la seconde moitié du $2^{\mathrm{e}}$ siècle.

\section{Lettre de Mara et l'histoire de Samosate}

L'argument le plus important contre la rédaction de la Lettre de Mara à la fin du $2^{\mathrm{e}}$ ou au début du $3^{\mathrm{e}}$ siècle est fondé sur l'interprétation de l'exil de Mara comme consécutif à la prise de Samosate par les Romains en 72. Nous allons examiner cette reconstruction des événements et ses rapports avec les deux passages de la Lettre (Lettre 16-23 et 68-75) qui relatent le vécu de l'auteur.

"16. J'ai entendu, en fait, au sujet de nos compagnons qui, en quittant Samosate, étaient affligés comme ceux qui blâment le destin. Et ils parlaient ainsi : 'Désormais, nous sommes éloignés de notre foyer et nous ne pouvons pas retourner dans notre ville, ni voir nos proches, ni nous adresser à nos dieux en louanges'. [...] 19. Et quand nous avons encore entendu, de la part de leurs anciens compagnons, qu'ils partaient vers la Séleucie, nous avons pris clandestinement le chemin vers eux, et nous avons uni notre malheur à celui qui est le leur. »

«68. En fait, en ces temps anciens, lorsque notre ville était érigée dans sa grandeur, tu as pu apprendre que des propos odieux ont été prononcés au sujet de nombreux hommes. 69. Nous reconnaissons alors que, de la part du destin, nous avons pleinement reçu l'amour suffisant et la dignité dans sa grandeur, mais le [même] destin nous a interdit de réaliser les choses qui ont été décidées par nous-mêmes. [...] 72. Car nous avons montré notre vérité que nous n'avons pas commis de faute envers l'empire. 73. Si alors les Romains nous permettent de revenir dans

${ }^{124}$ Il n'est pas question de punition divine dans les écrits chrétiens les plus proches chronologiquement de l'an 70 : Épître aux Hébreux (9, 15-28), 1 Épître de Pierre (2, 4-10) et Épître aux Corinthiens (29-39) de Clément de Rome. En revanche, ils développent l'idée de la substitution : les chrétiens sont destinés à remplacer les Juifs en tant que «peuple élu ». Les Juifs figurent seulement comme responsables de la mort de Jésus dans Évangile de Pierre 23 (moitié du $2^{\mathrm{e}}$ siècle).

${ }^{125}$ Dans le Martyre de Polycarpe (160 environ), la mort de Polycarpe est assimilée à la passion de Jésus et aux Juifs incombe le rôle des principaux instigateurs ; voir Martyre de Polycarpe, 12, 2 ; 13, 1 ; 17, 1-2 ; 18, 1. Sur l'hostilité des Juifs de Smyrne, voir aussi Apocalypse 2, 9.

${ }^{126}$ NoRELli 2005, p. 202 ; Norelli 1984, p. 254-258. L'autre texte où cette idée est explicitement formulée est le Contre les Juifs de Tertullien (écrit vers 197).

${ }^{127}$ NoRELLi 2005, p. 206. 
notre pays en justice et en honnêteté, ils agiront comme des hommes civilisés et ils seront appelés bons et honnêtes, avec le pays pacifique où ils habitent ; car ils nous montreront leur grandeur en nous laissant en hommes libres. "

Les fragments cités ne mentionnent aucun personnage, romain ou autre, et aucun événement, ce qui rend hautement hypothétique toute proposition de situer la Lettre par rapport à l'histoire de Samosate et de la Syrie romaine. Même les raisons de l'exil et de l'emprisonnement de Mara ne sont pas clairement exposées ${ }^{128}$.

Le premier passage nous apprend que Mara a rejoint ses compagnons qui ont quitté Samosate et se rendaient vers Séleucie ; il décrit une rencontre particulièrement douloureuse. Ce passage fait penser que Mara est originaire de Samosate et qu'il a rencontré ses compatriotes apportant de tristes nouvelles. Les souvenirs des exilés reçoivent la forme littéraire de lamentation, ce qui augmente considérablement le dramatisme, mais ne dit rien sur les circonstances de leur situation. Rien n'indique que la ville qu'ils ont quittée ait subi le siège ou qu'elle ait été détruite : «Car en pleurant ils se souvenaient de leurs pères et en se lamentant, de leurs mères ; et ils avaient du chagrin pour leurs frères et de la peine pour leurs épouses qu'ils ont abandonnées » (Lettre 18). Quand Mara dit: « Nous avons regardé nos frères et nos fils captifs, et nous nous sommes souvenus de nos compagnons morts qui ont été enterrés dans un lieu de fortune » (Lettre 21), les morts sont plutôt ses camarades d'exil.

Lorsqu'il décrit les conditions de sa captivité, Mara parle toujours de " nous », il se voit comme l'un des prisonniers. Tout ce que nous savons de son statut social est qu'il était un homme libre, sans doute un citoyen de Samosate, ayant reçu l'éducation grecque. La présence des mentions de richesses perdues fait penser à une expérience personnelle : «à cause de sa convoitise les malheureux sont emmenés en captivité » (Lettre 40). Néanmoins, à cause des fréquentes accusations de cupidité, il est impossible de préciser quand Mara parle des Romains et quand il parle des hommes vicieux en général. Quelle que soit la raison de sa captivité, Mara clame son innocence devant l'empire des Romains et espère être libéré, mais il se prépare aussi à mourir. Ici encore, Mara ne dit rien au sujet des circonstances de son emprisonnement, et le destin semble être la seule cause de son malheur.

Dans le second fragment autobiographique, Mara rappelle le bonheur passé de sa ville natale - dont il ne dit pas le nom -, mais il évoque les « propos odieux » qui ont causé tort à beaucoup d'hommes ; ensuite, il parle de la grandeur passée et de l'impossibilité de réaliser les « choses qui ont été décidées dans notre esprit ». Ces informations sont très énigmatiques et rendent le texte difficile à comprendre et traduire. Quand Mara parle de «paroles odieuses » prononcées au sujet de «nombreux hommes », il est impossible à savoir s'il est lui-même concerné par ce fait et de quelle façon. Il utilise le pluriel pour parler de « l'amour et la dignité » reçue, mais le texte n'est pas clair : à qui doit-on attribuer l'origine de ces largesses - à la ville ? au destin ? Il est aussi question de "choses décidées de nous-mêmes» qui n'ont pas été réalisées. L'assurance de l'absence de «faute envers l'Empire », fait penser que ces accusations sont portées devant les Romains qui ont le pouvoir de permettre aux prisonniers « de revenir dans notre pays dans la justice et la droiture » (Lettre 72-73). Mara s'attend à mourir, il parle de « prison » et de « chaînes ", mais il n'est pas certain qu'il soit réduit en esclavage : "Soyons obéissants à cet empire que le destin nous a donné, pas comme [aux] tyrans [qui] nous conduiront comme des esclaves » (Lettre 74). Sa plus grande peine est l'impossibilité de retourner au pays, qui dépend du bon vouloir des Romains.

\footnotetext{
${ }^{128}$ Les raisons financières de la conquête et de l'exil de Mara avancées par A. Merz et T. Tieleman ne peuvent être qu'une supposition, voir MERTZ, TIELEMAN 2008, p. 123-125.
} 
Le caractère énigmatique de ces informations rend périlleuse toute tentative de reconstruction des circonstances historiques de l'expérience de Mara - pour citer Frank Millar : "Searching in incomplete narrative sources for suitable contexts for enigmatic items of evidence is a notoriously treacherous process ${ }^{129}$. »

\section{Les hypothèses concernant l'histoire de Mara}

À partir de ces bribes d'informations les chercheurs ont essayé d'identifier les événements dont parle Mara et de préciser la date de la rédaction de sa Lettre ; ils ont utilisé deux points de repère : les informations sur le « roi sage des Juifs » et les prises de Samosate par les Romains en 72, en 164-165 et en 256. Présentons leurs opinions dans 1'ordre chronologique.

L'éditeur du texte syriaque de la Lettre, William Cureton, pense que Mara est un chrétien. Il situe son emprisonnement au temps de la guerre parthique de Lucius Verus (161-166), avec une prise de Samosate en 164-165. À terme, Cureton voudrait que le fils de Mara soit le futur évêque d'Antioche, Sérapion $(\dagger 190)^{130}$. Ces propositions ont été réfutées par Friedrich Schulthess, dont les analyses ont été davantage suivies. Il montre d'abord que Mara n'est pas chrétien, bien qu'il possède une certaine connaissance de cette religion. Quant à son exil, celui-ci est lié à la politique intérieure et non à une attaque des ennemis. Tout en reconnaissant l'insuffisance des données historiographiques dans la Lettre, Schulthess situe néanmoins sa rédaction après la première prise de Samosate par les Romains en 72 et avant la fin du $3^{\mathrm{e}}$ siècle $\mathrm{e}^{131}$. Cette datation a été restreinte aux années 72-160 par J.B. Aufhauser, dans une étude consacrée au Jésus historique. L'opinion d'Aufhauser a influencé de nombreux travaux dans ce domaine, concentrés exclusivement sur la mention du roi sage des Juifs. En prenant comme terminus post quem la prise de Samosate en 72, ils penchent, pour la plupart, vers une datation haute, dans le sillage de la proposition d'Aufhauser ${ }^{132}$. Cependant, dans les publications récentes l'identification du « roi sage des Juifs » est considérée comme un témoignage mineur et hautement problématique au point qu'elle ne figure plus dans la monographie consacrée au Jésus historique, réalisée par J.P. Meier ${ }^{133}$.

${ }^{129}$ MiLLAR 1993, p. 461-462.

${ }^{130}$ CURETON 1855, p. iii-Xv. L'autre argument en faveur de la rédaction dans la seconde moitié du $2^{\mathrm{e}}$ siècle est l'allusion aux Oracles Sibyllins concernant Samos, voir Spicilegium syriacum, p. xiv.

${ }^{131}$ SCHULTHESS 1897, p. 376-377.

132 AUfHAUSER 1925, p. 5-11. La datation haute est solidement installée dans la littérature. On peut citer les travaux des historiens allemands du $19^{\mathrm{e}}$ siècle (R. Eisler, H.G.A. Ewald, G. Bickell), puis les principaux travaux sur le Jésus historique qui mentionnent la Lettre de Mara : BLINZLER 1962, p. 34-388 (la fin du $1^{\text {er }}$ siècle) ; BRUCE 1974, p. 3 (vers 73); EvANS 1994, p. $455-45$ (la fin du $1^{\text {er }}$ siècle) ; MOREAU 1944, p. 9 (entre 73 et 399). La datation haute est défendue par l'historien italien MAZZARINO 1956. Pour soutenir la datation haute, la plus proche de 73, I. Ramelli s'appuie sur ces travaux-là, voir RAMELLI 2005, p. 546-547. Les chercheurs français semblent suivre l'avis de P. de Labriolle qui mentionne la Lettre parmi les écrits de la fin du $3^{\mathrm{e}}$ siècle, voir DE LABRIOLLE 2005 [1934], p. 312-313 ; LÉON-DUFOUR 1960, col. 1422-23 (vers 260).

${ }^{133}$ MEIER 2004, p. 61-64. L'édition anglaise est parue en 1991 et pourtant le silence sur la Lettre de Mara est passé inaperçu. L'auteur connaît la Lettre, mais il ne l'inclut pas parmi les témoignages non-chrétiens. En même temps, l'identification du « roi sage » avec Jésus a été contestée par F. Millar, qui situe la rédaction de la Lettre après 70 et avant la fin du $2^{\mathrm{e}}$ siècle, voir MiLlaR 1993, p. 462. Les spécialistes de l'histoire du christianisme observent que la Lettre de Mara est un témoignage incertain et situent sa rédaction plus tard, voir BROWN 1998, p. 382 (après 70 mais plutôt au $2^{\mathrm{e}}$ siècle) ; VAN VOORST 2000, p. 53-58 (seconde moitié du $2^{\mathrm{e}}$ siècle) ; NORELLI 2005, p. 197-207 (2 $2^{\mathrm{e}}$ siècle). 
L'approche nouvelle, attentive à l'ensemble du texte, a été proposée par Kathleen McVey en 1991. La chercheuse envisage trois prises de Samosate : en 72, en 164-165 et en 256, comme possibles références pour la captivité de Mara, mais reconnaît l'impossibilité d'une identification certaine. En se basant sur les éléments anti-juifs (ou reconnus pour tels) ainsi que sur le caractère éclectique (stoïcien, médio-platonicien, pythagoricien) des idées philosophiques, McVey suppose que la Lettre est un pseudépigraphe chrétien, composé au $4^{\mathrm{e}}$ siècle ${ }^{134}$. Le débat suscité par cette proposition a permis de la réviser et dans ses derniers travaux, McVey soutient le rapport étroit entre la Lettre de Mara et la seconde sophistique, en ramenant sa rédaction au $2^{\mathrm{e}}-3^{\mathrm{e}}$ siècle et voyant dans la mention du « roi sage des Juifs » une interpolation tardive ${ }^{135}$.

Cependant, le premier travail de K. McVey a attiré l'attention des chercheurs sur la composition de la Lettre de Mara. Dans ce sens, Catherine Chin analyse la forme rhétorique de la Lettre et considère les modestes références historiographiques comme des éléments purement littéraires $^{136}$. Le constat que la Lettre est conservée dans un seul manuscrit syriaque du $7^{\mathrm{e}}$ siècle $(\mathrm{BL}$ Add. 14658) est suivi par la proposition de situer la rédaction du texte au $5^{\mathrm{e}}$ ou $6^{\mathrm{e}}$ siècle, pour le rapprocher chronologiquement des autres textes du manuscrit ${ }^{137}$. Une datation moins tardive, bien que toujours fondée sur l'analyse de la forme littéraire, est suggérée par Ute Possekel, dans l'étude des Sentences de Théano - l'écrit faisant partie du même manuscrit. Tenant compte des nombreux emprunts à la littérature gnomique, Possekel propose le $3^{\mathrm{e}}$ siècle comme date de la composition ; cette proposition est retenue par Paolo Bettiolo dans ses travaux sur les Sentences de Ménandre $e^{138}$.

L'hypothèse de la datation haute est défendue, dans plusieurs articles, par Ilaria Ramelli qui s'inspire notamment de la reconstruction faite par J. Blizler. Elle lui ajoute sa propre reconstruction des origines du christianisme édessenien remontant au $1^{\text {er }}$ siècle ; or, cette argumentation repose sur des documents peu fiables en tant que sources historiographiques (légendes, apocryphes, textes théologiques, etc. ${ }^{139}$. La même position quant à la date de la composition est adoptée par A. Merz et T. Tieleman. Tout en reconnaissant la fragilité des données historiographiques, ils inscrivent néanmoins la Lettre dans le contexte de la prise de Samosate en 72 et s'aventurent dans une reconstruction très poussée, en présentant Mara comme membre de l'aristocratie locale, combattant dans une bataille contre les Romains, ami du roi Antiochos IV de Commagène, qui doit sa connaissance du monde grec aux voyages dans sa suite ${ }^{140}$. Cette reconstruction est partagée aussi par D. Rensberger qui préfère néanmoins situer la rédaction après 70 et avant la fin du $2^{\mathrm{e}}$ siècle $^{141}$. Néanmoins, Rensberger soutient la datation haute à travers ses observations concernant la langue et l'écriture de la Lettre de Mara, caractéristiques

134 MCVEY 1990, p. 261-62 et 270.

${ }^{135}$ MCVEY 2015a, p. 305-326 ; MCVEY 2015 b.

${ }^{136}$ CHIN 2006, p. 145-171.

${ }^{137}$ CHIN 2006, p. 167-169. Ce manuscrit contient une vingtaine de textes philosophiques attribués à Serge d'Reš 'aina, Aristote, Porphyre, Bardesane, Isocrate, Platon et Pythagore, voir WriGHT 1872, p. 1154-1160 ; HugONNARD-Roche 2007, p. 279-291. Pour la Lettre de Mara, Hugonnard-Roche reprend la rédaction au 4 siècle, à la base du premier article de $\mathrm{K}$. McVey.

138 PosseKel 1998, p. 7-36. Cette datation est retenue par Bettiolo 2000, p. 438 ; Bettiolo 2004, p. 292293 ; BETTIOLO 2003, p. 100-101.

${ }^{139}$ RAMELLI 2005, p. 553-563 ; RAMELLi 2004, p. 77-104. La liste des publications d'I. Ramelli, relatives aux origines du christianisme syriaque, se trouve en RAMELLI 2005, p. 550 n. 22.

${ }^{140}$ Mertz, Tieleman 2008, p. 109 ; 122-125; 128-131.

${ }^{141}$ Rensberger 2010, p. 5-6. Il se réclame explicitement de Millar 1993, p. 461-462. 
d'une langue très ancienne, dont l'orthographe montre une certaine ressemblance avec l'écriture palmyrénienne et celle utilisée dans les écrits juifs en araméen ${ }^{142}$.

L'aperçu des positions prises par les chercheurs modernes montre l'importance de deux références - la mention du « roi sage » identifié à Jésus et de la dispersion des Juifs, d'un côté, et les bribes d'informations sur les exils de Samosate, de l'autre. Si la première information invite à prendre l'an 135 comme terminus post quem de la rédaction de la Lettre, la seconde renvoie aux trois dates - 72, 164-165 et 256 - correspondant aux trois prises de Samosate par les Romains. Cependant, plusieurs auteurs signalent qu'aucune des trois ne peut être positivement retenue à partir de ce que dit Mara dans son texte. Les choix se font par défaut et la comparaison de la Lettre avec les sources historiographiques permet de constater à quel point tout rapprochement est fragile.

Étudions surtout l'hypothèse la plus souvent retenue, celle qui veut que Mara parle de la prise de Samosate en 72-73. Si les deux autres dates ont été écartées, c'est parce qu'elles concernent les guerres parthiques et la Lettre ne fait aucunement allusion aux Parthes. Cependant, le rapport avec les événements de l'an 72 reste problématique. Avant tout, il n'est pas très exact de parler de la "prise », car la ville, dont l'indépendance fut purement formelle, n'était probablement pas assiégée à cette époque ${ }^{143}$. On ne peut pas parler d'une annexion non plus, car déjà en l'an 17 après J.C., la Commagène fut annexée par les Romains, probablement à la demande des nobles du royaume ${ }^{144}$. En 37-38 Caligula restaura le royaume pour le confier temporairement - à son ami Antiochos IV roi de Commagène (38-72), dont le nom Gaius Julius Antiochos IV Épiphane atteste qu'il fut citoyen romain. Ami proche de Caligula, Antiochos tomba en brève disgrâce après la mort de celui-ci, mais l'empereur Claude le confirma à nouveau dans ses titres en 41. Sous Néron, ce même roi participa aux guerres contre les Parthes et les Arméniens. En 70, il envoya même ses troupes à Jérusalem en aide aux Romains - ce qui montre sa loyauté, voire le degré de sa dépendance envers Rome.

L'annexion définitive du royaume de Commagène fit partie d'un vaste projet de réorganisation militaire et administrative de la frontière avec l'empire des Arsacides, mais le prétexte immédiat fut une accusation futile par le préfet de la Syrie, Cesennius Paetus, qui prétendait qu'Antiochos IV complotait avec les Parthes ${ }^{145}$. D'après l'analyse de Jakub Kozłowski, Samosate a joué un rôle important dans une nouvelle organisation conçue en vue de prochaines campagnes militaires - ce qui pourrait expliquer le caractère ambigu des événements ${ }^{146}$. D'après Flavius Josèphe, le roi n'opposa aucune résistance et seuls ses deux fils engagèrent une bataille, ce qui les obligea à s'enfuir en Perse. Cependant, Antiochos fit tout pour éviter

\footnotetext{
${ }^{142}$ La langue est très riche en expressions originales, traduites ad hoc du grec ; les locutions adverbiales ne sont pas figées et la syntaxe n'obéit pas toujours aux règles de la grammaire syriaque classique, voir RENSBERGER 2010, p. 11-14.

${ }^{143}$ L'analyse des inscriptions et des témoignages archéologiques permet seulement de constater la présence des légions (la III Gallica et la IV Scytica) dans cette région frontalière. Ainsi, le siège de Samosate à l'époque de Vespasien reste hypothétique, voir MILLAR 1993, p. 82-83 ; p. 461.

144 Telle est la raison invoquée par Flavius Josèphe, Antiquités judaïques, 18, 53. Ce territoire fut déjà administré par un préfet romain Q. Serveaus, voir SARTRE 2001, p. 502-504.

${ }^{145}$ Les sources historiographiques pour l'histoire de la Samosate et de ses souverains au $1^{\text {er }}$ siècle se limitent à des mentions chez Flavius Josèphe ; Guerre des Juifs 5, 11 ; 7, 7 ; Ps. Aurèle Victor, Epitome 8, 13 ; Eutrope, Abrégé 7, 19 ; Dion Cassius, Histoire 49, 20. La campagne de 72-73 est mentionnée par Ps. Aurèle Victor et Eutrope qui n'en donnent pas de raisons. Sur les circonstances de l'incorporation de la Commagène, voir DĄBROWA 1980 ; BRAUND 1984, p. 91-103 ; KOZŁOWSKI 2011, p. 199-225.

${ }^{146}$ Sur les aspects politiques et militaires de l'opération, voir KOZŁOWSKI 2011, p. 199-225.
} 
l'affrontement bien que - toujours selon l'analyse de Kozłowski - l'armée samosatène pût facilement résister aux Romains ${ }^{147}$. L'emprisonnement d'Antiochos fut bref, car Vespasien ne voulut pas humilier son ancien ami. Le roi donc quitta Tarse en homme libre pour s'installer d'abord à Sparte et puis à Rome où ses fils - graciés rapidement par l'empereur - purent le rejoindre rapidement ${ }^{148}$. Antiochos mourut l'année suivante à Rome et ses fils rejoignirent la classe sénatoriale. Si on regarde les cas d'Emèse, d'Aréthuse et des principautés du Liban ainsi que de la Nabatène, on constate que les incorporations des royaumes vassaux se faisaient de manière semblable, à savoir par les dépositions des dynasties régnantes - déjà clients de Rome depuis deux ou trois générations - qui, certes, prenaient la voie de l'exil, mais aussi rejoignaient rapidement les rangs des sénateurs de l'Empire romain ${ }^{149}$.

Dans la Lettre de Mara il n'y a aucune mention du roi ou d'un conflit armé, ce qui rend hautement problématique son rapport aux événements que nous venons de présenter. Il est seulement question de Romains, responsables de l'emprisonnement de l'auteur. La situation décrite par Mara est avant tout l'exil et l'emprisonnement, ce qui semble indiquer un conflit interne et non une guerre. Dans la période allant de 66 avant J.-C. jusqu'à 226 après J.C., les Romains ont mené plusieurs opérations militaires contre les Parthes. Puisque dans le texte il n'y a aucune mention des Parthes non plus, il se pourrait que Mara raconte les souffrances de la population dues aux agissements de l'administration romaine accompagnant les opérations militaires, comme par exemple l'imposition supplémentaire ou l'emprisonnement de personnes suspectes de connivence avec l'ennemi. Il semble alors que plutôt que de vouloir inscrire la Lettre dans le contexte très précis d'une des prises de Samosate, on devrait davantage prendre en considération le contexte du conflit militaire prolongé qui a connu plusieurs moments particulièrement intenses : sous Trajan (113-117), sous Hadrien (161-165) et sous Septime Sévère (195-197). Les opérations militaires ont continué au temps de Caracalla (216), jusqu'à la prise de Ctésiphon par les Romains en 226. La force du témoignage de Mara réside dans le fait qu'il relate les souffrances de la population civile, en dehors des grandes campagnes militaires, soigneusement décrites par les historiographes anciens et les historiens modernes. Il est donc le témoin d'une période troublée qu'il décrit en des termes singulièrement poétiques :

«48. Moi alors, mon enfant, j’ai scruté les hommes - dans quelle misérable condition ils se trouvent! 49. Et je me suis étonné qu'ils ne soient pas épuisés par les maux qui les entourent. 50. Même les guerres ne leur ont pas suffi, ni les chagrins, ni les maladies, ni la mort, ni la pauvreté ! Mais comme les animaux féroces ils s'attaquent l'un à l'autre dans la haine, [pour voir] lequel d'entre eux infligera le plus de mal à son compagnon. 51. Car ils sont allés audelà des limites de ce qui est établi et ils transgressent toutes les bonnes lois, parce qu'ils suivent leur propre désir ; tant que l'homme poursuit l'objet de [son] désir, comment pourraitil faire avec justice ce qui lui convient ? [...] 54. Désormais qu'on s'étonne, quand le monde se consume dans le rire de mépris; quand ils n'ont aucune manière de vivre déterminée, à laquelle ils s'adonnent. 55. Et chaque noble parmi eux, quand [il est] dans la bataille, cherche

${ }^{147}$ KoZłOWSKI 2011, p. 215-216. L'historien polonais s'appuie sur les informations données par Flavius Josèphe et Dion Cassius, sur la participation d'Antiochos aux campagnes militaires des Romains. En outre, en tant qu'état-tampon, Commagène devait assurer la protection contre les Perses, ce qui nécessite une armée considérable.

${ }^{148}$ Flavius Josèphe, Guerres des Juifs, 7, 212-243. Le fils aîné d'Antiochos IV, C. Iulius Achelaus Antiochus Epiphanes a épousé la fille de Tiberius Claudius Balbilus, homme politique et astrologue. Son fils C. Iulius Antiochus Epiphanes Philopappus fut sénateur romain, mais il passa toute sa vie à Athènes.

149 SARTRE 2001, p. 469-527. 
à acquérir le nom de vainqueur, mais les vaillants ne voient pas par combien de désirs insensés l'homme est emprisonné dans le monde. "

\section{Conclusion}

Notre étude a cherché à mettre ensemble les éléments d'analyse littéraire et historiographique, afin de rendre moins fragiles certaines hypothèses concernant l'origine et la nature de la Lettre de Mara, ainsi que d'indiquer de nouvelles pistes de recherche.

Premièrement, nous avons mis en évidence le caractère pédagogique de la Lettre - conformément à son rôle parmi les autres écrits pédagogiques regroupés dans le manuscrit BL Add. 14658. Ce rapport étroit avec la paideia hellénistique renvoie au climat intellectuel de l'époque, marqué par le mouvement de la seconde sophistique et sa capacité singulière à proposer une éducation à la fois philosophique et rhétorique. C'est ainsi qu'il est possible de mieux comprendre la nature éclectique et superficielle des connaissances philosophiques de Mara et sa manière de les utiliser dans l'argumentation.

Deuxièmement, nous avons analysé les séries des exempla qui montrent particulièrement bien à quel point Mara est capable de faire la synthèse de son double héritage, grec et oriental. À travers des exemples tirés de la littérature grecque, il développe une réflexion sur le destin et sur la sage attitude à adopter face à des changements inattendus. Les personnages qu'il donne en exemple s'inscrivent parfaitement dans sa logique et même quelques arrangements avec les données biographiques restent conformes à l'esprit des auteurs grecs du $2^{\mathrm{e}}$ siècle. Cette observation est très importante par rapport à l'identification du « sage roi des Juifs » à Jésus, qui ne doit pas être considérée comme une donnée historiographique, mais comme l'expression d'une christologie propre à certains milieux judéo-chrétiens et chrétiens de la Syrie.

Troisièmement, nous avons proposé d'abandonner les efforts de rattacher la Lettre de Mara à des événements historiques précis, notamment à la prise de Samosate en 72. Ce rapprochement est fait par défaut, en absence d'indices permettant de relier positivement l'exil de Mara à cet épisode. Grâce à ce changement de perspective, Mara devient le témoin d'une période troublée par les guerres entre les Romains et les Parthes arsacides, mais son témoignage concerne les douloureuses expériences de la population civile, obligée de multiples façons à payer les coûts des campagnes militaires.

L'ensemble de ces éléments permet de confirmer la proposition de situer la rédaction de la Lettre dans une période qui va des dernières décennies du $2^{\mathrm{e}}$ siècle jusqu'à la moitié du $3^{\mathrm{e}}$ siècle - et cela sans recourir aux hypothèses supplémentaires d'une interpolation ou d'une composition scolaire tardive. 


\section{ANNEXE}

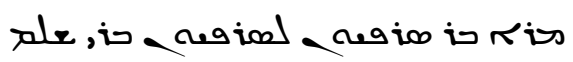

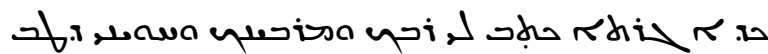
טa. כi حd. x

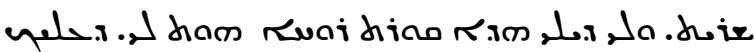

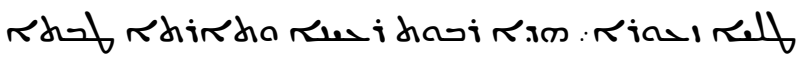
كm d.

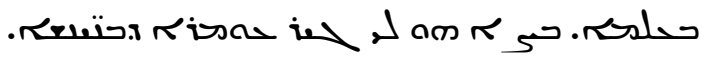

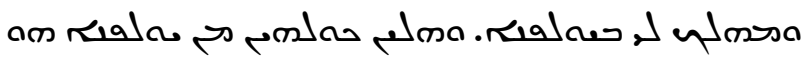

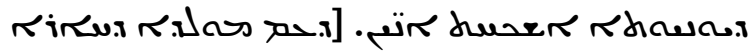
[

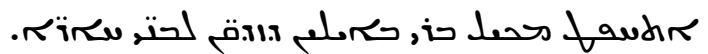

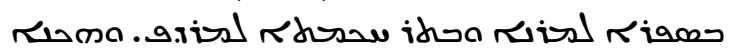
rambia : as dis.

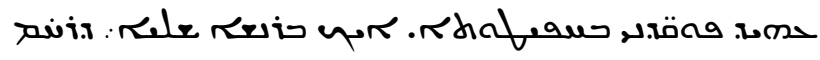

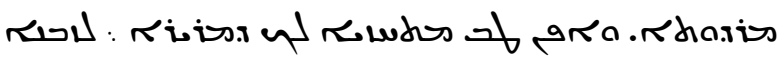

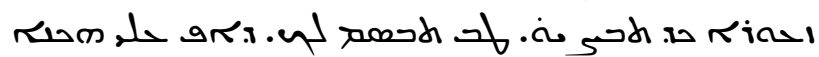
$x_{5}$ i

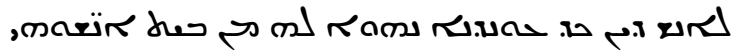

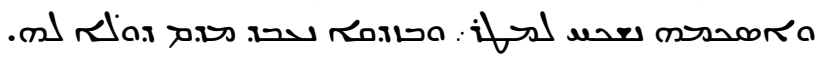

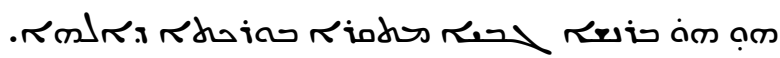

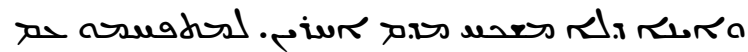
.mbaina

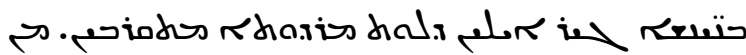

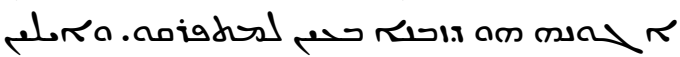

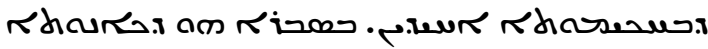

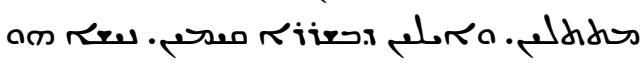

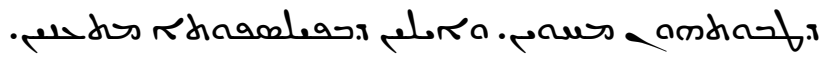

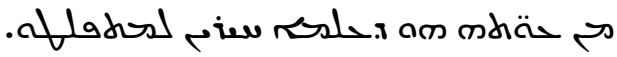

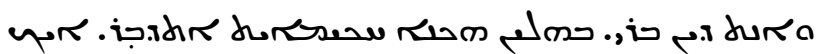

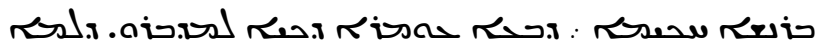

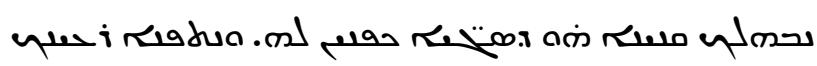

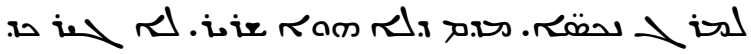

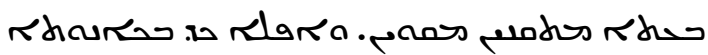

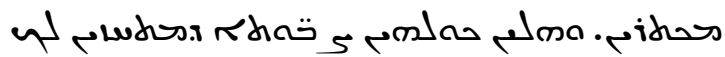

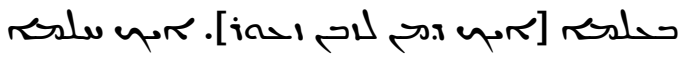

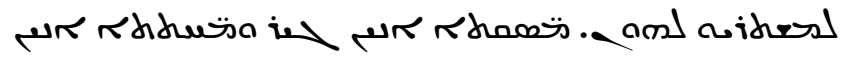
הוتעم. 


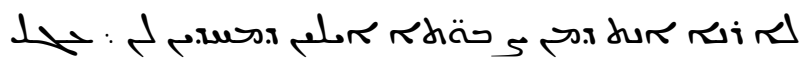

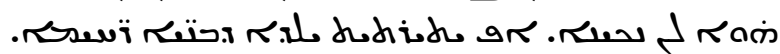

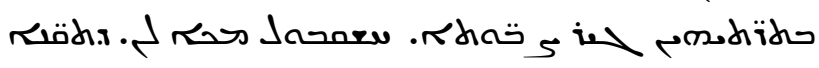

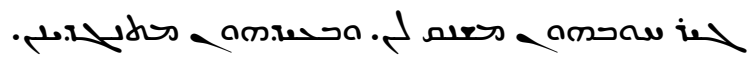

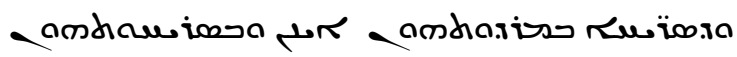
- Noudos

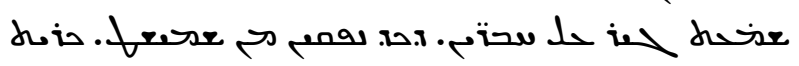

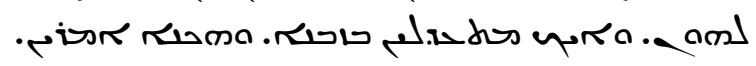

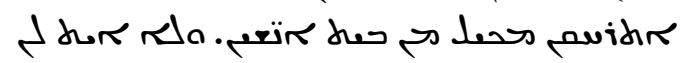

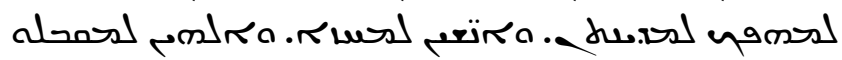

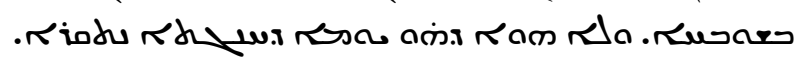

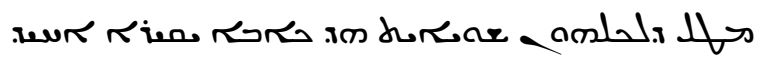

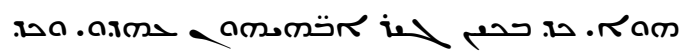

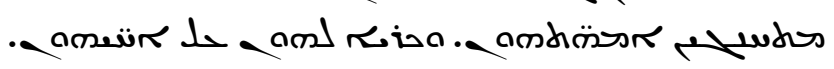

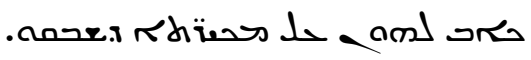

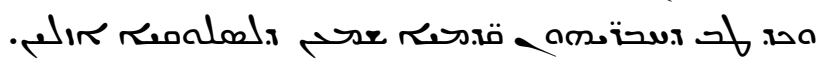

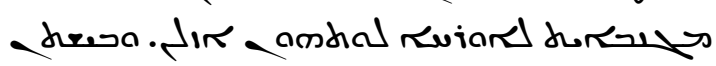

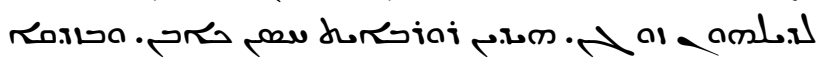

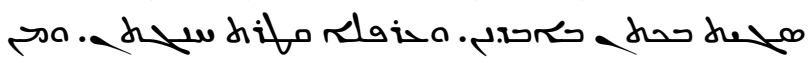

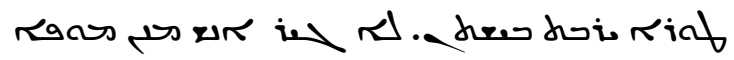

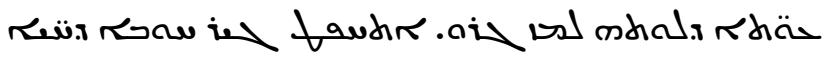

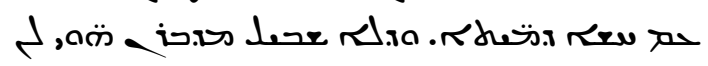

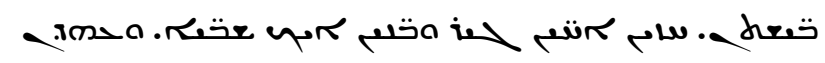

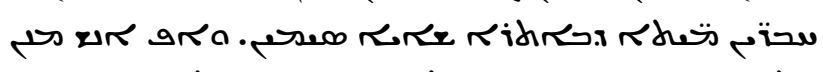

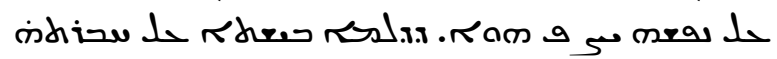

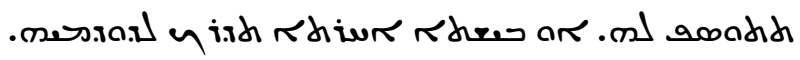

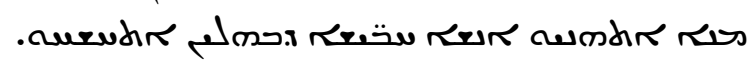

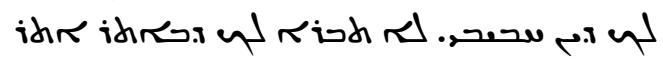

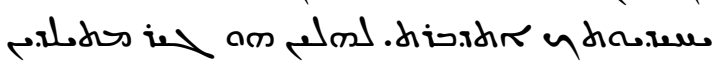

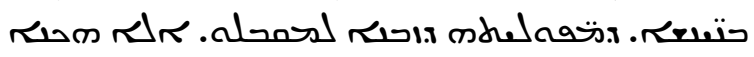

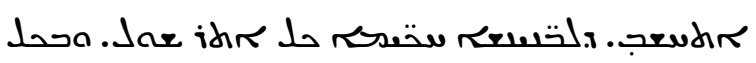

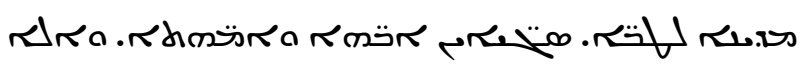

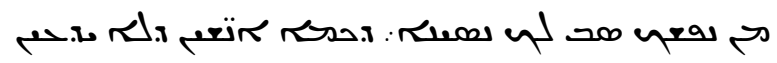

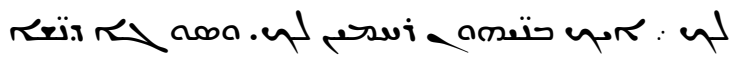

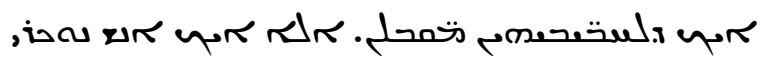

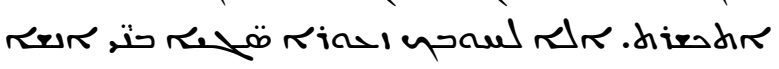
.nlaradir

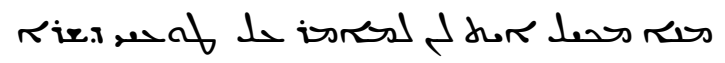

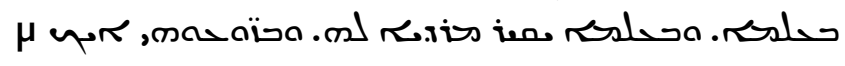
مس

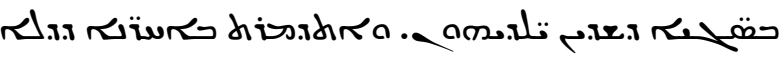

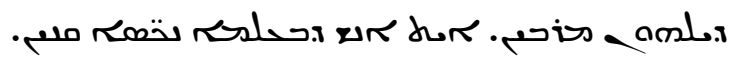

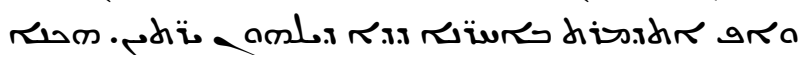




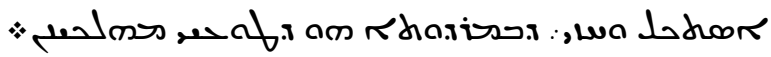

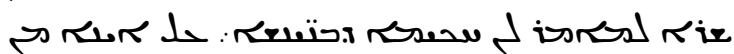

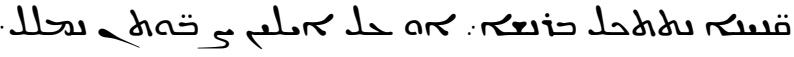

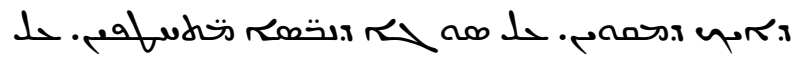

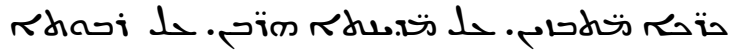

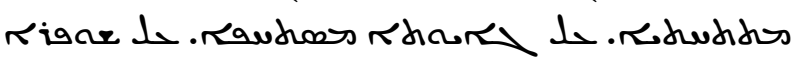

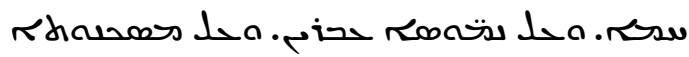
هل

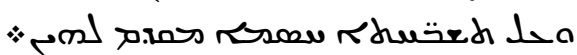

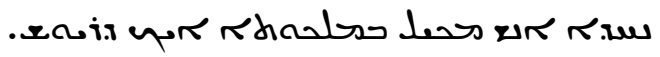

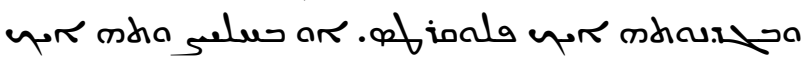

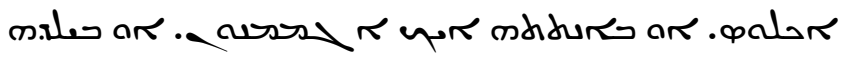

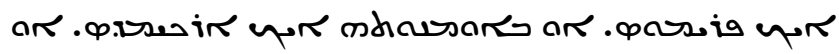
כuרs atha

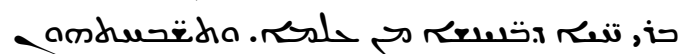

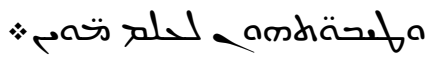

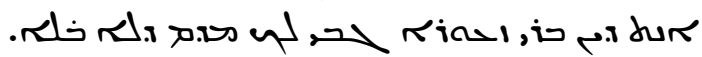

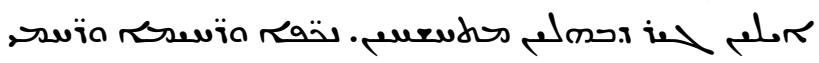

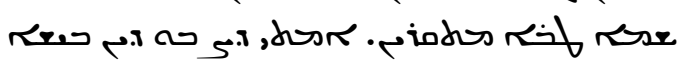

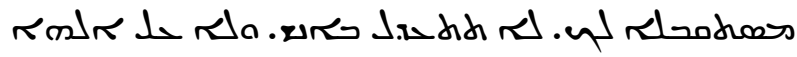
م.

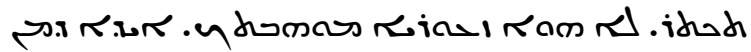

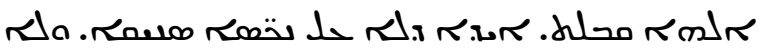
حل

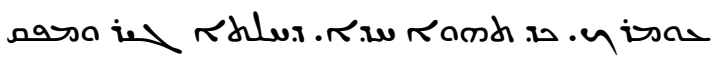

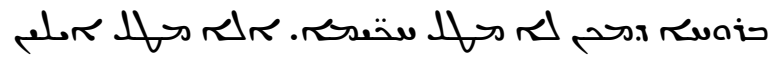
זירו

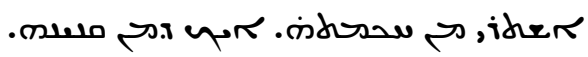

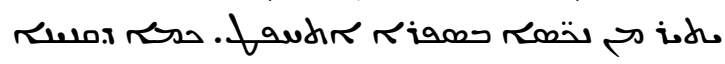
il

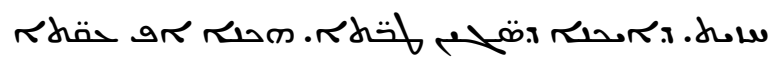
s

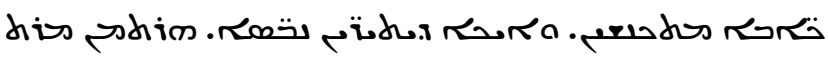
غע.

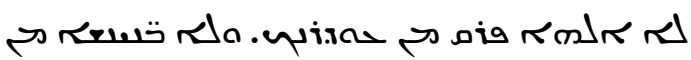

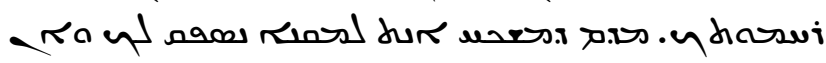

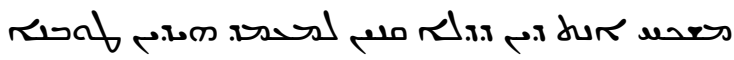
אים

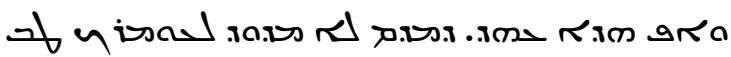

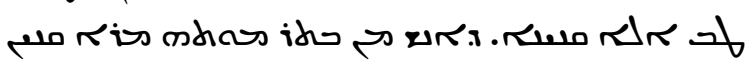

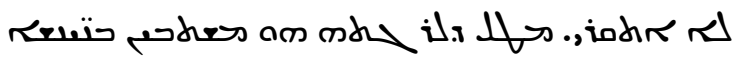

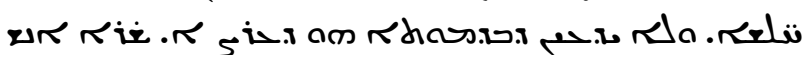




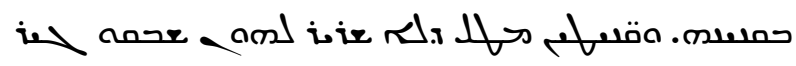

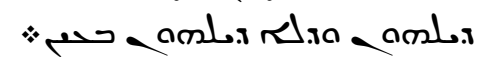

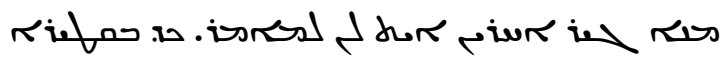

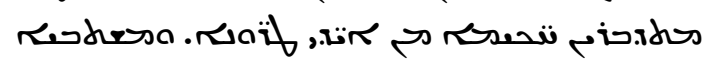

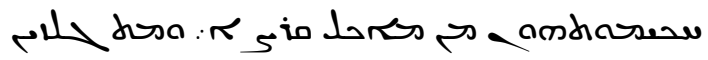
حנמת

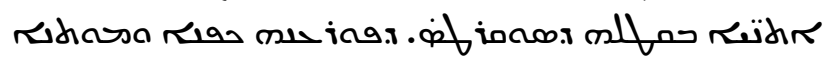

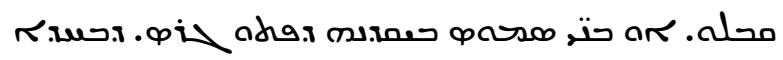

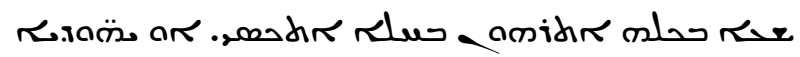

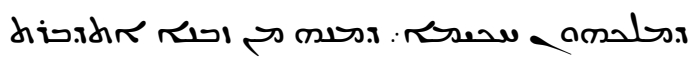

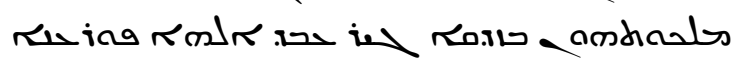

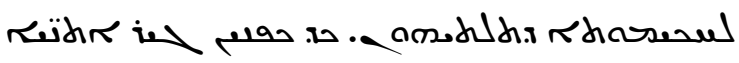

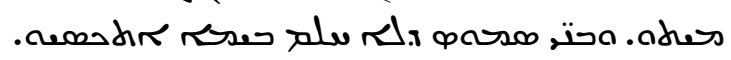

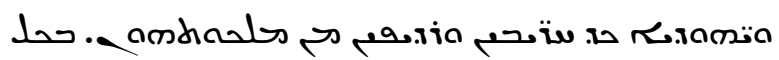

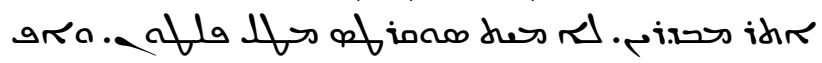

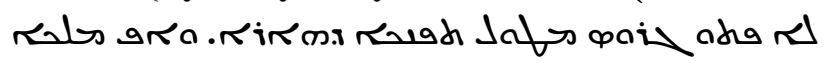

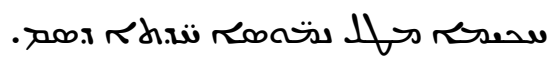

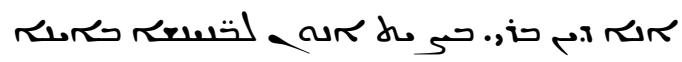

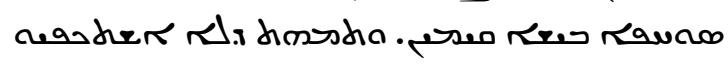
حت.

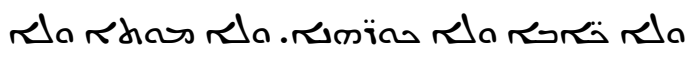

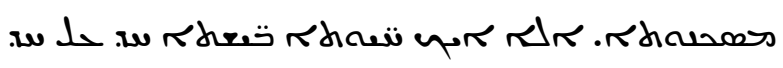

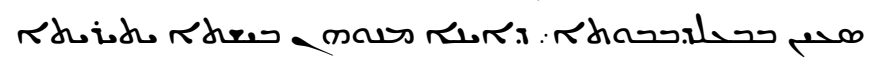

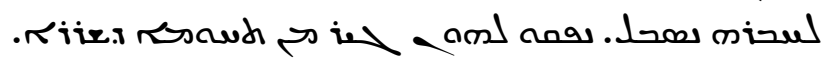

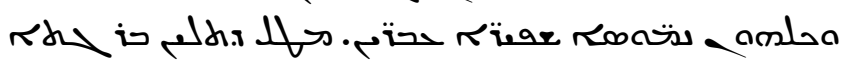

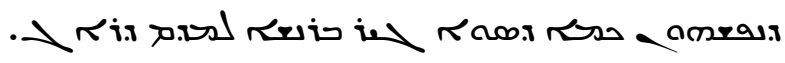

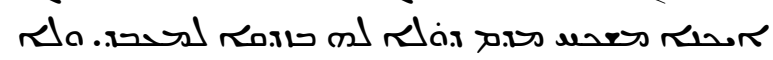

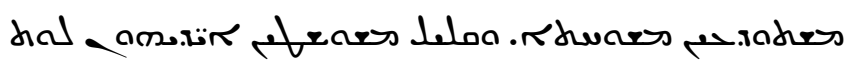

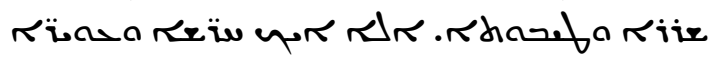

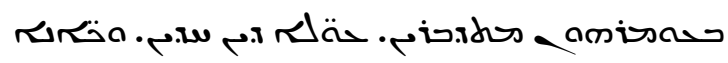

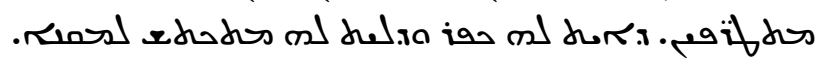

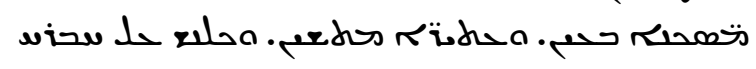

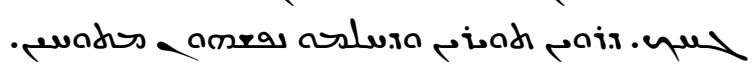

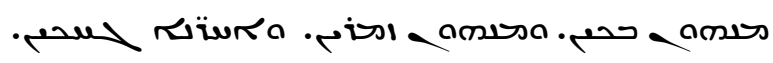

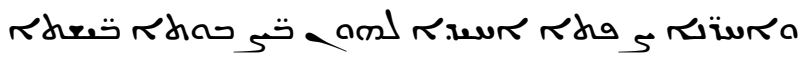

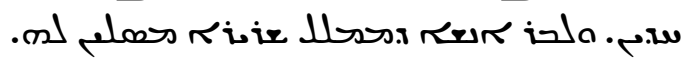

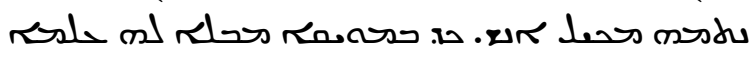

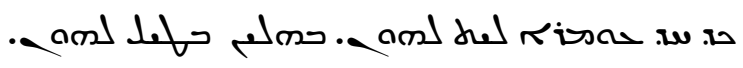

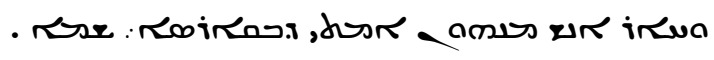

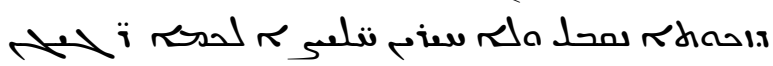
ته

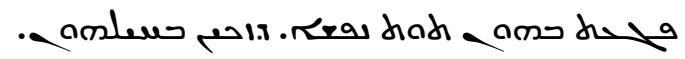

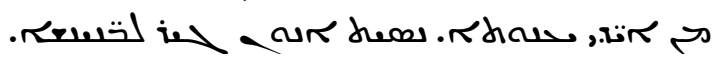




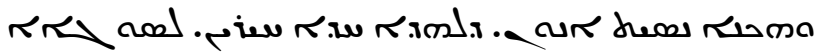

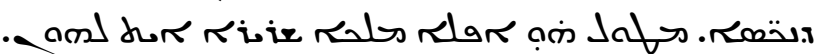

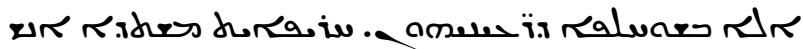

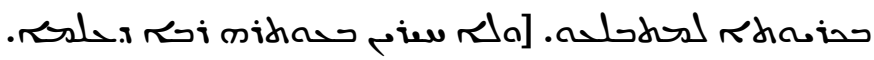

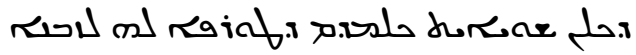

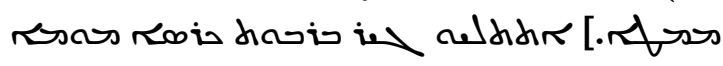

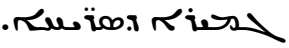

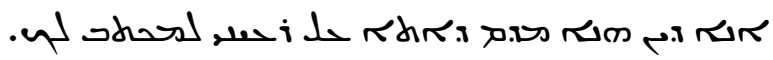

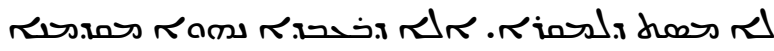

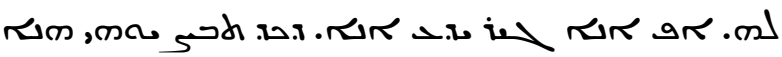

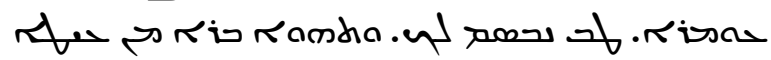

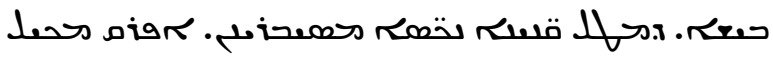

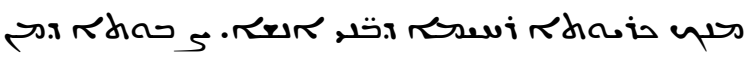

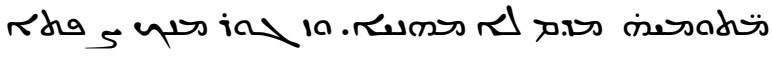

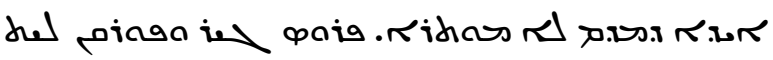

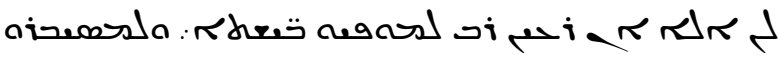

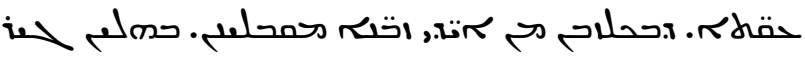

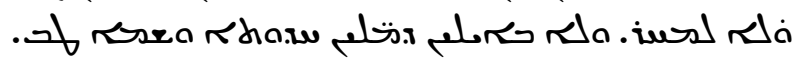

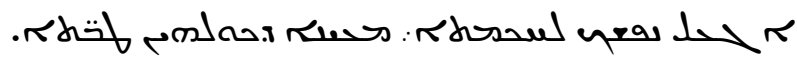
urin asod plia.r. Rhoch.

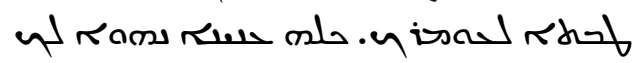

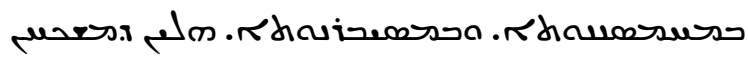

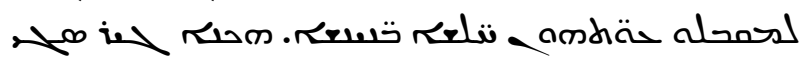

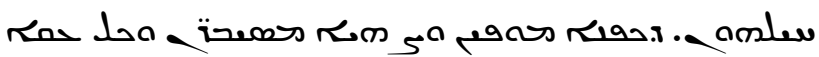

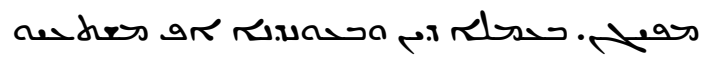

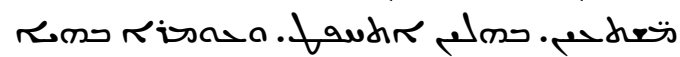

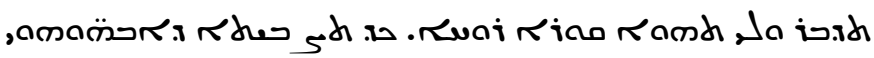
.riodid

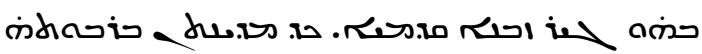

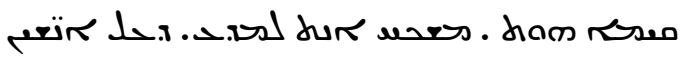

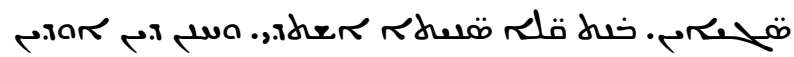

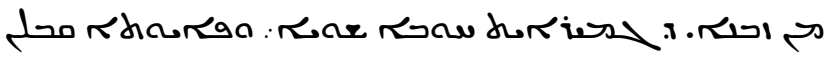

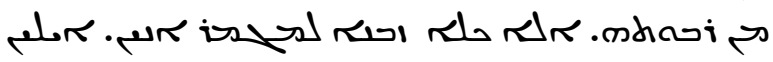

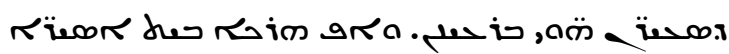

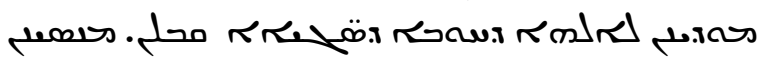

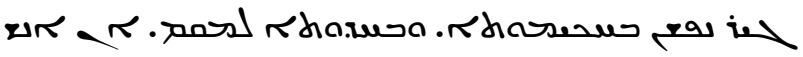

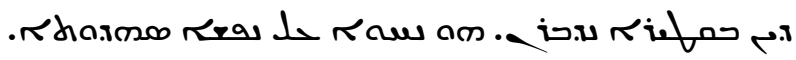

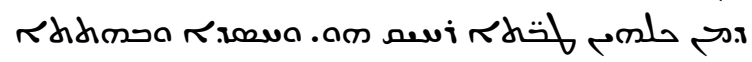

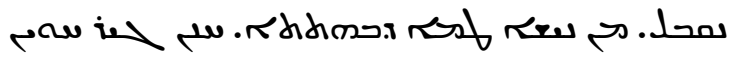

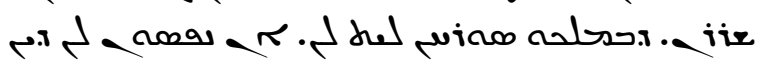

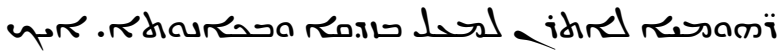

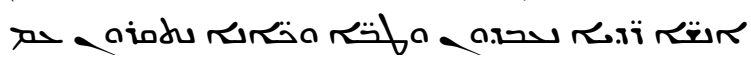




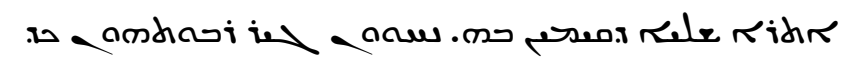

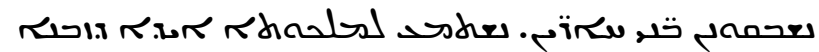
משכ ل.

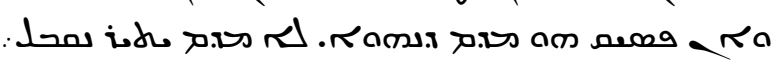

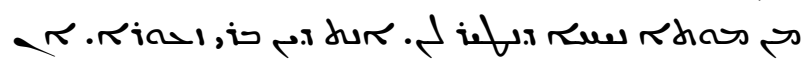

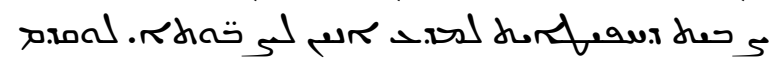

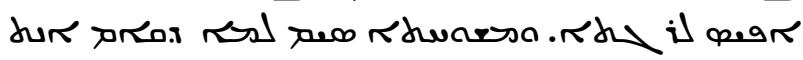

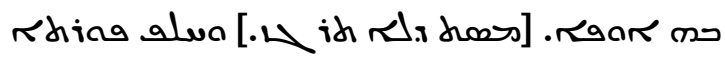
ר a

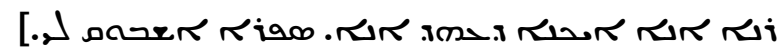

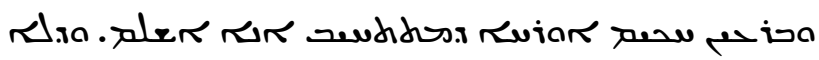

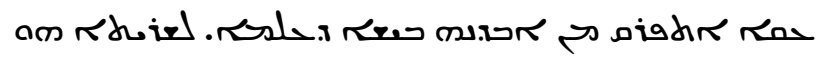

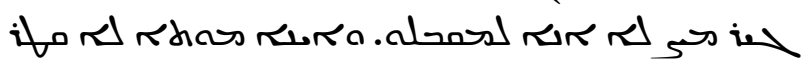

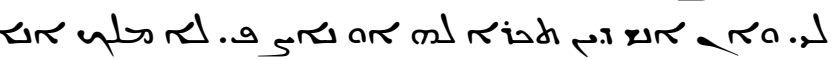

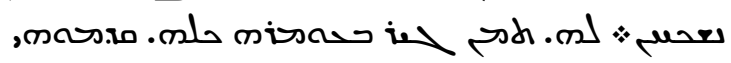

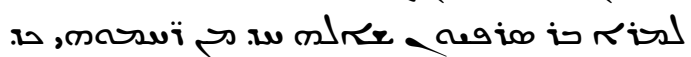

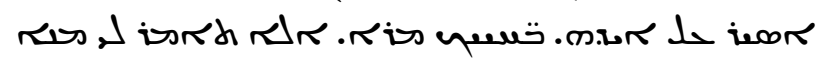

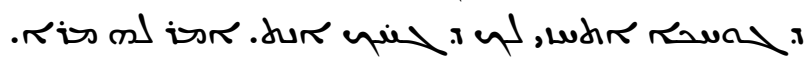

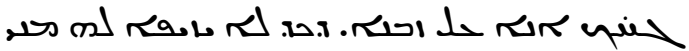
כ ש.

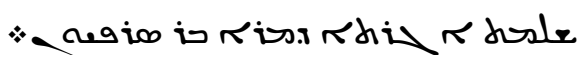




\section{Notes}

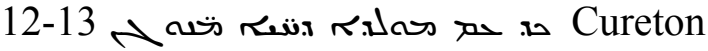

23 riods x Cureton

24 asuasl Cureton

26 rioks Cureton

30 ambiareb Cureton

34 sla Cureton

38 [] om. Schulthess

45 rusio Cureton

53 ambiasor Cureton

68 , add. Schulthess

84 rhosishulthess

108 r Cureton

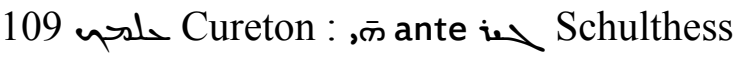

115 Cureton

116 Cureton

118 تسن Cureton

لנתרמ Cureton

Schulthess

146 قureton

165 Schulthess

173-175 [ ] om. Schulthess

בח Cureton

Cureton

184 sing Cureton

186 Cureton

194 مereton

214 موفم Schulthess 


\section{Traduction}

\section{Mara fils de Sérapion, à Sérapion mon fils, salut}

1. Quand ton maître et tuteur ${ }^{150} \mathrm{~m}$ 'a écrit une lettre et m'a fait savoir que toi, enfant de quelques ans ${ }^{151}$, tu es très assidu à l'étude, j'ai béni Dieu, parce que toi, qui est un petit garçon sans guide, tu as commencé avec une grande sollicitude. 2. Quant à moi, ceci était ma joie, parce que j'ai entendu [parler] à ton sujet, ô petit garçon, de la grande intelligence et de la conscience droite ${ }^{152}$ : la chose ${ }^{153}$ qui ne se trouve pas facilement chez beaucoup. 3. Voilà, pourquoi j'ai écrit pour toi ce souvenir ${ }^{154}$ [de] ce que j'ai cherché dans le monde, car j'ai scruté la façon de vivre des hommes ${ }^{155}$ et j'ai été amené à l'étude. $<4$. Tout ce que j'ai trouvé dans l'étude [des sciences] des Grecs est lié à la naissance de la liberté. $>^{156}$

5. Désormais, consacre-toi, mon fils, aux choses qui conviennent aux hommes libres : l'examen des lettres ${ }^{157}$ et la poursuite de la sagesse ; et de cette manière cherche à être affermi en ce que tu as commencé. 6. Et souviens-toi de mes préceptes avec diligence, comme un homme de paix qui aime l'instruction ${ }^{158}$. 7 . Même si cela te paraît très amer pendant un court temps, quand tu apprends, il te sera très doux ; parce que la même chose m'est arrivée.

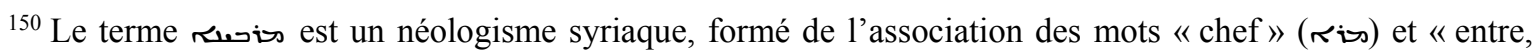

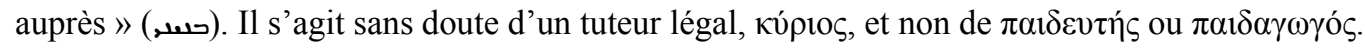

${ }^{151}$ Mara souligne souvent que son fils est très jeune en utilisant des expressions qui conviendraient à un $\pi \alpha 1 \delta$ íov; voir Lettre, vv. 2. 3, 4, 69, 148 et 51. Ce mot désigne un enfant qui commence son éducation, voir MARROU 1948, p. 157.

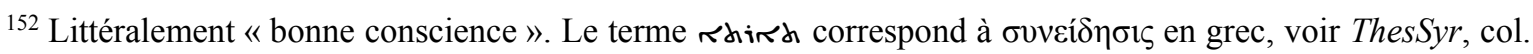
4376.

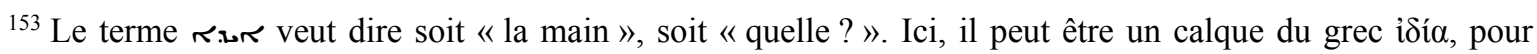
désigner les propriétés, les caractéristiques.

${ }^{154}$ Il s'agit peut-être d'un genre littéraire de « mémoires », vं $\pi$ $\mu v \eta ́ \mu \alpha \tau \alpha$ - les notes servant d'aide-mémoire ; voir SCHULTHESS 1897, p. 366. Ce terme est utilisé également par Arrien pour décrire sa rédaction des Entretiens d'Epictète (Lettre d'Arrien à Lucius Gellius, 2) et par Marc Aurèle pour ses Pensées (Pensées III, 14). Dans ce sens, les $\dot{\pi} \pi \circ \nu_{\eta} \mu \alpha \tau \alpha$ servent d'appui à une relecture fréquente, à une méditation. Sur les notes personnelles concernant une manière de vivre, voir BÉNATOUÏL 2009, p. 22-29. I. Ramelli rapproche ce terme des commentarii historiographiques latins, voir RAMELLI 2012, p. 211.

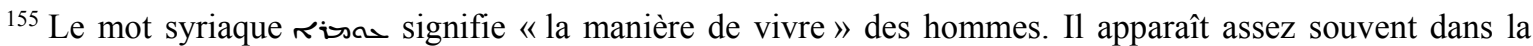
Lettre ; voir v. $5 ; 98-99 ; 105-107 ; 110-111 ; 120-123 ; 130 ; 154-155$. Les traducteurs proposent de l'associer à l'habitus ; voir SCHULTHESS 1897, p. 367 ; ou encore au $\sigma \chi \tilde{\eta} \mu \alpha$ (translittéré en v. 14) ; voir RENSBERGER 2010, p. 13-14.

156 Texte corrompu, surtout la dernière partie. Cureton traduit cette phrase : ... and all those things of the instruction of Greeks I have found them wrecked together with the birth of life, p. 70. (...détruites pendant la naissance de la vie). Schulthess propose de lire خa (de : mélanger, composer) à la place de $\lambda$ (de : faire naufrage), ce qui donne Von all'dem, was zur griechischen Lehre gehört (aus der griechischen Lehre kommt), habe ich gefunden, dass es mit der Geburt des Freien verbunden ist, p. 366, n. 3. J'adopte cette correction.

${ }^{157}$ Le terme syriaque ${ }^{2}$ iao terme correspond aux $\gamma \rho \alpha ́ \mu \mu \alpha \tau \alpha$ en grec; il désigne donc des activités littéraires très variées, ainsi qu'un scribe, un grammairien ou un homme de lettres, voir: ThesSyr. col. 2707-2709. Cela correspond aux emplois des $\gamma \rho \alpha ́ \mu \mu \alpha \tau \alpha$ dans le monde grec. Selon Theresa Morgan, les $\gamma \rho \alpha ́ \mu \mu \alpha \tau \alpha$ s'appliquent à tous les genres littéraires, la poésie et la prose ; voir MORGAN 1998, p. 90. Sur la « grammaire » grecque, voir HADOT 1992, p. 41-42.

${ }^{158}$ L'instruction, Rhoxis, apparaît souvent dans la Lettre vv. 10-11 ; 16-17 ; 143-145 ; moins évident en vv. 27 et 56. Le substantif vient de la racine ( $\kappa_{\text {xi }}$ ) qui signifie « marcher, avancer, s'instruire ». Elle est utilisée pour tous les termes dérivant du verbe $\pi \alpha \iota \delta \varepsilon v ́ \varepsilon ı$, voir ThesSyr, col. 3819-3822.
} 
8. Quand un homme est séparé des siens, qu'il soit capable de garder sa manière d'être ${ }^{159}$ et qu'il fasse avec justice ce qu'il lui convient [de faire]. 9. Celui-ci est un homme choisi, appelé «bénédiction de Dieu », et aucune chose ne peut être comparée avec sa liberté.

10. Car ces hommes qui suivent l'instruction, cherchent à se libérer des épreuves du destin ${ }^{160}$ ; et ceux qui persévèrent dans la sagesse, sont soutenus dans l'espérance de la justice ; et ceux qui se tiennent dans la vérité montrent signe de leur vertu ${ }^{161}$ et ceux qui se consacrent à la philosophie ${ }^{162}$ sont libérés de l'attention portée aux misères du monde.

11. Et toi alors, mon fils, dans ces choses-là, agis avec sagesse, comme un homme sage qui cherche à mener une vie pure. Est-ce que la richesse convoitée par beaucoup pourrait t'apporter la paix et faire revenir ton esprit à désirer les biens, cette chose qui n'est pas réelle ? 12. Car [les biens] obtenus malhonnêtement ne restent pas et même [obtenus] avec droiture, ils ne durent pas. 13. Et toutes les choses désirées qui t'apparaissent dans le monde $<$ comme ce qui est de courte durée>, elles vont s'évanouir comme un rêve - car ainsi sont les hauts et les bas des destins. 14. Et quant à la vaine gloire qui occupe la vie des hommes, ne crois pas qu'elle appartienne à ces choses désirées qui nous rendent heureux : rapidement elle devient pour nous un malheur. 15. Et plus encore la naissance des enfants bien-aimés nous blesse au moyen de deux choses, également de part et d'autre ${ }^{163}$ lorsqu'ils sont honnêtes, l'amour pour eux nous tourmente et nous sommes charmés par leur ; lorsqu'ils sont méchants, nous nous lamentons de leur rébellion et de leur perversité.

16. J'ai entendu, en fait, au sujet de nos compagnons qui, en quittant Samosate ${ }^{164}$ étaient affligés comme ceux qui blâment le destin. Et ils parlaient ainsi : " Désormais, nous sommes éloignés de notre foyer et nous ne pouvons pas retourner dans notre ville, ni voir nos proches, ni nous adresser à nos dieux ${ }^{165}$ en louanges. »17. Celui-là n'était-il pas appelé «jour de lamentation ${ }^{166}$ », parce que tous également étaient saisis par la même lourde douleur ? 18. Car en pleurant ils se souvenaient de leurs pères et en se lamentant - de leurs mères; et ils avaient du chagrin pour leurs frères et de la peine pour leurs épouses qu'ils ont abandonnées.

\footnotetext{
${ }^{159}$ Le mot 2 rost une transcription du grec $\sigma \chi \tilde{\eta} \mu \alpha$ en syriaque, voir RENSBERGER 1897, p. 13-14.

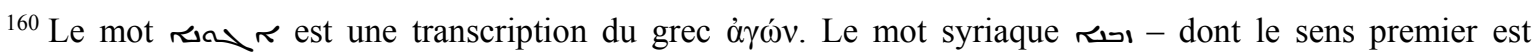
« temps » - peut signifier aussi « destin ». Ce choix de traduction apparaît déjà chez Schulthess et chez Cureton, mais Rensberger en fait le terme technique permettant d'approcher la notion de destin ; voir RENSBERGER 1897, p. 14-18.

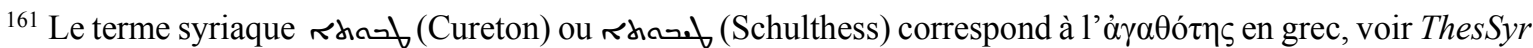
col. 1417-1418.

${ }^{162}$ Le mot rinaol.g est un calque du grec, «philosophie». À la différence des autres termes grecs qu'on trouve dans la Lettre, celui-ci est entré dans la langue syriaque pour désigner aussi bien la philosophie et son étude, que la vie monastique, voir ThesSyr, col. 3105-3108.

${ }^{163}$ Le mot uragnifie « à part égale » et il est très rare. Il se trouve dans la version syriaque d'Is 65,7 et dans une inscription à Harran, datée du 2e-3e siècle, voir SEGAL 1957, p. 514-517.

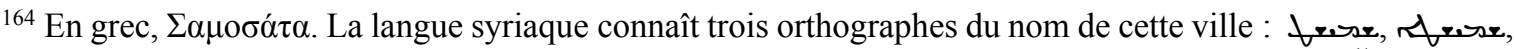
†rse; voir ThesSyr, col. 4230; WeISSBACH 1920, col. 2220-2224. Sur le rapport entre l'ancienne Šut Mišut et Samosate dans les sources araméennes, voir OPPENHEIMER 1983, p. 436-442.

${ }^{165}$ Le mot (nos dieux) est le seul cas d'utilisation du pluriel. On note une certaine ressemblance avec les prières en 2 Baruch $3,5-6 ; 5,1$.

${ }^{166}$ Voir Jér 9, 19.
} 
19. Et quand nous avons encore entendu, de la part de leurs anciens compagnons, qu'ils partaient vers la Séleucie ${ }^{167}$ nous avons pris clandestinement le chemin vers eux, et nous avons uni notre malheur à celui qui est le leur. 20. Alors notre douleur a grandement augmenté, et pour une bonne raison nos pleurs ont abondé dans notre ruine ; nos soupirs se sont épaissis en sombre nuage et notre malheur a dépassé une montagne. Car personne parmi nous n'était en mesure de surmonter ses propres afflictions. L'amour des vivants a renforcé la tristesse [à cause] des morts, et nos malheurs nous ont menés vagabonds. 21. Car nous avons regardé nos frères et nos fils captifs, et nous nous sommes souvenus de nos compagnons morts qui ont été enterrés dans un lieu de fortune. 22. Et chacun de nous était inquiet pour lui-même, dans la peur qu'un malheur en plus s'associe à lui, ou qu'un malheur neuf dépasse le précédent. 23. Est-ce que les prisonniers ${ }^{168}$ ont eu besoin de faire une expérience pareille ${ }^{169}$ ?

24. Mais pour toi, mon bien-aimé, ne t'inquiète pas que tu sois tout seul, transféré d'un endroit à l'autre ; car pour cela sont nés les hommes : pour supporter les changements du destin. 25. Pense plutôt ainsi : que pour les hommes sages chaque lieu est pareil, et pour les vertueux il y a dans chaque ville de nombreux pères et mères. 26. Mais prends de ta propre expérience : combien d'hommes qui - sans te connaître - t'aiment comme leur fils ? Et nombreuses les femmes qui te reçoivent comme leur bien-aimé ? Cependant, en tant qu'étranger tu as eu beaucoup de chance : seulement à cause de ton petit amour ${ }^{170}$, de nombreuses gens ont voulu de toi.

27. Que pouvons-nous donc dire au sujet de l'erreur qui s'est installée dans le monde et dans le monde [elle est] pour lui une dure instruction; et dans ses troubles nous sommes secoués comme un roseau au vent? 28. Car je me suis étonné de nombreuses [gens] qui exposent leurs nouveau-nés et j'ai été stupéfait par d'autres qui élèvent ceux qui ne sont pas à eux. Il y a des gens qui obtiennent les richesses avec labeur ${ }^{171}$; et même j'ai été stupéfait par d'autres qui héritent ce qui ne leur appartient pas. Ainsi comprends et vois que nous progressons en instruction ${ }^{172}$ qui se fait dans l'erreur.

29. Viens nous parler, ô sage parmi les hommes : à quelles choses l'homme peut-il se fier ? De quels biens désirés pouvons-nous dire qu'ils sont durables? De l'abondance des richesses? Elles sont arrachées. De forteresses ? Elles sont pillées. De villes ? Elles sont dévastées. De gloire ? Elle est humiliée. De puissance ? Elle est renversée. De beauté ? Elle se fane. De lois?

\footnotetext{
${ }^{167}$ L'orthographe 2 pour «Séleucie» est la plus commune en syriaque. Plusieurs villes grecques portaient ce nom, la plus connue étant Séleucie près d'Antioche. Mara bar Serapion se réfère probablement à Séleucie - Zeugma, située dans le royaume de Commagène, mais il y a aussi une autre Séleucie, près d'Apamée. Pour une argumentation en faveur de Séleucie - Zeugma, au sud de Samosate, voir MiLlar 1993, p. 82-83 et 461. Cette ville est mentionnée aussi dans les sources araméennes, voir OPPENHEIMER 1983, p. 436-442.

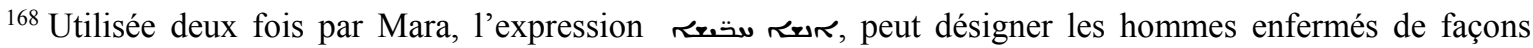
différentes - emprisonnés, assiégés ou reclus, voir ThesSyr, col. 1186-1188. Plus tard, elle est utilisée pour dire « ermite ».

${ }^{169}$ Nous suivons la traduction de Cureton : from having experience of this things.

${ }^{170}$ Schulthess ajoute le mot , et traduit « à cause de ton amour, mon petit fils », voir SCHULTHESS 1897, p. 369.

${ }^{171}$ Deux lectures sont possibles : «avec labeur " حسكلم (Schulthess, Ramelli) et "dans le monde " حلs ) (Cureton, Rensberger).

172 Schulthess propose de lire Rł.riss (parcours) à la place de Rhaxiss (instruction), voir SCHULTHESS 1897, p. 369.
} 
Elles tombent [en désuétude]. De pauvreté ? Elle est méprisée. D'enfants ? Ils meurent. D'amis ? Ils deviennent infidèles. Des honneurs? La jalousie les précède.

30. Quelqu'un se réjouit donc de son royaume comme Darius, et de sa prospérité comme Polycrate, ou de sa bravoure comme Achille, ou de sa femme comme Agamemnon, ou de sa descendance comme Priam, ou de ses compétences comme Archimède, ou de sa sagesse comme Socrate, ou de sa connaissance comme Pythagore ou de sa clairvoyance comme Palamède. 31 . Passent, mon fils, les vies des hommes dans le monde, mais leurs honneurs et leurs vertus demeurent pour toujours.

32. Ainsi toi, mon petit enfant, choisis pour toi ce qui ne périt pas, car ceux qui s'occupent de telles choses, sont considérés modestes, aimés et estimés ${ }^{173}$. 33. À chaque fois qu'un mal t'arrive, ne blâme personne, ne te mets pas en colère contre Dieu et ne murmure pas contre ton destin. 34. Si tu continues dans cet esprit, alors ton don n'était pas petit : celui que tu as reçu de Dieu, celui qui n'a pas besoin des richesses et ne fait pas approcher la pauvreté. 35. Sans peur tu conduiras donc ta vie, quand tu seras joyeux ; car la crainte est une excuse qui n'existe pas dans l'esprit de [ceux] qui sont sages, mais de ceux qui s'égarent loin de la loi. Car personne n'a jamais été dépouillé de sa sagesse de la même manière que de sa propriété.

36. [Il vaut mieux qu'on] s'occupe davantage des lettres que des richesses, car plus de propriété, d'autant plus de mal. 37. En effet, j'ai vu que, lorsque les biens sont nombreux, de même aussi arrivent les ennuis ; et où augmentent les splendeurs, là-même les chagrins se rassemblent aussi ; et où les richesses se sont agrandies, là-même il y a plusieurs années ${ }^{174}$ d'amertume. 38. Maintenant, si tu comprends et préserves avec zèle, Dieu n'arrêtera pas de t'aider, ni les hommes de t'aimer. 39. Quoi que tu sois capable d'acquérir, que cela te soit suffisant; et si tu es capable de vivre ${ }^{175}$ sans possessions, tu t'appelleras bienheureux, parce que personne ne te jalousera.

40. Et rappelle-toi encore de ceci : que rien ne trouble ta vie si fortement que la richesse ; aucun homme après sa mort n'est appelé « propriétaire ${ }^{176}$, [mais] à cause de sa convoitise les malheureux sont emmenés en captivité. 41. Ils ne savent pas que l'homme quitte ses propriétés, semblable à un étranger; et ils ont peur parce qu'ils ne sont pas dans leur droit ; car ils ont abandonné ce qui est à eux et cherchent ce qui ne leur appartient pas.

42. Quoi d'autre, en fait, avons-nous à dire, lorsque les sages sont menés sous contrainte ${ }^{177}$ par les mains de tyrans ${ }^{178}$, leur sagesse est emmenée en captivité par la calomnie et ils sont méprisés pour leur clairvoyance, sans pouvoir se défendre ? 43. Quel profit les Athéniens ontils tiré du meurtre de Socrate? En punition de ceci ils ont reçu la famine et la peste. 44. Ou les gens de Samos pour avoir brûlé Pythagore ? En une heure leur pays tout entier a été recouvert

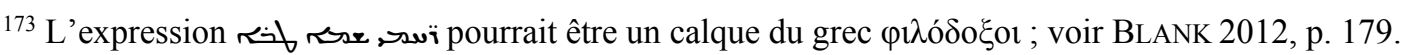

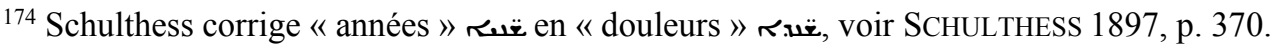

175 Schulthess corrige « faire » (حصى) en « vivre » (حصى), ce qui explicite le sens de la phrase, voir SCHULTHESS 1897 , p. 370 ; RAMELLi 2012, p. 224-225.

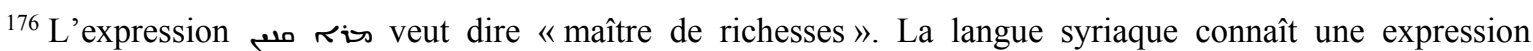

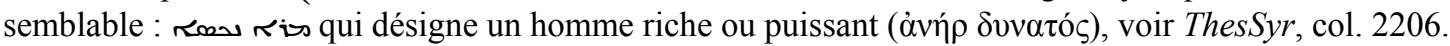

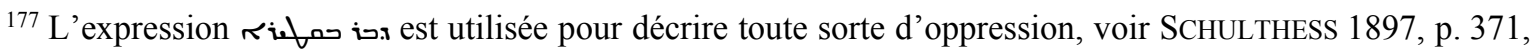
n. 2.

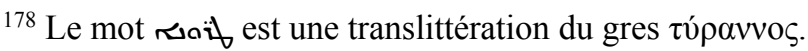


de sable ${ }^{179} 45$. Ou les Juifs pour leur sage roi $^{180}$ ? À partir de ce temps-là leur royaume a été pris. 46. Avec justice, en fait, Dieu a vengé la sagesse de ces trois-là, car les Athéniens sont morts de famine, les Samiens ont été irrémédiablement ${ }^{181}$ submergés par la mer, et les Juifs, après avoir été combattus et chassés de leur royaume, sont dispersés partout. 47. Socrate n'est pas mort, grâce à Platon ; ni Pythagore, grâce à la statue d'Héra, ni le sage roi, à cause des lois nouvelles qu'il a données.

48. Moi alors, mon enfant, j'ai scruté les hommes - dans quelle misérable condition ils se trouvent ! 49. Et je me suis étonné qu'ils ne soient pas épuisés par les maux qui les entourent. 50. Même les guerres ne leur ont pas suffi, ni les chagrins, ni les maladies, ni la mort, ni la pauvreté ! Mais comme les animaux féroces ils s'attaquent l'un à l'autre dans la haine, [pour voir] lequel d'entre eux infligera le plus de mal à son compagnon. 51. Car ils sont allés au-delà des limites de ce qui est établi et ils transgressent toutes les bonnes lois, parce qu'ils suivent leur propre désir ; tant que l'homme poursuit l'objet de [son] désir, comment pourrait-il faire avec justice ce qui lui convient ? 52. Ils ne reconnaissent pas la modération et rarement ils tendent les mains vers la vérité et la vertu, mais ils se conduisent dans leur manière de vivre comme sourds et aveugles. 53. Les injustes se réjouissent et les justes sont accablés ; celui qui possède renonce et celui qui n'a pas s'efforce de posséder ; les pauvres cherchent et les riches cachent et chacun se moque de son voisin ; les ivrognes sont inconscients, et les sobres regrettent [de ne pas l'être $]^{182}$; quelques-uns pleurent et quelques autres chantent; les uns rient et les autres s'occupent d'eux-mêmes; ils se réjouissent de mauvaises choses, et ils jettent dehors l'homme qui dit la vérité.

54. Désormais qu'on s'étonne, quand le monde se consume dans le rire de mépris ${ }^{183}$; quand ils n'ont aucune manière de vivre déterminée, à laquelle ils s'adonnent. 55. Et chaque noble ${ }^{184}$ parmi eux, quand [il est] dans la bataille, cherche à acquérir le nom de vainqueur, mais les vaillants ne voient pas par combien de désirs insensés l'homme est emprisonné dans le monde. 56. Pourvu que, petit à petit, le regret leur vienne tout seul, à ceux qui conquièrent par leur force et se condamnent par leur propre cupidité. 57. Car je connais les hommes par expérience et voici ce que j'ai appris sur eux : ils regardent une seule chose - l'abondance des richesses. Parce dans ce domaine ils ne suivent aucun conseil sûr, mais l'inconsistance de leurs opinions, l'homme est d'un coup plongé dans la tristesse au point d'en être consumé. [58. Et ils ne reg ardent pas les immenses richesses du monde que nous [recevons] de même, quel que soit le

\footnotetext{
${ }^{179}$ Une allusion à l'oracle sibyllin, un jeu de mots, sur Samos qui sera ensablée et Délos qui sera invisible :

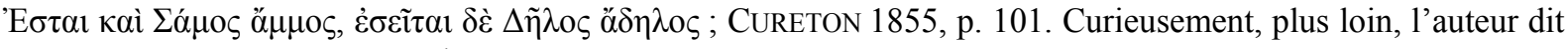
que Samos a été recouverte par l'eau.

${ }^{180}$ Le texte ne contient pas de verbe relatif à ce que les Juifs ont fait. Cureton ajoute by the death (CURETON 1855, p. 73 ) et il est suivi en cela par les autres traducteurs qui voient en cette phrase une allusion à Jésus.

${ }^{181}$ Cureton propose de traduire $ه$ comme without remedy (CURETON 1855, p. 74) Schulthess signale qu'il s'agit d'un terme rare, dérivé de l'hébreu, voir SCHULTHESS 1897, p. 371-372 n.7.

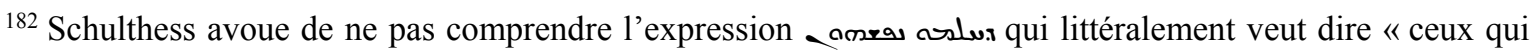
sont sains / solides en eux-mêmes ", mais dans la note il suppose que l'intention de l'auteur est d'indiquer le contraire des ivrognes ; voir SCHULTHESS 1897, p. 372, n. 5. La traduction de Cureton-those that have recovered themselves - obscurcit la logique antithétique de la phrase.

${ }^{183}$ Une phrase obscure que Schulthess renonce à traduire, p. 373, n. 1. Cureton propose while the world consumes in derision, voir CURETON 1855, p. 74.

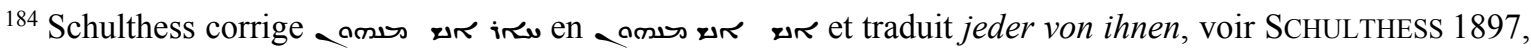
p. 373 n. 2.
} 
tourment réservé par le destin.] ${ }^{185} 59$. Car ils pleurent après la vaine gloire, le défaut parfait des vicieux.

60. En fait, tout ceci m'est venu à l'esprit pour t'en écrire ; il ne suffit pas d'en parler, mais il convient que cela soit mis en pratique. 61. Car je sais aussi que lorsque tu pratiqueras cette manière de vivre, elle te rendra vertueux et tu seras hors des ennuis ; parce que nous souffrons à cause de la possession des richesses. 62. Éloigne de toi désormais la peine, ô aimé des hommes : cette chose sert toujours à rien - et chasse loin de toi cette préoccupation qui n'apporte aucun avantage. 63. Car nous n'avons ni moyens et ni salut ${ }^{186}$, mais la grandeur de l'esprit [seulement], pour vaincre les malheurs et supporter les chagrins que nous recevons tous les jours des mains du destin. 64. Il convient, en fait, de faire attention à ces choses-là, et non à celles qui sont pleines de joie et d'estime. 65. Consacre-toi à la sagesse, source de toutes les vertus et trésor qui ne périt pas ; là-bas tu poseras ta tête et tu te reposeras, car elle sera pour toi un père et une mère, et une bonne compagne pour ta vie. 66. Garde toute la familiarité avec la persévérance et la patience ; à elles peuvent faire appel les hommes faibles [dans] leurs chagrins, car leur force augmente à tel point qu'ils peuvent supporter la faim et endurer la soif, et ils surmontent toute peine, et même dans le labeur et la séparation ${ }^{187}$ ils se racontent des histoires [amusantes]. 67. Prête attention à ceci, afin que tu mènes une vie tranquille et tu seras pour moi une consolation, lorsqu'on t'appellera « ornement des parents ».

68. En fait, en ces temps anciens, lorsque notre ville était érigée dans sa grandeur, tu as pu apprendre que des propos odieux ont été prononcés au sujet ${ }^{188}$ de nombreux hommes. 69 . Nous reconnaissons alors que, de la part du destin, nous avons pleinement reçu l'amour suffisant et la dignité dans $\mathrm{sa}^{189}$ grandeur, mais le [même] destin nous a interdit de réaliser les choses qui ont été décidées par nous-mêmes. 70. Et ici, en prison, nous rendons grâce à Dieu parce que nous avons gagné l'amour de beaucoup, car nous nous soumettons à l'épreuve de tenir dans la sagesse et dans la joie. 71. Si quelqu'un alors nous traite avec violence, il rendra témoignage de lui-même : qu'il est loin de toutes les vertus; et il recevra le blâme et la honte, [venant] de son intention impure qui est honteuse. 72. Car nous avons montré notre vérité que nous n'avons pas commis de faute envers l'empire ${ }^{190} 73$. Si alors les Romains nous permettent de revenir

${ }^{185}$ Un passage abîmé que Cureton reconstruit et traduit : and they regard not the vast riches of the worlds, that whatever there be of trouble it bring us all equally to the same time, voir CURETON 1855, p. 75. Absent dans la traduction de Schulthess.

186 J'adopte la correction

${ }^{187}$ Le terme veut dire d'abord séparation par la déportation (Schulthess), mais aussi par la mort (Cureton).

${ }^{188}$ Schulthess traduit von vielen Menschen mais reconnaît que sa traduction demande qu'il y ait un $>$ dans le texte syriaque. Ramelli suit la traduction de Schulthess.

${ }^{189} \mathrm{Il}$ est difficile de dire à quoi se rapporte l'enclitique pronominal du mot mhosi , « sa (m.) grandeur ». Le substantif masculin le plus proche est le וحس "destin» ou 《temps ». Telle est l'interprétation de Cureton. Schulthess corrige l'enclitique en féminin (il suffit d'ajouter un point diacritique) et rapporte la « grandeur» à la ville, voir SCHULTHESS 1897 , p. 374, n. 6. D. Rensberger garde le masculin et y voit une allusion au roi de Commagène, voir RAMELLI 2012, p. 227-228.

${ }^{190}$ Cette phrase a reçu deux lectures, très différentes. B. Pratten (et R. Payne-Smith), pensent que Mara est un Perse emprisonné par les Romains, ils traduisent donc : For we have shown our truth - that truth which in our now ruined kingdom we possessed not: PRATTEN 1978 [1867], p.738, n. 6. En revanche, Rensberger qui croit que Mara parle du faux prétexte utilisé pour l'incorporation de la Samosate en 72 traduit no fault attaches to us in any kingdom, voir RAMELLI 2012, p. 228. 
dans notre pays en justice et en honnêteté, ils agiront comme des hommes civilisés ${ }^{191}$ et ils seront appelés bons et honnêtes, avec le pays pacifique où ils habitent ; car ils nous montreront leur grandeur en nous laissant en hommes libres. 74. Soyons obéissants à cet empire que le destin nous a donné, pas comme [aux] tyrans [qui] nous conduiront comme des esclaves. 75. Et s'il est décidé que quelque chose arrive, nous n'allons recevoir rien de plus que la mort inévitable qui nous est réservée.

76. Toi, alors, mon petit enfant, si tu souhaites connaître davantage [ces] choses désirées, maîtrise d'abord le désir et applique la modération à ce [en quoi tu persévères, sois satisfait suffisamment pour ne pas être en colère, écoute la vertu plutôt que la rage. 77. Moi, désormais je médite sur ces choses, autant que je m'en souviens ; je laisse cet écrit derrière moi] ${ }^{192}$ et avec un esprit sage je peux accomplir le chemin qui m'est imparti. 78. Et sans peine je vais me libérer de la mauvaise corruption du monde, car je prie pour recevoir la libération et peu m'importe quelle sera la mort. 79. Si toutefois quelqu'un veut être affligé ou angoissé, je lui déconseille cela ; car dans sa vie tout entière, il nous trouvera devant lui.

80. L'un de ses amis a demandé à Mara, le fils de Sérapion, lorsqu'il était enchaîné à ses côtés : "Sur ta vie, Mara, je t'en prie dis-moi : quelle est cette chose drôle qui se présente à toi que tu ris ? "Mara lui dit: "Je ris du destin, parce que sans avoir emprunté le mal de moi, il me l'a remboursé." Ici se termine la lettre de Mara fils de Sérapion.

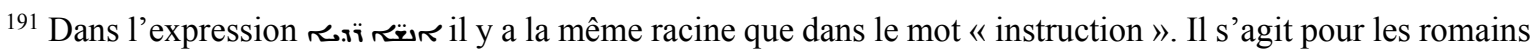
de se montrer éduqués, instruits, des $\pi \varepsilon \pi \alpha 1 \delta \varepsilon v \mu \varepsilon ́ v o 1$.

${ }^{192}$ La partie du texte entre [ ] n'est pas traduite par Schulthess qui note à ce propos qu'il s'agit d'une section très abîmée, voir SCHULTHESS 1897, p. 375, n. 3.
} 


\section{BIBLIOGRAPHIE}

ANDERSON 1993 : G. ANDERSOn, The Second Sophistic. A Cultural Phenomenon in the Roman Empire, London, New York, Routledge.

AudET 1952 : J.-P. AudET, « La Sagesse de Ménandre l’Égyptien », Revue biblique, 59, p. 5581.

AufHAUser 1925 : J.B. AufHauser, Antike Jesus-Zeugnisse, 2e édition augmentée, Bonn.

Аверинцев 1985 : Сергей Сергеевич Аверинцев, «Стоическая житейская мудрость глазами образованного сирийца предхристианской эпохи (Увещевательное послание Мары бар Сарапиона к сыну) », dans Борис Борисович Пиотровский (éd.), Античная культура и современная наука, Москва, Наука, p. 67-75.

BAR-KochVA 2010 : B. BAR-KochVA, The Image of the Jews in Greek Literature, University of California Press, Berkeley.

BARDET 2002 : S. BARDET, Le Testimonium Flavianum. Examen historique, considérations historiographiques, Paris, Cerf.

BeEntjes 2012 : P.C. BeEntJes, "Where is Wisdom to be found? », dans A. Merz, T. TiEleman (éd.), The Letter of Mara bar Sarapion in Context. Proceedings of the Symposium Held at Utrecht University, 10-12 December 2009, Leiden, Boston, Brill, p. 155-165.

BÉNATOUÏL 2006 : T. BÉNATOUÏL, Faire usage : la pratique du stö̈cisme, Vrin, Paris.

BÉNATOUÏL 2009 : T. BÉNATOUïL, Les stoïciens III. Musonius - Epictète - Marc Aurèle, Les Belles Lettres, Paris.

Bettiolo 2000 : P. Bettiolo, « Letteratura siriaca », in Patrologia - I Padri orientai (secoli $V$-VIII), éd. A. Di Bernardino, Genova, Marinetti, p. 503-603.

Bettiolo 2003 : P. Bettiolo, «Dei casi della vita, della pietà e del buon nome intorno ai 'Detti' siriaci di Menandro ", in Aspetti di letteratura gnomica nel mondo antico, éd. M.S. FUNGHI, vol. 1, Leo S. Olschki Editore, Firenze, p. 83-103.

Bettiolo 2004 : P. Bettiolo, " Gnomologia siriaci: un censimento », in Aspetti di letteratura gnomica nel mondo antico, éd. M.S. FUNGHI, vol. II, Leo S. Olschki Editore, Firenze, p. 289304.

BLANK 2012 : D.L. BLANK, « Mara bar Serapion and Greek Philosophy », dans A. MERZ, T. Tieleman (éd.), The Letter of Mara bar Sarapion in Context. Proceedings of the Symposium Held at Utrecht University, 10-12 December 2009, Leiden, Boston, Brill, p. 167-182.

BLINZLER 1962 : J. BlinzLER, Le procès de Jésus, Paris, Mamé.

BLÖMER 2012 : M. BLÖMER, « Religious Life of Commagene in the Late Hellenistic and Early Roman Period », dans A. Merz, T. Tieleman (éd.), The Letter of Mara bar Sarapion in Context. Proceedings of the Symposium Held at Utrecht University, 10-12 December 2009, Leiden, Boston, Brill, p. 95-128.

BoISMARD 1988 : M.-E. BoISMARD, Moïse ou Jésus. Essai de christologie johannique, Leuven, University Press-Peeters.

Boulanger 1923 : A. Boulanger, Aelius Aristide et la sophistique dans la province d'Asie au II siècle de notre ère, Paris.

Bowersock 2002: G.W. Bowersock, «Philosophy in the Second Sophistic », dans G. 
Clark, T. Rajak (éd.), Philosophy and Power in the Graeco-Roman World, Oxford, 2002, p. $157-170$.

BRAUnd 1984 : D. BRAUnd, Rome and the Friendly Kings. The Character of Client Kingship, London, New York.

Brown 1994 : R.E. Brown, La communauté du disciple bien-aimé, Paris, Cerf.

Brown 1998 : R.E. Brown, The Death of the Messiah, from Gethsemane to the Grave, vol. 1, Yale.

BruCE 1974 : F.F. BRUCE, Jesus and Christian Origins outside the New Testament, Grand Rapids.

BYL 2011 : S. BYL, La médecine à l'époque hellénistique et romaine, Paris, L'Harmattan.

CAMERon 1932: A. CAMERON, « The Exposure of Children and Greek Ethics », Classical Review, 46, p. 105-114.

Chadwick 1959 : H. Chadwick (éd.), The Sentences of Sextus. A Contribution to the History of Early Christian Ethics, Cambridge University Press.

ChIN 2006 : C.M. ChIN, « Rhetorical Practice in the Chreia Elaboration of Mara bar Serapion », Hugoye : Journal of Syriac Studies 9.2, p. 145-171.

Cureton 1855 : W. Cureton, «The Epistle of Mara, son of Serapion », dans Spicilegium

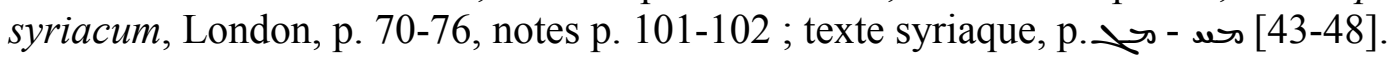

DĄBROWA 1980 : E. DĄBROWA, L'Asie mineure sous les Flaviens. Recherches sur la politique provinciale, Kraków.

De Jong 2012 : A. De Jong, « Mara’s God(s) and Time », dans A. Merz, T. Tieleman (éd.), The Letter of Mara bar Sarapion in Context. Proceedings of the Symposium Held at Utrecht University, 10-12 December 2009, Leiden, Boston, Brill, p. 141-154.

DE LABRIOLLE 2005 : P. DE LABRIOLle, La réaction païenne. Étude sur la polémique antichrétienne du I ${ }^{e r}$ au $V^{e}$ siècle, Paris [1934].

DENIS 2000 : A.-M. DENIS (et alii), Introduction à la littérature religieuse judéo-hellénistique, 2 vol., Turnhout, Brepols.

DESIDERI 2007 : P. DESIDERI, «Dio's exile: politics, philosophy, literature », dans J.F. GAERTNER (éd.), Writing Exile: The Discourse of Displacement in Greco-Roman Antiquity and Beyond, Leiden, Boston, Brill, p. 193-207.

Detienne 1970 : M. Detienne, «La cuisine de Pythagore », Archives de sociologie des religions, 20, p. 141-162.

DRIJVERS 1992 : H.J.W. DrIJVERS, « Syrian Christianity and Judaism », dans J. LIEU, J. NorTH and T. RAJAK (éd.), The Jews among pagans and Christians in the Roman Empire, London, New York, p. 124-146.

DRIJVERS 1996 : H.J.W. DRIJVERS, «Early Syriac Christianity : some recent publications », Vigiliae Christianae, 50, p. 159-177.

Dubois 2011 : J.-D. Dubois, Jésus apocryphe, Paris, Mame-Desclée, 2011.

ESLER 1994 : P.F. ESLER, «The social function of 4 Ezra », Journal for the Study of the Ne Testament 53, p. 99-123.

Evans 1994 : C.A. Evans, Jesus in Non-Christian Sources, dans B.D. Chilton, C.A. Evans 
(éd.), Studying the Historical Jesus : Evaluations of the State of Current Research, Leiden, Brill, p. 455-457.

FACELla 2012 : M. FACELlA, « Languages, Cultural Identities and Elites in the Land of Mara bar Serapion », dans A. MERZ, T. TIELEMAN (éd.), The Letter of Mara bar Sarapion in Context. Proceedings of the Symposium Held at Utrecht University, 10-12 December 2009, Leiden, Boston, Brill, p. 67-94.

Fraser 1978 : P.M. Fraser, "The Kings of Commagene and the Greek World», dans S. SAHIN et alii (éd.), Studien zur Religion und Kultur Kleinasiens, Leiden, p. 359-373.

Goldenberg 1982 : R. GoldenberG, «Early Rabbinic Explanations of the Destruction of Jerusalem », Journal of Jewish Studies, 1-2, p. 517-525.

HadAs-Lebel 1990 : M. HADAs-LeBel, Jerusalem contre Rome, Paris, Cerf.

Hadas-Lebel 2009 : M. Hadas-Lebel, Rome, la Judée et les Juifs, Paris, Picard.

HADOT 1992 : I. HADOT, Arts libéraux et philosophie dans la pensée antique. Contribution à l'histoire de l'éducation et de la culture dans l'Antiquité, Paris, Vrin.

HADOT 1998a : P. HADOT, « La figure du sage dans l'Antiquité gréco-latine », dans Études de philosophie ancienne, Paris, Les Belles Lettres, p. 233-257 [première édition : 1991, p. 926].

HADOT 1998b : P. HADOT, «La philosophie antique : une éthique ou une pratique », dans Études de philosophie ancienne, Paris, Les Belles Lettres, p. 207-232 [première parution dans P. Demont (éd.), Problèmes de morale antique, Université d'Amiens, 1993, p. 7-37].

HADOT 2003 : P. HADOT, « La philosophie comme manière de vivre », dans Exercices spirituels et la philosophie antique, Paris, p. 289-304 [première édition 1993].

HugOnNARD-Roche 2004 : H. HugONNARD-Roche, «Éthique et politique au premier âge de la tradition syriaque », Mélanges de l’Université Saint-Joseph 56, p. 99-119.

HugOnNARD-Roche 2007 : H. HugOnNARD-Roche, « Le corpus philosophique syriaque au VI ${ }^{\mathrm{e}}-\mathrm{VII}^{\mathrm{e}}$ siècles ", dans C. D'ANCONA (éd.), The Libraries of the Neoplatonists, Leiden, Brill, p. 279-291.

JONES 2011 : K.R. JONES, Jewish Reactions to the Destruction of Jerusalem in A.D. 70, Leiden, Boston, Brill.

KAMINKA 1926 : A. KAMINKA, « Les rapports entre le rabbinisme et la philosophie stoïcienne », Revue des Études Juives, 82, p. 233-252.

KING 2011 : D. KING, « Origenisme in Sixth Century Syria : The Case of a Syriac Manuscript of Pagan Philosophy », dans A. FÜRST (éd.), Origenes und sein Erbe in Orient und Okzident, Munster, Aschendorff, p. 189-212.

KOZŁOWSKI 2011 : J. KoZŁOWSKI, «Inkorporacja państw wasalnych (71/72 n.e.) a stosunki z krćlestwem Arsacydow » [Incorporation des états vassaux (71-72 C.E.) et les rapports avec le royaume des Arsacides], dans Studia Flaviana, Poznań, p. 199-225.

LAMPE 1986 : G.W.H. LAMPE, A Patristic Greek Lexicon, Oxford.

LÉON-Dufour 1960 : X. LÉOn-Dufour, «Passion », dans Dictionnaire de la Bible. Supplement, vol. 6, Paris, col. 1422-23.

LÉVY 1927 : I. LÉvy, La légende de Pythagore de Grèce en Palestine, Paris. 
Marrou 1948 : H.-I. Marrou, Histoire de l'éducation dans l'Antiquité, 1. Le monde grec, Paris, Seuil.

MAZZARINO 1956 : S. MAZZARINO, L'impero romano, vol. 2, Bari.

MCVEY 1990 : K.E. MCVEY, «A Fresh Look at the Letter of Mara bar Serapion to His Son », dans R. LAVEnANT (éd.), V Symposium Syriacum Leuven 1988 (Orientalia Christiana Analecta, 236), Rome, p. 257-272.

MCVEY 2015a : K.E. MCVEY, «The Letter of Mara bar Serapion to His Son and the Second Sophistic: Palamedes and the 'Wise King of the Jews' ", dans M.E. DoERfLER, E. FiAnO, K.R. Smith (éd.), Syriac Encounters: Papers from the Sixth North American Syriac Symposium, Duke University, 26-29 June 2011 (Eastern Christian Studies, 20), Leuven, Peeters, p. 305-326.

MCVey 2015b : K.E. MCVEY, « Mara bar Serapion's Letter to his Son and Dio Chrysostom's Oration 13 'On Exile' », communication au $7^{\mathrm{e}}$ North American Syriac Symposium, le 21-24 juin, 2015.

MEIER 2004 : J.P. MeIER, Un certain Juif, Jésus : les données de l'histoire, vol. 1. Les sources, les origines, les dates, trad. de l'anglais par J.-B. Degorce, C. EHLINGER, N. LuCAS (coll. Lectio Divina), Paris, les Éditions du Cerf.

Mertz, Tieleman 2008 : A. Mertz, T. Tieleman, « The Letter of Mara Bar Sarapion. Some Comments on its Philosophical and Historical Context», dans A. HoutMAn, A. DE Jong, M. Misset-VAN DE WEG (éd.), Empsychoi Logoi. Religious Innovations in Antiquité. Studies in Honour of Pieter Willem van der Horst, Leiden, Brill, p. 107-133.

Merz, Tieleman 2012 : A. Merz, T. Tieleman (éd.), The Letter of Mara bar Sarapion in Context. Proceedings of the Symposium Held at Utrecht University, 10-12 December 2009, Leiden, Boston, Brill.

Millar 1993 : F. Millar, The Roman Near East 31 BC - AD 337, Cambridge, Harvard University Press.

Millar 2006 : F. Millar, Rome, the Greek World and the East, vol. 3. The Greek World, the Jews and the East, Edited by H.M. Cotton, G.M. Rogers, The University of North Carolina Press.

Mimouni 1994 : S.C. Mimouni, « Le judéo-christianisme syriaque », dans R. LAVENANT, VI Symposium Syriacum 1992, University of Cambridge, Faculty of Divinity, 30 August - 2 September 1992, Roma, p. 269-279.

Mimouni 1998 : S.C. Mimouni, Le judéo-christianisme ancien. Essais historiques, Paris, Cerf.

Mimouni 2012 : S.C. Mimouni, Le judaïsme ancien du VIe siècle avant notre ère au III siècle de notre ère : des prêtres au rabins, PUF, Paris.

Mimouni 2015 : S.C. Mimouni, Jacques le Juste, frère de Jésus de Nazareth, Bayard.

MOREAU 1944 : J. MOREAU, Les plus anciens témoignages profanes sur Jésus, Bruxelles.

Morgan 1998: T. Morgan, Literate Education in the Hellenistic and Roman World, Cambridge University Press.

Morgan 2007 : T. Morgan, Popular Morality in the Early Roman Empire, Cambridge University Press.

Neusner 1965 : J. Neusner, A history of the Jews in Babylonia, vol. 1. The Parthian period, 
Leiden.

NeUSNER 1970 : J. NeUSNER, A Life of Yohanan ben Zakkaï, Leiden, Brill.

NEUSNER 1972 : J. NeUSNER, « Judaism in a Time of Crisis : Four Reponses to the Destruction of the Second Temple », Judaism 21, p. 312-327

Norelli 1984 : E. Norelli, « Due testimonia attribuiti a Esdra », Annali di storia dell'esegesi, 1, p. 254-258.

NoRelli 2005 : E. NoRelli, «La presenza di Gesù nella letteratura gentile dei primi due secoli », Ricerche storico-bibliche 2, p. 175-215.

OPPENHEIMER 1983 : A. OPPENHEIMER, Babylonia Judaica in the Talmudic Period, Wiesbaden, L. Rechert.

PERNOT 1993 : L. PERNOT, La rhétorique de l'éloge dans le monde gréco-romain, 1. Histoire et technique, Paris.

PERnot 2000 : L. Pernot, La Rhétorique dans l'Antiquité, Livre de poche, Paris.

Pevarello 2013 : D. Pevarello, The Sentences of Sextus and the Origins of Christian Ascetism, Tübingen, Mohr Siebeck.

POKORNY 2012 : P. POKORNY, « Jesus as the Ever-Living Lawgiver in the Letter of Mara bar Serapion », dans A. Merz, T. TIELEMAN (éd.), The Letter of Mara bar Sarapion in Context. Proceedings of the Symposium Held at Utrecht University, 10-12 December 2009, Leiden, Boston, Brill, p. 129-139.

PosseKel 1998 : U. PosseKel, « Der 'Rat der Theano'. Eine pythagoreische Spruchsammlung in syrischen Übersetzung », Le Muséon, 111, p. 7-36.

Pratten 1978 : B.P. Pratten, «A Letter of Mara, Son of Serapion », dans The Ante-Nicene Fathers. American Reprint Revised and Chronologically Arranged by A. Cleveland Coxe, vol. 8, Grand Rapids, Michigan, p. 735-738 [première édition en 1867].

PRESTON 2001 : R. PRESTON, « Roman questions, Greek answers : Plutarch and the construction of identity », dans S. GoldHILL (éd.), Being Greek under Rome. Cultural Identity, the Second Sophistic and Development of Empire, Cambridge University Press, p. 86-119.

Puech 2012 : V. Puech, Les Juifs dans le monde hellénistique, Paris, Ellipses.

RAMELLI 1999 : I. RAMELLI, « Stoicismo e Cristianesimo in area siriaca nella seconda metà del I secolo d.C. », Sileno, 25, p. 197-212.

RAMELLI 2004 : I. RAMELLI, « La lettra di Mara bar Serapion : linee introduttive, traduzione $e$ note essenziali », Stylos, 13, p. 77-104.

RAMELLI 2005 : I. RAMELLI, « Gesù tra i sapienti greci perseguitati ingiustamente in un antico documento filosofico pagano di lingua siriaca », Rivista di Filosofia Neoscolastica, 97, p. 545-570.

RAMELli 2012: I. RAMELli, «Mara bar Serapion: Comments on the Syriac Edition, Translation, and Notes by David Rensberger », dans A. MERZ, T. TIELEMAN (éd.), The Letter of Mara bar Sarapion in Context. Proceedings of the Symposium Held at Utrecht University, 10-12 December 2009, Leiden, Boston, Brill, p. 205-231.

RENAN 1852 : E. RENAN, «Lettre à M. Reinaud sur quelques manuscrits syriaques du Musée britannique contenant des traductions des auteurs grecs profanes et des traités philosophiques », Journal asiatique IV série, XIX tome, avril 1852, p. 293-333. 
RENSBERGER 2010 :D. RENSBERGER, « Reconsiderating the Letter of Mara bar Serapion », dans E.M. MeYers, P.V.M. Flesher (éd.), Aramaic in Postbiblical Judaism and Early Christianity, Winona Lake, Indiana, p. 3-21.

SARTRE 2001 : M. SARTRE, D'Alexandre à Zénobie. Histoire du Levant antique IVe siècle av. J.-C. - III siècle ap. J.-C., Paris, Fayard.

SChUlthess 1897 : F. SChUlthess, «Der Brief des Mara bar Serapion. Ein Beitrag zur Geschichte der syrischen Litteratur», Zeitschrift der Deutschen Morgenländischen Gesellschaft, 51, p. 365-391.

SCHWARTZ 1990 : D.S. SCHWARTZ, Agrippa I The Last King of Judea, Tübingen.

Segal 1957 : J.B. Segal, « Two Syriac Inscription from Harran », Bulletin of the School of Oriental and African Studies, 20, p. 513-522.

Stanley Jones 2009: F. Stanley Jones, «Jewish Christians as Heresiologists and as Heresy », Rivista di storia del cristianesimo 6, p. 333-347.

StANLEy Jones 2012: F. STANLEy JONES, Pseudoclementina Elchasaiticaque inter Judeochristiana. Collected Studies (Orientalia Lovaniensia Analecta, 203), Peeters.

Stanley Jones 2012a : F. STANLEY Jones, « The Martyrdom of James in Hegesippus, Clement of Alexandria, and Christian Apocrypha, Including Nag Hammadi : A Study of Textual Relations », dans Pseudoclementina, p. 291-304 [première publication en 1990].

Stanley Jones 2012b: F. Stanley Jones, «Sonship in Some Early Jewish Christian Traditions », dans Pseudoclementina, p. 467-490 [première publication en 2007].

StOnE 1981 : M.E. StOne, «Reactions to Destructions of the Second Temple. Theology, Perception and Conversion », Journal for the Study of Judaism, 12, p. 195-202.

ThesSyr : R. PAYNE SMITH, Thesaurus syriacus, vol. 1- 2, Oxford, 1879-1901.

VAN VoORST 2000 : R.E. VAN VoORST, Jesus Outside the New Testament. An Introduction to the Ancient Evidence, Grand Rapids, Cambridge.

WeISSBACH 1920 : F.-H. WeISSBACH, «Samosata» dans Realencyclopädie der classischen Altertumswissenschaft, col. 2220-2224.

Wright 1872 : W. Wright, Catalogue of Syriac Manuscripts in the British Museum Acquired Since the Year 1838, vol. 3, London, p. 1154-1160.

ZEEGERS-VANDER VORST 1978 : N. ZEEGERS-VANDER VORST, «Une gnomologie d'auteurs grecs en traduction syriaque », dans Symposium Syriacum 1976 (Orientalia Christiana Analecta, 205), Rome, Pontificio Istituto Orientale, p. 163-177. 
